\title{
Cooperative Heterometallic Catalysts for Lactide Ring-Opening Polymerization: Combining Aluminum with Divalent Metals
}

\section{Electronic Supporting Information}

\author{
Anand J. Gaston, Zoe Greindl, Carole A. Morrison, Jennifer A. Garden* \\ EaStCHEM School of Chemistry, University of Edinburgh, EH9 3FJ, UK \\ Email: j.garden@ed.ac.uk
}

\section{Contents}

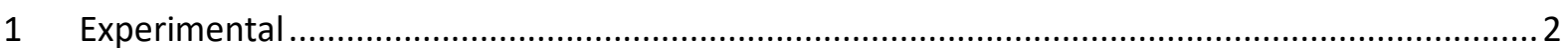

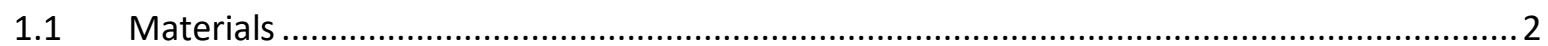

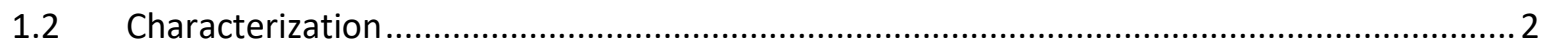

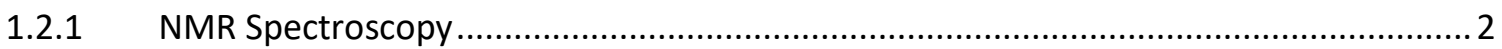

1.2.2 Size-Exclusion Chromatography (SEC) .......................................................... 2

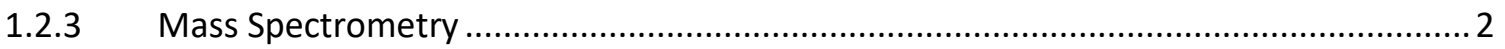

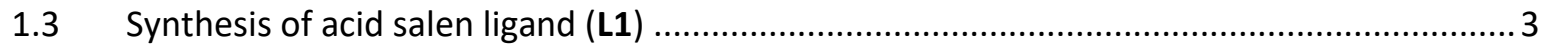

1.4 Synthesis of acid salen Al complex (C1) ...............................................................

1.5 General procedure for the synthesis of acid salen $\mathrm{Zn}(\mathbf{C 2})$ and $\mathrm{Mg}\left(\mathbf{C 3} / \mathbf{C 3}^{\prime}\right)$ complexes ....... 4

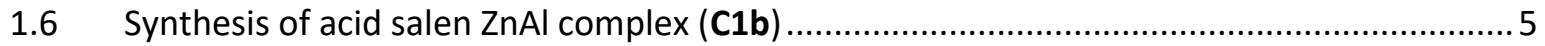

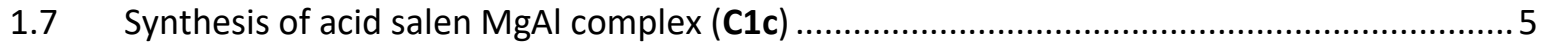

1.8 General procedure for the synthesis of acid salen LiAl and CaAl complexes (C1a and C1d).. 6

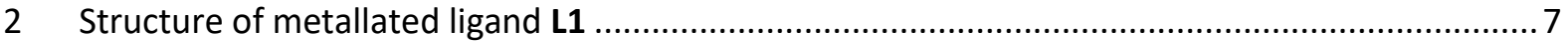

$3{ }^{1} \mathrm{H}$ NMR spectroscopic comparison of ligands and complexes ......................................... 8

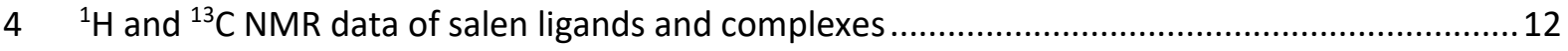

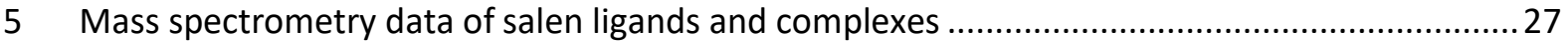

6 General procedure for the ring opening polymerization of $r a c$-lactide ..................................32

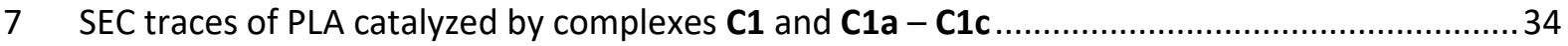

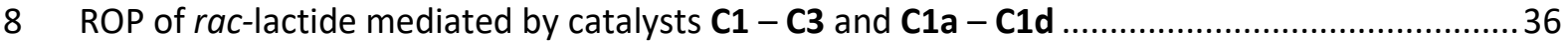

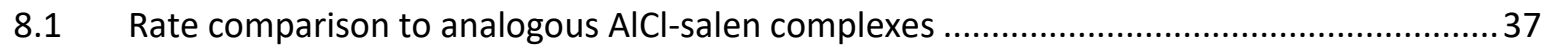

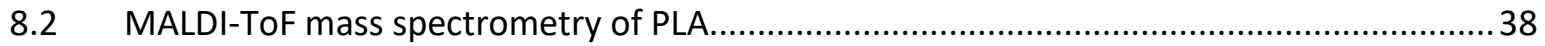

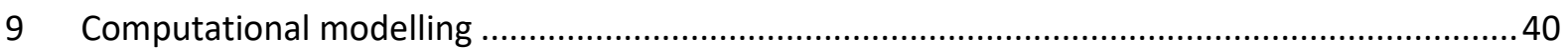




\section{Experimental}

\section{$1.1 \quad$ Materials}

All manipulations involving air- or moisture-sensitive compounds were performed either in a glove box or using standard Schlenk techniques under an argon atmosphere. All reagents and solvents were obtained from Sigma-Aldrich, Fisher Scientific, Honeywell and Fluorochem and used without further purification unless stated otherwise. Dry THF was collected from a solvent purification system (Innovative Technologies), dried over activated 4 Å molecular sieves and stored under argon. DMSO$d_{6}$ solvent for NMR spectroscopy studies was dried by filtration through and stored over activated $4 \AA$ molecular sieves under argon. Rac-lactide was purified three times by recrystallization in toluene followed by sublimation.

\subsection{Characterization}

\subsubsection{NMR Spectroscopy}

${ }^{1} \mathrm{H},{ }^{13} \mathrm{C}$, and 2D NMR (COSY, HSQC) spectra were recorded on a Bruker AVA500 spectrometer at $303 \mathrm{~K}$ (500 MHz for ${ }^{1} \mathrm{H}$ and $126 \mathrm{MHz}$ for ${ }^{13} \mathrm{C}$ ). Chemical shifts $(\delta)$ are given in ppm and coupling constants $(J)$ are given in $\mathrm{Hz}$. ${ }^{1} \mathrm{H}$ NMR spectra were referenced with respect to the solvent peaks for $\mathrm{CDCl}_{3}-d_{1}(\delta=$ $7.27 \mathrm{ppm})$ and DMSO- $d_{6}(\delta=2.50 \mathrm{ppm}) .{ }^{13} \mathrm{C}$ NMR spectra were referenced with respect to the solvent peaks for $\mathrm{CDCl}_{3}-d_{1}(\delta=77.2 \mathrm{ppm})$ and DMSO- $d_{6}(\delta=39.5 \mathrm{ppm})$.

\subsubsection{Size-Exclusion Chromatography (SEC)}

SEC analyses of the filtered polymer samples were carried out in GPC grade THF at a flow rate of $1 \mathrm{~mL}$ $\min ^{-1}$ at $35^{\circ} \mathrm{C}$ on a 1260 Infinity II GPC/SEC single detection system with mixed bed C PLgel columns $(300 \times 7.5 \mathrm{~mm})$.

\subsubsection{Mass Spectrometry}

Mass spectrometry analysis for salen ligand $\mathbf{L} \mathbf{1}$ was carried out using nominal mass electron ionization mass spectrometry in the positive ion mode, collected on a Thermo Fisher Scientific TRACE ${ }^{\mathrm{TM}}$ GC Ultra gas chromatograph. Mass analysis for the poly(lactic acid) (PLA) polymers and the $\mathbf{C 1}, \mathbf{C} \mathbf{3}$ and $\mathbf{C 1 a}$ salen-metal complexes was carried out using MALDI mass spectrometry, collected on a Bruker Daltonics UltrafleXtreme ${ }^{\mathrm{TM}}$ MALDI-ToF/ToF MS instrument. The PLA polymer, the dithranol matrix and the cationizing agent, potassium iodide, were dissolved in THF at $10 \mathrm{mg} \mathrm{mL}^{-1}$, and the solutions were 
mixed in the volume ratio of 2:2:1, respectively. A droplet $(2 \mu \mathrm{L})$ of the mixture was placed on the sample plate and used for the MALDI-ToF MS analysis. Mass analysis for complexes C2 and C1b was carried out using Bruker Daltonics 12T SolariX Fourier Transform Ion Cyclotron Resonance Mass Spectrometer using atmospheric pressure photoionization (APPI).

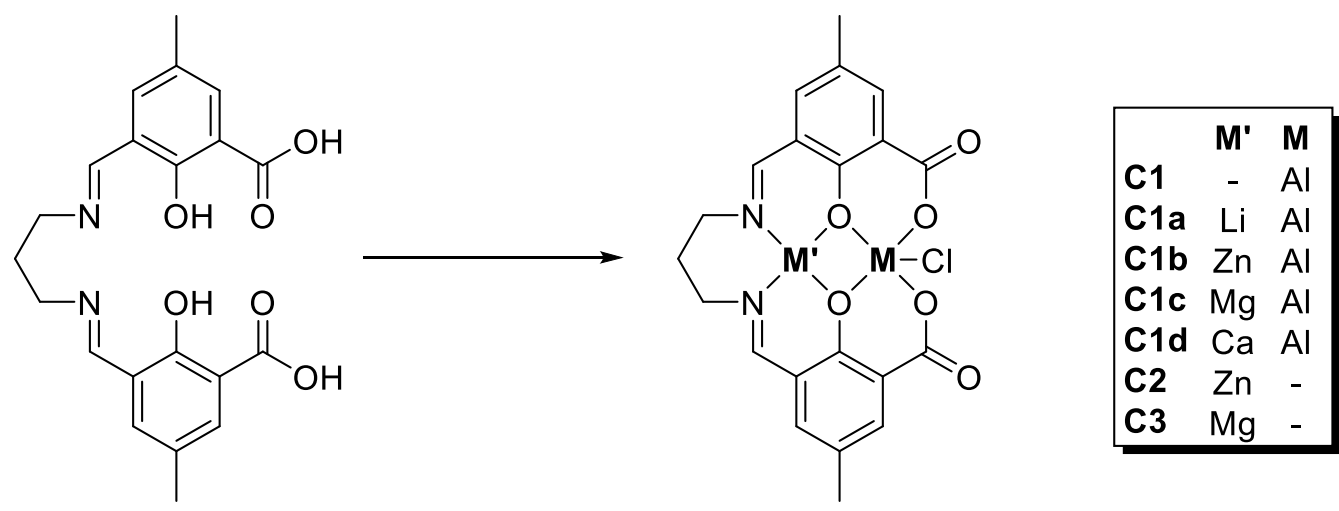

Scheme S1 Structural comparison of acid-salen mono- and bi-metallic complexes.

\subsection{Synthesis of acid salen ligand (L1)}

A solution of propylenediamine $(0.11 \mathrm{~g}, 1.5 \mathrm{mmol})$ in ethanol $(2.5 \mathrm{~mL})$ was added dropwise to a solution of 3-formyl-5-methylsalicylic acid $(0.54 \mathrm{~g}, 3 \mathrm{mmol})$ in ethanol $(7.5 \mathrm{~mL})$, which upon reflux for 1.5 hours resulted in the formation of a yellow suspension. After cooling, the suspension was filtered and washed with cold ethanol resulting in the product isolated as a yellow powder $\mathbf{L} \mathbf{1}(0.41 \mathrm{~g}, 1.03$ $\mathrm{mmol}, 69 \%) .{ }^{1} \mathrm{H}$ NMR and ${ }^{13} \mathrm{C}$ NMR spectra of the products were consistent with reported literature values. ${ }^{1}$

Ligand L1: ${ }^{1} \mathrm{H}$ NMR (500 MHz, $d_{6}$-DMSO): $\delta=12.86(\mathrm{~s}, 2 \mathrm{H}, \mathrm{OH}), 8.71(\mathrm{~s}, 2 \mathrm{H}, \mathrm{N}=\mathrm{CH}), 7.88(\mathrm{~d}, \mathrm{~J}=2.6 \mathrm{~Hz}$, $2 \mathrm{H}, \operatorname{Ar}-\mathrm{H}), 7.38(\mathrm{~d}, \mathrm{~J}=2.6 \mathrm{~Hz}, 2 \mathrm{H}, \mathrm{Ar}-\mathrm{H}), 3.81\left(\mathrm{t}, \mathrm{J}=6.5 \mathrm{~Hz}, 4 \mathrm{H}, \mathrm{N}-\mathrm{CH}_{2}\right), 2.22\left(\mathrm{~d}, \mathrm{~J}=6.6 \mathrm{~Hz}, 2 \mathrm{H}, \mathrm{C}-\mathrm{CH}_{2}\right)$, $2.20\left(\mathrm{~s}, 6 \mathrm{H}, \mathrm{Ar}-\mathrm{CH}_{3}\right)$ ppm. ${ }^{13} \mathrm{C} \mathrm{NMR}\left(126 \mathrm{MHz}, d_{6}\right.$-DMSO): $\delta=189.4(\mathrm{O}=\mathrm{C}-\mathrm{OH}), 167.8(\mathrm{~N}=\mathrm{CH}), 140.6(\mathrm{Ar}-$ $\mathrm{CH}), 139.4(\mathrm{Ar}-\mathrm{CH}), 137.3(\mathrm{Ar}-\mathrm{COH}), 122.1\left(\mathrm{Ar}-\mathrm{C}-\mathrm{CH}_{3}\right), 118.9$ (Ar-C-C=N), $115.3(\mathrm{Ar}-\mathrm{C}-\mathrm{COOH}), 48.6$ (N$\left.\mathrm{CH}_{2}\right), 29.1\left(\mathrm{C}-\mathrm{CH}_{2}\right), 19.5$ (Ar-C-CH$)$ ppm. MALDI-ToF-MS: $\mathrm{m} / z$ [salen] ${ }^{+}$: calculated 397.42; found 397.2.

\subsection{Synthesis of acid salen Al complex (C1)}

At $-78{ }^{\circ} \mathrm{C}$ diethylaluminum chloride $(0.5 \mathrm{~mL}, 0.5 \mathrm{mmol}, 1 \mathrm{M}$ in hexanes) was added dropwise to a suspension of L1 (200 mg, $0.5 \mathrm{mmol})$ in THF (6 mL), stirred for 16 hours and slowly raised to room temperature. The solvent was removed in vacuo, resulting in the formation of $\mathbf{C 1}$ as a yellow powder 
(212 mg, $0.46 \mathrm{mmol}, 93 \%)$. The product was characterized by multinuclear NMR $\left({ }^{1} \mathrm{H},{ }^{13} \mathrm{C}, \mathrm{COSY}, \mathrm{HSQC}\right.$ ) spectroscopy.

Complex C1: ${ }^{1} \mathrm{H}$ NMR (500 MHz, $d_{6}$-DMSO): $\delta=12.36(\mathrm{~s}, 2 \mathrm{H}, \mathrm{OH}), 8.81(\mathrm{~d}, \mathrm{~J}=14.5 \mathrm{~Hz}, 2 \mathrm{H}, \mathrm{N}=\mathrm{CH}), 8.12$ $(\mathrm{s}, 2 \mathrm{H}, \mathrm{Ar}-\mathrm{H}), 7.45(\mathrm{~s}, 2 \mathrm{H}, \mathrm{Ar}-\mathrm{H}), 4.07\left(\mathrm{~s}, 4 \mathrm{H}, \mathrm{N}-\mathrm{CH}_{2}\right), 2.26$ (s, 6H, Ar- $\left.\mathrm{CH}_{3}\right), 2.25$ (m, 2H, C-CH $)$ ppm. ${ }^{13} \mathrm{C}$ NMR (126 MHz, $d_{6}$-DMSO): $\delta=170.6$ (O=C-OH), 167.4 ( $\left.\mathrm{N}=\mathrm{CH}\right), 165.9$ (Ar-COH), 142.4 (Ar-CH), 139.2 (Ar-CH), $124.7\left(\mathrm{Ar}-\mathrm{C}-\mathrm{CH}_{3}\right), 124.0(\mathrm{Ar}-\mathrm{C}-\mathrm{C}=\mathrm{N}), 115.9(\mathrm{Ar}-\mathrm{C}-\mathrm{COOH}), 52.6\left(\mathrm{~N}-\mathrm{CH}_{2}\right), 28.4\left(\mathrm{C}-\mathrm{CH}_{2}\right), 19.4$ ( $\mathrm{Ar}-$ $\left.\mathrm{C}-\mathrm{CH}_{3}\right)$ ppm. ${ }^{27} \mathrm{Al}$ NMR spectroscopy was performed, however the resonances were too broad to detect. MALDI-ToF-MS: $\mathrm{m} / \mathrm{z}$ [salen(Al)]: calculated 421.11; found 421.1. Elemental Analysis: predicted: C $54.97 \%$, H 4.39 \%, N $6.11 \%$; found: C $54.01 \%$, H $4.41 \%$, N $5.82 \%$.

1.5 General procedure for the synthesis of acid salen Zn (C2) and Mg (C3/C3') complexes Diethylzinc ( $61.75 \mathrm{mg}, 0.5 \mathrm{mmol}$ ) or di- $n$-butylmagnesium $(0.5 \mathrm{~mL}, 0.5 \mathrm{mmol}, 1 \mathrm{M}$ in heptane and ether) was added dropwise to a suspension of $\mathbf{L} \mathbf{1}(200 \mathrm{mg}, 0.5 \mathrm{mmol})$ in THF $(6 \mathrm{~mL})$ and stirred for 16 hours. The solvent was removed in vacuo, resulting in the formation of $\mathbf{C 2}$ as a pale yellow powder $(203 \mathrm{mg}$, $0.44 \mathrm{mmol}, 87 \%$ ) or a mixture of $\mathbf{C 3}$ and $\mathbf{C 3}^{\prime}$ as a yellow powder (197 $\left.\mathrm{mg}, 0.47 \mathrm{mmol}, 93 \%\right)$. The products were characterized by multinuclear NMR $\left({ }^{1} \mathrm{H},{ }^{13} \mathrm{C}, \mathrm{COSY}, \mathrm{HSQC}\right)$ spectroscopy.

Complex C2: ${ }^{1} \mathrm{H}$ NMR (500 MHz, $d_{6}$-DMSO): $\delta=15.95(\mathrm{~s}, 2 \mathrm{H}, \mathrm{COOH}), 8.34(\mathrm{~d}, \mathrm{~J}=1.4 \mathrm{~Hz}, 2 \mathrm{H}, \mathrm{N}=\mathrm{CH}$ ), $7.80(\mathrm{~d}, \mathrm{~J}=2.5 \mathrm{~Hz}, 2 \mathrm{H}, \mathrm{Ar}-\mathrm{H}), 7.37$ (d, J = $2.4 \mathrm{~Hz}, 2 \mathrm{H}, \mathrm{Ar}-\mathrm{H}), 3.89-3.84\left(\mathrm{~m}, 4 \mathrm{H}, \mathrm{N}-\mathrm{CH}_{2}\right), 2.23(\mathrm{~s}, 6 \mathrm{H}, \mathrm{Ar}-$ $\left.\mathrm{CH}_{3}\right), 1.99$ (ddt, J = 10.5, 7.2, 3.7 Hz, 2H, C-CH2) ppm. $\left.{ }^{13} \mathrm{C} \mathrm{NMR} \mathrm{(126} \mathrm{MHz,} d_{6}-\mathrm{DMSO}\right): \delta=168.2(\mathrm{~N}=\mathrm{CH})$, $168.0(\mathrm{O}=\mathrm{C}-\mathrm{OH}), 166.2$ (Ar-COH), 140.7 ( $\mathrm{Ar}-\mathrm{CH}), 135.8$ (Ar-CH), $123.2\left(\mathrm{Ar}-\mathrm{C}-\mathrm{CH}_{3}\right), 120.4$ (Ar-C-C=N), 118.2 (Ar-C-COOH), $62.0\left(\mathrm{~N}-\mathrm{CH}_{2}\right), 29.6\left(\mathrm{C}_{-} \mathrm{CH}_{2}\right), 19.5\left(\mathrm{Ar}-\mathrm{C}-\mathrm{CH}_{3}\right)$ ppm. APPI-MS: $m / z$ [salen(Zn) + Na] $]^{+}$ calculated 483.05; found 483.56. Elemental Analysis: predicted: C 54.62 \%, H 4.37 \%, N $6.07 \%$; found: C $54.54 \%$, H $4.60 \%$, N $6.12 \%$.

Complex C3: ${ }^{1} \mathrm{H}$ NMR (500 MHz, $d_{6}$-DMSO): $\delta=16.42(\mathrm{~s}, 2 \mathrm{H}, \mathrm{COOH}), 8.21(\mathrm{~s}, 2 \mathrm{H}, \mathrm{N}=\mathrm{CH}), 7.75$ (d, J = 2.6 $\mathrm{Hz}, 2 \mathrm{H}, \mathrm{Ar}-\mathrm{H}), 7.35(\mathrm{~d}, \mathrm{~J}=2.6 \mathrm{~Hz}, 2 \mathrm{H}, \mathrm{Ar}-\mathrm{H}), 3.82-3.76\left(\mathrm{~m}, 4 \mathrm{H}, \mathrm{N}-\mathrm{CH}_{2}\right), 2.23\left(\mathrm{~s}, 6 \mathrm{H}, \mathrm{Ar}-\mathrm{CH}_{3}\right), 1.92(\mathrm{~m}, 2 \mathrm{H}$, $\mathrm{C}-\mathrm{CH}_{2}$ ) ppm. ${ }^{13} \mathrm{C} \mathrm{NMR}\left(126 \mathrm{MHz}, d_{6}\right.$-DMSO): $\delta=168.5(\mathrm{O}=\mathrm{C}-\mathrm{OH}), 165.8(\mathrm{~N}=\mathrm{CH}), 166.2(\mathrm{Ar}-\mathrm{COH}), 140.3$ (Ar-CH), 134.9 (Ar-CH), 122.6 ( $\left.\mathrm{Ar}-\mathrm{C}-\mathrm{CH}_{3}\right), 122.4$ (Ar-C-C=N), 117.9 (Ar-C-COOH), $62.4\left(\mathrm{~N}-\mathrm{CH}_{2}\right), 30.2$ (C$\left.\mathrm{CH}_{2}\right), 19.6\left(\mathrm{Ar}-\mathrm{C}-\mathrm{CH}_{3}\right) \mathrm{ppm}$.

Complex C3': ${ }^{1} \mathrm{H}$ NMR (500 MHz, $d_{6}$-DMSO): $\delta=12.89(\mathrm{~s}, 2 \mathrm{H}, \mathrm{OH}), 8.70(\mathrm{~s}, 2 \mathrm{H}, \mathrm{N}=\mathrm{CH}), 7.80(\mathrm{~s}, 2 \mathrm{H}, \mathrm{Ar}-$ $H), 7.42(\mathrm{~s}, 2 \mathrm{H}, \mathrm{Ar}-\mathrm{H}), 3.78\left(\mathrm{~s}, 4 \mathrm{H}, \mathrm{N}-\mathrm{CH}_{2}\right), 2.18\left(\mathrm{~s}, 6 \mathrm{H}, \mathrm{Ar}-\mathrm{CH}_{3}\right), 1.26\left(\mathrm{~m}, 2 \mathrm{H}, \mathrm{C}-\mathrm{CH}_{2}\right) \mathrm{ppm}$. 
MALDI-ToF-MS: $m / z$ [salen(Mg)]: calculated 419.11; found 419.2. Elemental Analysis: predicted: C $59.95 \%$, H 4.79 \%, N 6.66 \%; found: C 58.77 \%, H 6.22 \%, N 5.30 \% (discrepancy attributed to complex air-sensitivity).

\subsection{Synthesis of acid salen ZnAl complex (C1b)}

Diethylzinc (27.2 mg, $0.22 \mathrm{mmol}$ ) was added dropwise to a suspension of $\mathbf{C 1}(100 \mathrm{mg}, 0.22 \mathrm{mmol})$ in DMSO (6 mL) and stirred for 16 hours. The solvent was removed in vacuo, by heating to $100^{\circ} \mathrm{C}$ under high vacuum for approximately 4 hours, resulting in the formation of a yellow powder $(110 \mathrm{mg}, 0.21$ mmol, 96\%). The product was characterized by multinuclear NMR $\left({ }^{1} \mathrm{H},{ }^{13} \mathrm{C}, \mathrm{COSY}, \mathrm{HSQC}\right)$ spectroscopy.

Complex C1b: ${ }^{1} \mathrm{H}$ NMR $\left(500 \mathrm{MHz}, d_{6}\right.$-DMSO): $\delta=8.43(\mathrm{~s}, 2 \mathrm{H}, \mathrm{N}=\mathrm{CH}), 7.99(\mathrm{~s}, 2 \mathrm{H}, \mathrm{Ar}-\mathrm{H}), 7.40(\mathrm{~s}, 2 \mathrm{H}, \mathrm{Ar}-$ $H)$, 4.20-3.70 (m, 4H, N-CH2), $2.26\left(\mathrm{~s}, 6 \mathrm{H}, \mathrm{Ar}-\mathrm{CH}_{3}\right), 2.25,1.24\left(\mathrm{~m}, 2 \mathrm{H}, \mathrm{C}-\mathrm{CH}_{2}\right)$ ppm. ${ }^{13} \mathrm{C} \mathrm{NMR}(126 \mathrm{MHz}$, $d_{6}$-DMSO): $\delta=169.6(\mathrm{~N}=\mathrm{CH}), 165.8(\mathrm{O}=\mathrm{C}-\mathrm{OH}), 159.6(\mathrm{Ar}-\mathrm{COH}), 140.2(\mathrm{Ar}-\mathrm{CH}), 138.0(\mathrm{Ar}-\mathrm{CH}), 125.9$ (Ar$\left.\mathrm{C}-\mathrm{CH}_{3}\right), 123.3(\mathrm{Ar}-\mathrm{C}-\mathrm{C}=\mathrm{N}), 112.0(\mathrm{Ar}-\mathrm{C}-\mathrm{COOH}), 62.6\left(\mathrm{~N}-\mathrm{CH}_{2}\right), 29.5\left(\mathrm{C}-\mathrm{CH}_{2}\right), 19.5\left(\mathrm{Ar}-\mathrm{C}-\mathrm{CH}_{3}\right) \mathrm{ppm} .{ }^{27} \mathrm{Al}$ NMR spectroscopy was performed, however the resonances were too broad to detect. APPI-MS: $m / z$ [salen $(\mathrm{ZnAlCl})+\mathrm{H}+\mathrm{DMSO}^{+}$pyridine] $^{+}$: calculated 678.06; found 678.05. Elemental Analysis: predicted (C1b - 2.5 DMSO): C 43.52 \%, H 4.64 \%, N 3.90 \%; found: C $42.89 \%$, H 4.73 \%, N 3.85 \%. 1:1 Al:Zn ratio verified by ICP-OES analysis.

\subsection{Synthesis of acid salen MgAl complex (C1c)}

Under argon atmosphere di- $n$-butylmagnesium $(0.5 \mathrm{~mL}, 0.5 \mathrm{mmol}, 1 \mathrm{M}$ in heptane and ether) was added dropwise to a solution of $\mathbf{C 1}(229 \mathrm{mg}, 0.5 \mathrm{mmol})$ in DMSO $(16 \mathrm{~mL})$ and stirred for 16 hours. The solvent was removed in vacuo, by heating to $100^{\circ} \mathrm{C}$ under high vacuum for approximately 4 hours, resulting in the formation of a yellow powder $(220 \mathrm{mg}, 0.46 \mathrm{mmol}, 92 \%)$. The product was characterized by multinuclear NMR $\left({ }^{1} \mathrm{H},{ }^{13} \mathrm{C}, \mathrm{COSY}, \mathrm{HSQC}\right)$ spectroscopy.

Complex C1c: ${ }^{1} \mathrm{H}$ NMR (500 MHz, $\left.d_{6}-\mathrm{DMSO}\right): \delta=8.40(\mathrm{~s}, 2 \mathrm{H}, \mathrm{N}=\mathrm{CH}), 8.01(\mathrm{~d}, \mathrm{~J}=2.5 \mathrm{~Hz}, 2 \mathrm{H}, \mathrm{Ar}-\mathrm{H}), 7.46$ (d, J = 2.6 Hz, 2H, Ar-H), $3.91\left(\mathrm{~s}, 4 \mathrm{H}, \mathrm{N}-\mathrm{CH}_{2}\right), 2.27\left(\mathrm{~s}, 6 \mathrm{H}, \mathrm{Ar}-\mathrm{CH}_{3}\right), 2.04$ (s, 2H, C-CH $)$ ppm. ${ }^{13} \mathrm{C}$ NMR (126 $\left.\mathrm{MHz}, d_{6}-\mathrm{DMSO}\right): \delta=168.7(\mathrm{~N}=\mathrm{CH}), 165.9(\mathrm{O}=\mathrm{C}-\mathrm{OH}), 157.1(\mathrm{Ar}-\mathrm{COH}), 140.5(\mathrm{Ar}-\mathrm{CH}), 137.7(\mathrm{Ar}-\mathrm{CH})$, $126.4\left(\mathrm{Ar}-\mathrm{C}-\mathrm{CH}_{3}\right), 122.8$ ( $\left.\mathrm{Ar}-\mathrm{C}-\mathrm{C}=\mathrm{N}\right), 121.6(\mathrm{Ar}-\mathrm{C}-\mathrm{COOH}), 64.9\left(\mathrm{~N}^{-} \mathrm{CH}_{2}\right), 29.5\left(\mathrm{C}-\mathrm{CH}_{2}\right), 19.6\left(\mathrm{Ar}-\mathrm{C}-\mathrm{CH}_{3}\right)$ ppm. ${ }^{27} \mathrm{Al}$ NMR spectroscopy was performed, however the resonances were too broad to detect. A publication quality mass spectrum was not obtained for this complex, attributed to the air- and moisture-sensitivity of the complex. Elemental Analysis: predicted (C1c - 2 DMSO): C 47.11 \%, H 4.74 \%, N $4.40 \%$; found: C $47.40 \%$, H 5.10 \%, N $4.14 \%$. 1:1 Al:Mg ratio verified by ICP-OES analysis. 
1.8 General procedure for the synthesis of acid salen LiAl and CaAl complexes (C1a and C1d)

LiHMDS (18.2 mg, $0.11 \mathrm{mmol}$ ) or Ca(HMDS) $2(19.9 \mathrm{mg}, 0.055 \mathrm{mmol})$ was added slowly to a suspension of $\mathbf{C 1}(50 \mathrm{mg}, 0.11 \mathrm{mmol})$ in DMSO $(6 \mathrm{~mL})$ and stirred for 16 hours. The solvent was removed in vacuo, by heating to $100^{\circ} \mathrm{C}$ under high vacuum for approximately 4 hours, resulting in the formation of $\mathbf{C 1 a}$ as a pale yellow powder ( $49 \mathrm{mg}, 0.11 \mathrm{mmol}, 96 \%$ ) and C1d also as a pale yellow powder ( $47 \mathrm{mg}, 0.095$ mmol, 95\%). The products were characterized by multinuclear NMR $\left({ }^{1} \mathrm{H},{ }^{13} \mathrm{C}, \mathrm{COSY}, \mathrm{HSQC}\right)$ spectroscopy.

Complex C1a: ${ }^{1} \mathrm{H}$ NMR (500 MHz, $d_{6}$-DMSO): $\delta=8.20(\mathrm{~s}, 2 \mathrm{H}, \mathrm{N}=\mathrm{CH}), 7.81(\mathrm{~d}, \mathrm{~J}=2.7 \mathrm{~Hz}, 2 \mathrm{H}, \mathrm{Ar}-\mathrm{H}), 7.21$ $(\mathrm{d}, \mathrm{J}=2.7 \mathrm{~Hz}, 2 \mathrm{H}, \mathrm{Ar}-\mathrm{H}), 3.82-3.77\left(\mathrm{~m}, 4 \mathrm{H}, \mathrm{N}-\mathrm{CH}_{2}\right), 2.21\left(\mathrm{~s}, 6 \mathrm{H}, \mathrm{Ar}-\mathrm{CH}_{3}\right), 1.86\left(\mathrm{~s}, 2 \mathrm{H}, \mathrm{C}-\mathrm{CH}_{2}\right) \mathrm{ppm} .{ }^{13} \mathrm{C}$ NMR (126 MHz, $d_{6}$-DMSO): $\delta=167.6$ (O=C-OH), 164.3 ( $\left.\mathrm{N}=\mathrm{CH}\right), 160.4(\mathrm{Ar}-\mathrm{COH}), 139.0(\mathrm{Ar}-\mathrm{CH}), 135.6$ (Ar-CH), $123.4\left(\mathrm{Ar}-\mathrm{C}-\mathrm{CH}_{3}\right), 122.8(\mathrm{Ar}-\mathrm{C}-\mathrm{C}=\mathrm{N}), 122.5(\mathrm{Ar}-\mathrm{C}-\mathrm{COOH}), 63.9\left(\mathrm{~N}-\mathrm{CH}_{2}\right), 31.6\left(\mathrm{C}-\mathrm{CH}_{2}\right), 19.7(\mathrm{Ar}-$ $\left.\mathrm{C}-\mathrm{CH}_{3}\right)$ ppm. ${ }^{27} \mathrm{Al} \mathrm{NMR}$ spectroscopy was performed, however the resonances were too broad to detect. MALDI-ToF-MS: $m / z$ [salen(LiAl) $-\mathrm{H}+\mathrm{Li}^{+}$: calculated 435.25; found 435.2. Elemental Analysis: predicted (C1a - 2 DMSO): C 48.35 \%, H $5.03 \%$, N $4.51 \%$; found: C $48.26 \%$, H $5.41 \%$, N $4.40 \%$.

Complex C1d: ${ }^{1} \mathrm{H}$ NMR (500 MHz, $d_{6}$-DMSO): $\delta=8.24$ (d, J = $1.7 \mathrm{~Hz}, 2 \mathrm{H}, \mathrm{N}=\mathrm{CH}$ ), 7.85 (d, J = $2.6 \mathrm{~Hz}, 2 \mathrm{H}$, $\operatorname{Ar}-H), 7.30(\mathrm{~d}, \mathrm{~J}=2.7 \mathrm{~Hz}, 2 \mathrm{H}, \mathrm{Ar}-\mathrm{H}), 4.47,3.45\left(\mathrm{t}, \mathrm{m}, \mathrm{J}=12 \mathrm{~Hz}, 4 \mathrm{H}, \mathrm{N}-\mathrm{CH}_{2}\right), 2.24\left(\mathrm{~s}, 6 \mathrm{H}, \mathrm{Ar}-\mathrm{CH}_{3}\right), 2.17,1.35$ (dd, q, J = 15.2, 5.1, 2H, C-CH $)$ ppm. ${ }^{13} \mathrm{C}$ NMR (126 MHz, $d_{6}$-DMSO): $\delta=167.0$ (O=C-OH), $165.2(\mathrm{~N}=\mathrm{CH})$, $159.2(\mathrm{Ar}-\mathrm{COH}), 138.8$ (Ar-CH), $136.0(\mathrm{Ar}-\mathrm{CH}), 124.0\left(\mathrm{Ar}-\mathrm{C}-\mathrm{CH}_{3}\right), 123.8$ ( $\left.\mathrm{Ar}-\mathrm{C}-\mathrm{C}=\mathrm{N}\right), 122.6$ (Ar-C-COOH), $64.8\left(\mathrm{~N}^{-} \mathrm{CH}_{2}\right), 33.5\left(\mathrm{C}-\mathrm{CH}_{2}\right), 19.7\left(\mathrm{Ar}-\mathrm{C}-\mathrm{CH}_{3}\right) \mathrm{ppm}$. Publication quality mass spectra could not be obtained for this complex nor could accurate elemental analysis, which was attributed to the highly air- and moisture-sensitive nature of the complex. 2:1 Al:Ca ratio verified by ICP-OES analysis. 


\section{Structure of metallated ligand L1}

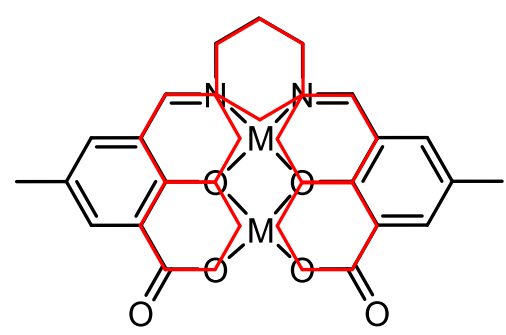

Figure S1 Structure of L1 metallated by generic metal, M, highlighting the formation of five sixmembered rings.
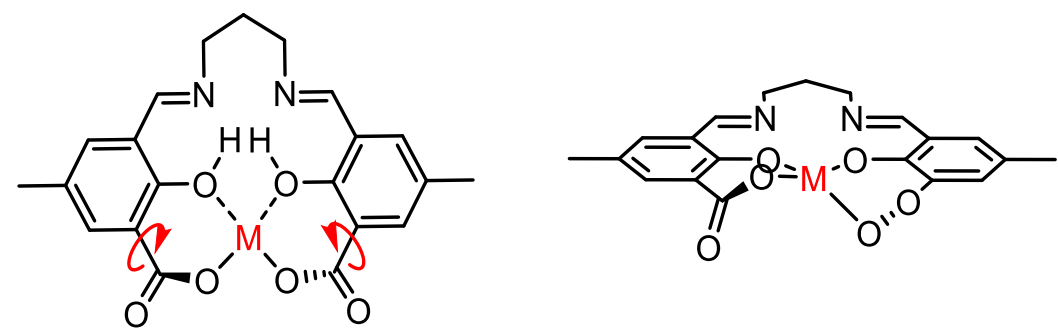

Figure S2 General structure of any metal, $\mathrm{M}$, chelated within the $\mathbf{L} 1$ ligand $\mathrm{O}_{2} \mathrm{O}_{2}$ binding pocket displaying possible rotation around the $\mathrm{Ph}-\mathrm{COO}$ bond to increase the available metal coordination geometries. 
$3 \quad{ }^{1}$ H NMR spectroscopic comparison of ligands and complexes

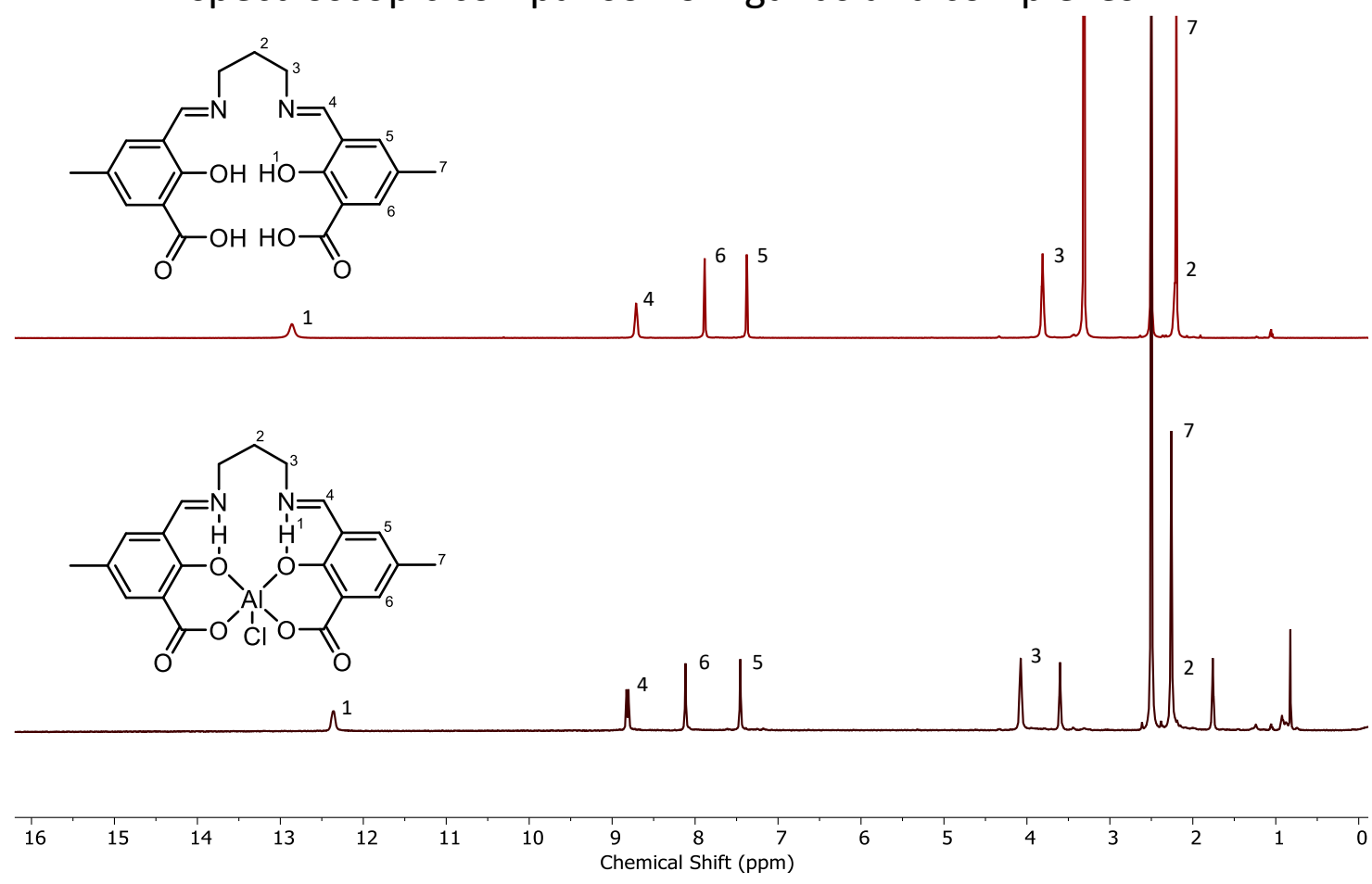

Figure S3 ${ }^{1} \mathrm{H}$ NMR spectra $\left(d_{6}\right.$-DMSO) of the $\mathbf{L} \mathbf{1}$ ligand (top) and the $\mathbf{C 1} \mathrm{Al}$-complex (bottom) at 303K.

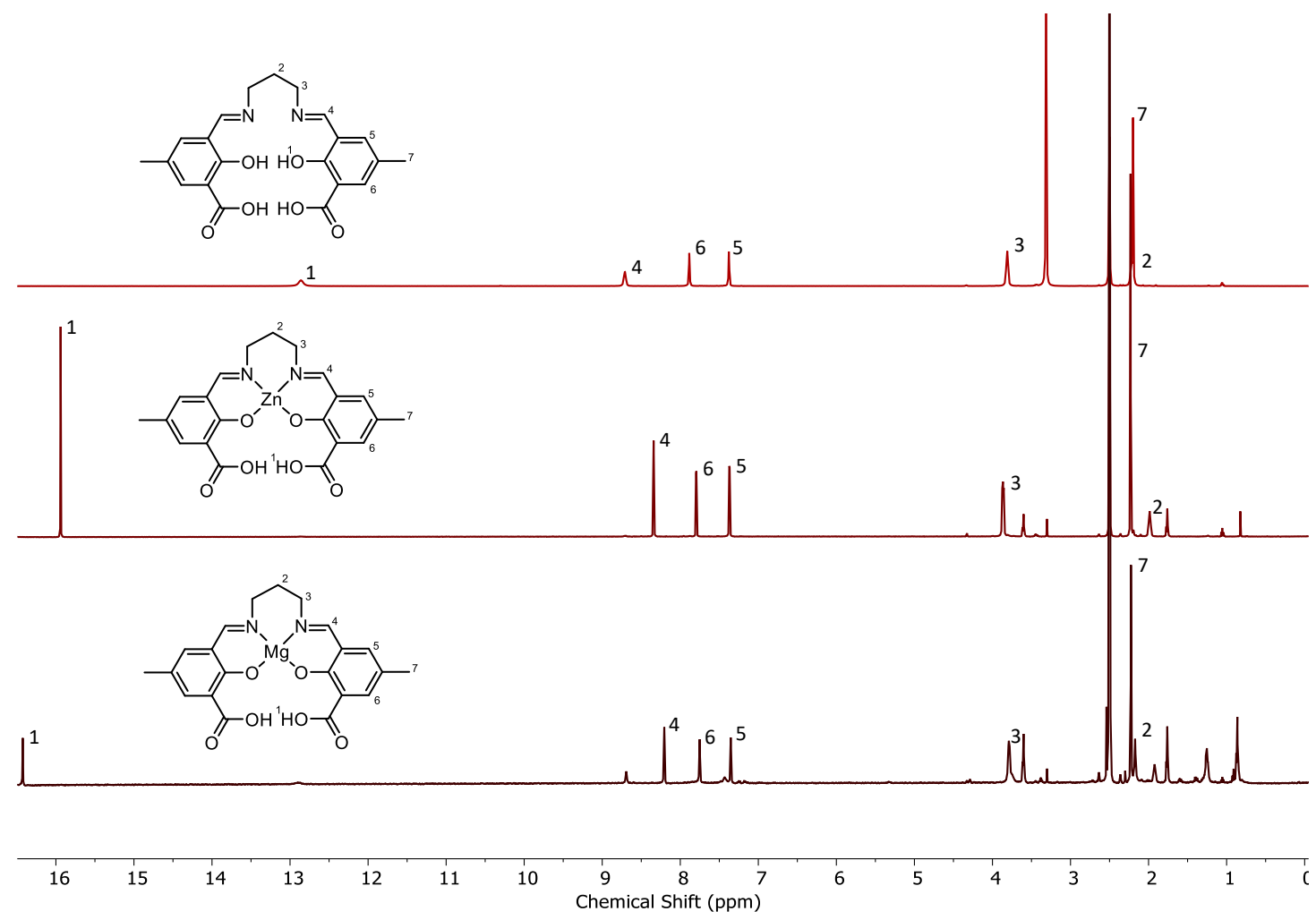

Figure S4 ${ }^{1} \mathrm{H}$ NMR spectra ( $d_{6}$-DMSO) of the $\mathbf{L 1}$ ligand (top), the $\mathbf{C 2} \mathrm{Zn}$-complex (middle) and a mixture of the $\mathbf{C 3}^{\prime}$ and $\mathbf{C 3} \mathbf{M g}$-complexes (bottom) at 303K. 

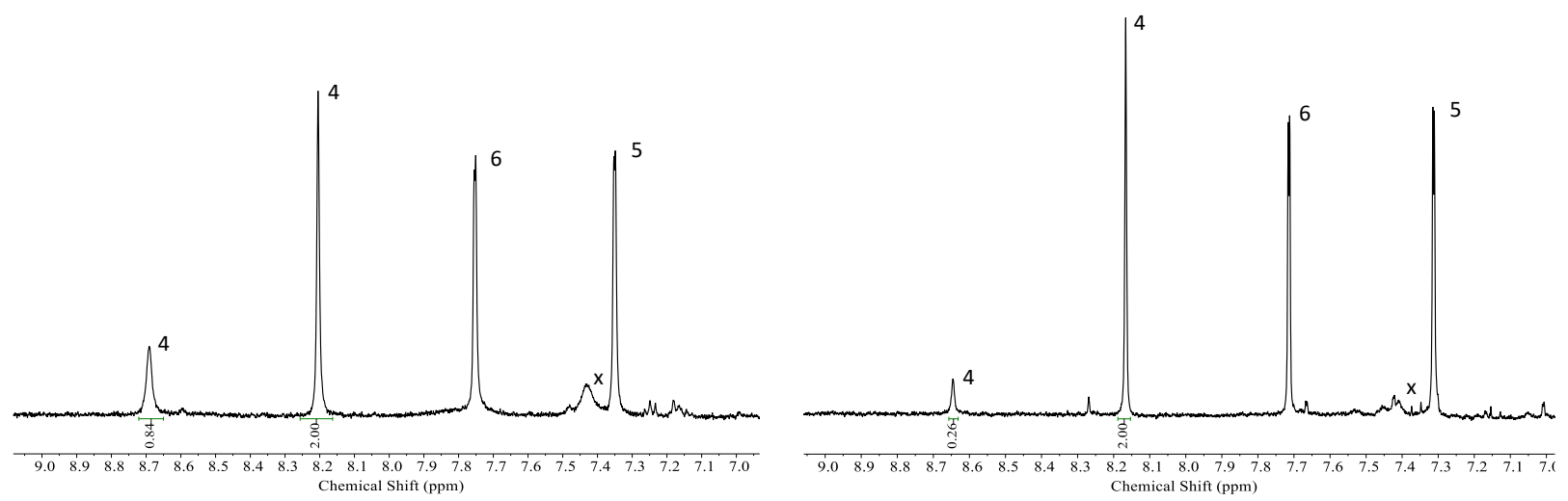

Figure $55{ }^{1} \mathrm{H}$ NMR spectra ( $d_{6}$-DMSO, 303K) of a mixture of complexes $\mathrm{C} 3$ and $\mathrm{C3}^{\prime}$, before (left) and after (right) 3 hours of heating at $120^{\circ} \mathbf{C}$ in DMSO. The ratio of C3:C3' changes from 5:2 to 10:1.

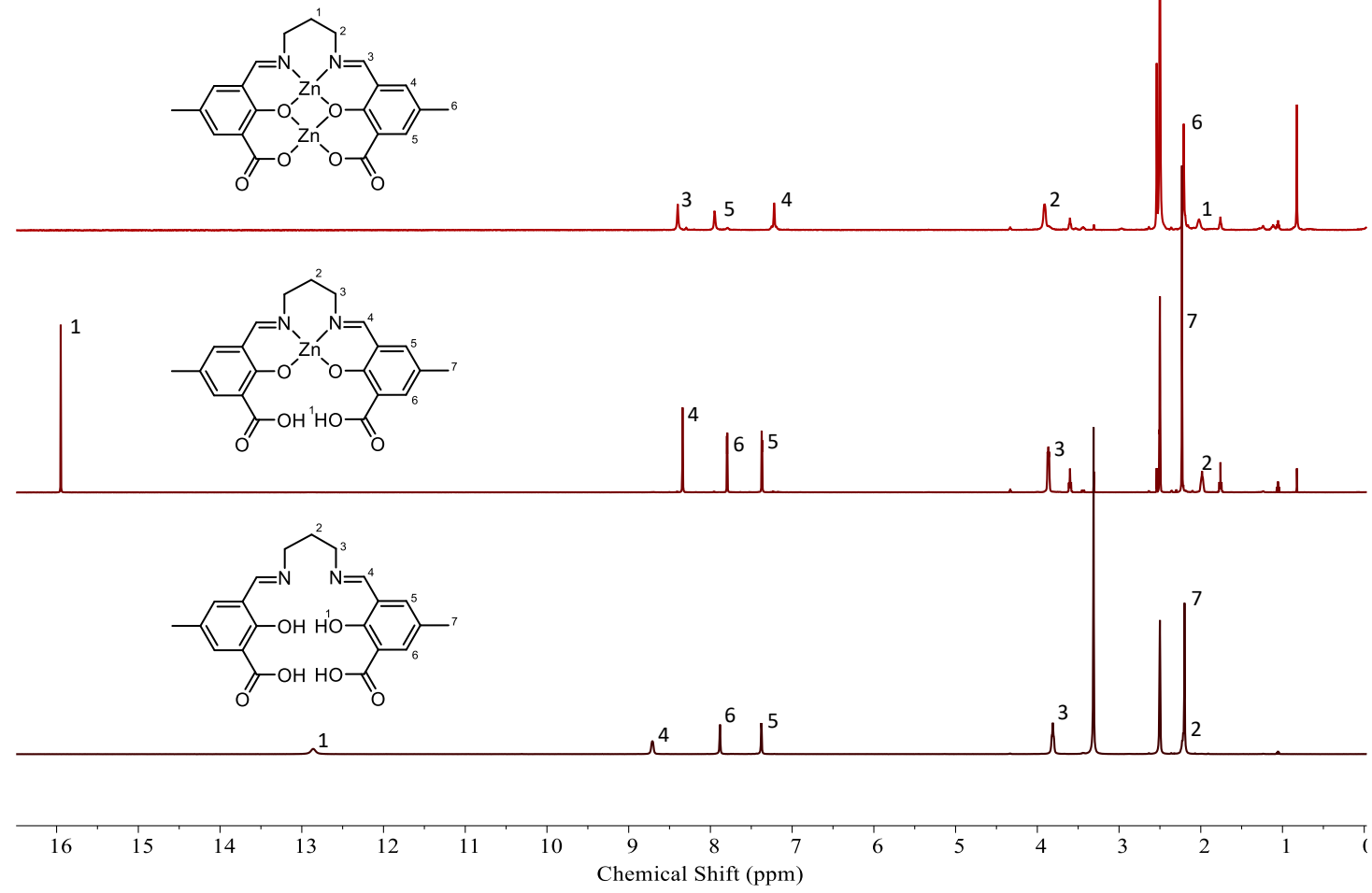

Figure $\mathbf{S 6}{ }^{1} \mathrm{H}$ NMR spectra ( $d_{6}$-DMSO) of ligand $\mathbf{L 1}$ (bottom), the reaction with 1 eq of $\mathrm{Et}_{2} \mathrm{Zn}$ (C2) (middle) and the reaction with 2 eq of $\mathrm{Et}_{2} \mathrm{Zn}$ (top) at $303 \mathrm{~K}$. 


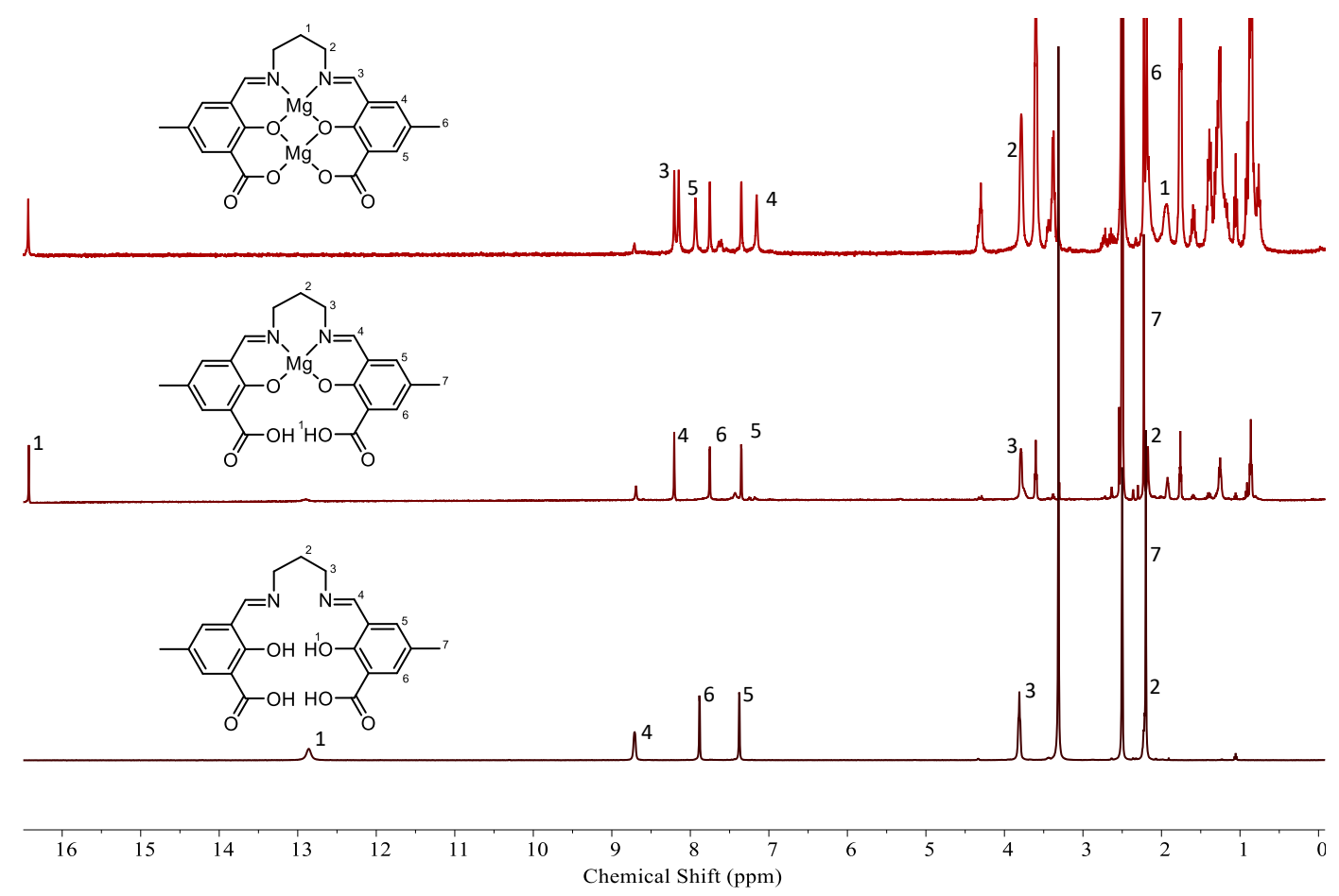

Figure $\mathbf{S 7}{ }^{1} \mathrm{H}$ NMR spectra ( $d_{6}$-DMSO) of ligand $\mathbf{L} 1$ (bottom), the reaction with 1 eq of ${ }^{\mathrm{n}} \mathrm{Bu}_{2} \mathrm{Mg}$ (C3/C3') (middle) and the reaction with 2 eq of ${ }^{n} \mathrm{Bu}_{2} \mathrm{Mg}$ (top) at $303 \mathrm{~K}$.

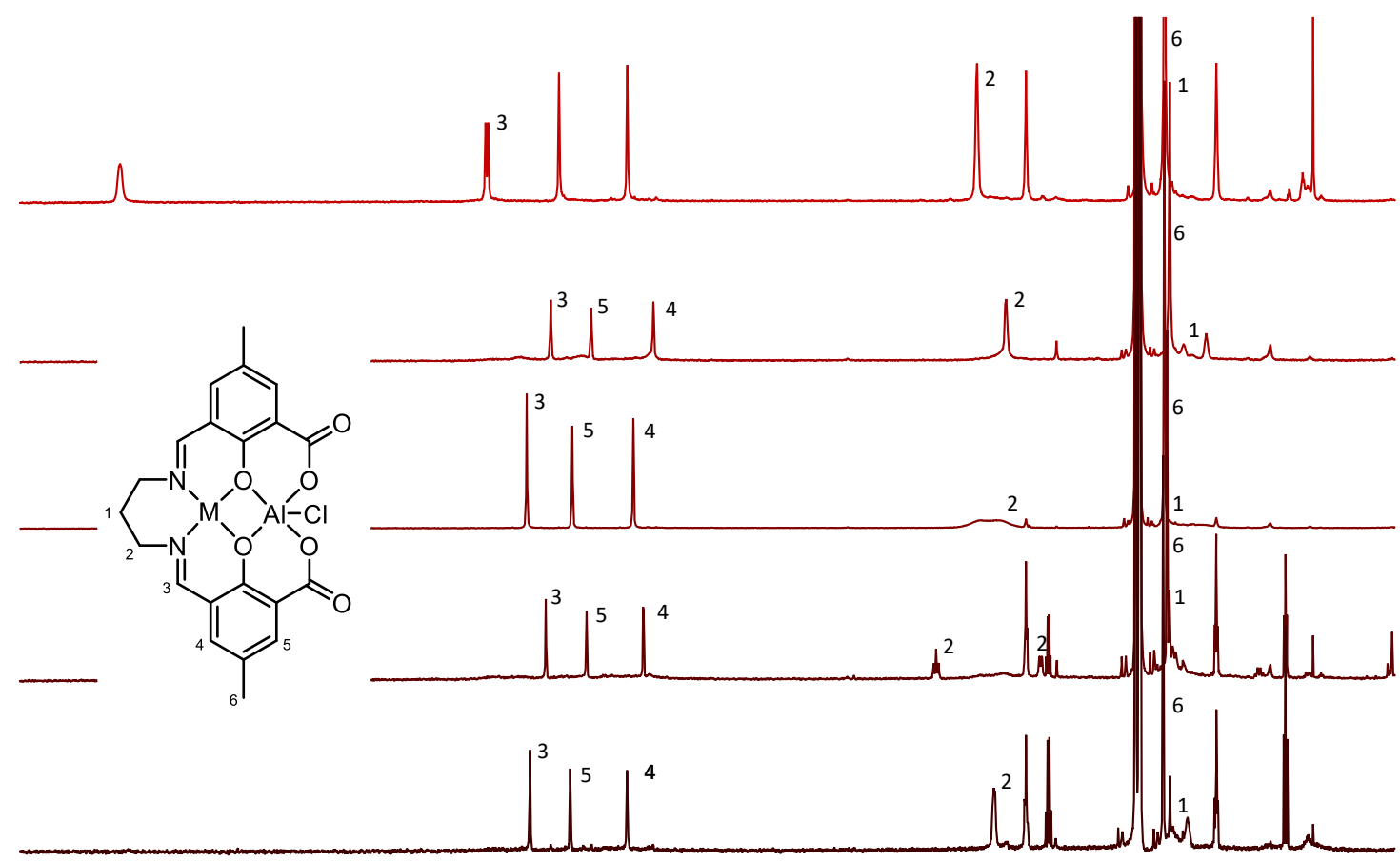

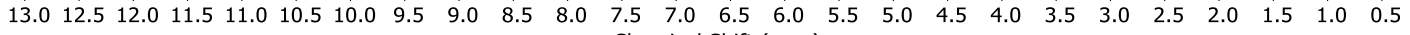
Chemical Shift (ppm)

Figure S8 ${ }^{1} \mathrm{H}$ NMR spectra ( $d_{6}$-DMSO) of (from top to bottom) C1 (Al complex), C1a (AlLi-complex), C1b (AlZn-complex), C1d (AlCa-complex) and C1c (AIMg-complex) at 303K. 


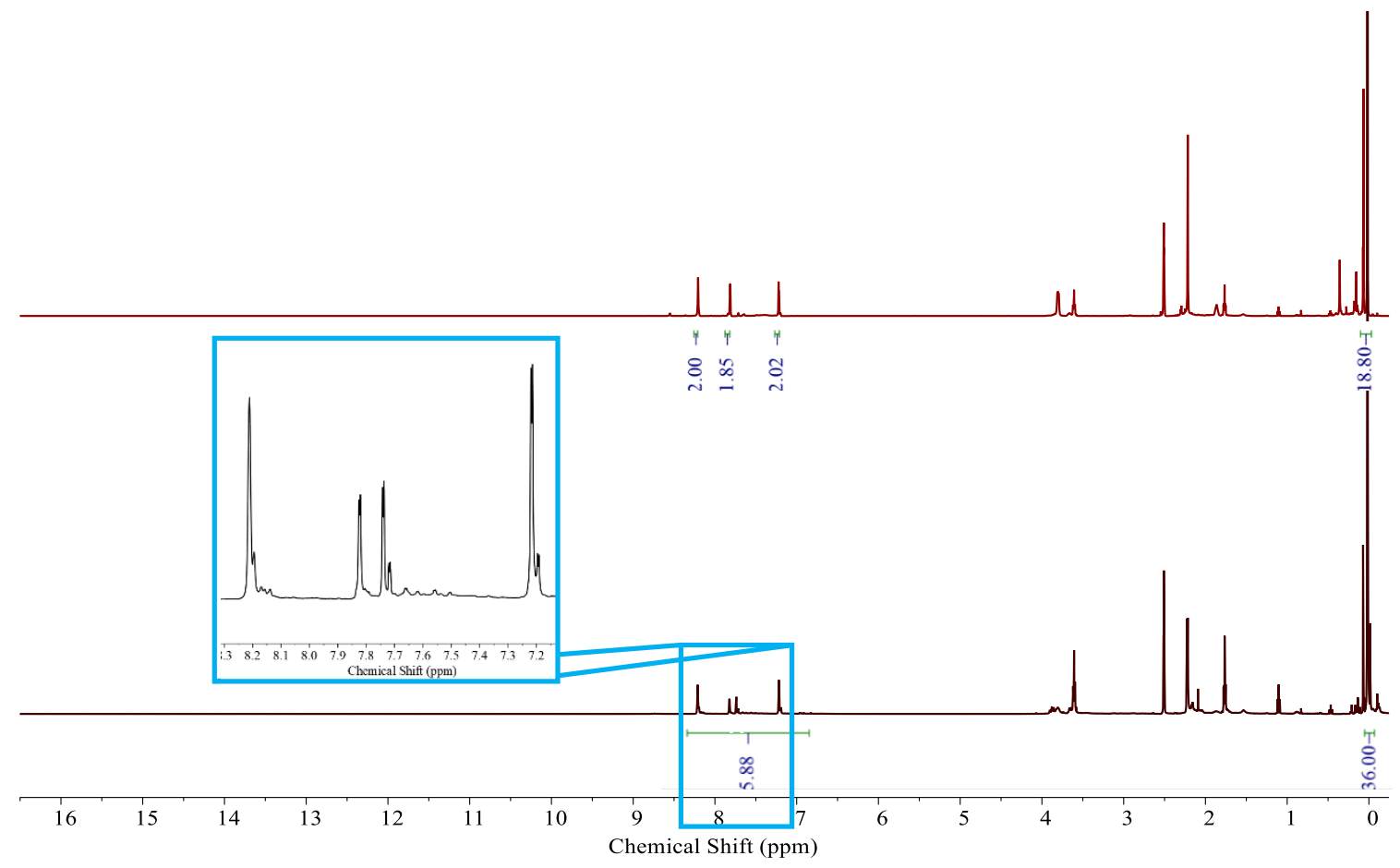

Figure S9 ${ }^{1} \mathrm{H}$ NMR spectra ( $d_{6}$-DMSO) of the in situ reaction of complex C1 ligand +2 equivalents of LiHMDS (bottom), and the reaction with 1 equivalent of LiHMDS (top) at 303K. Aromatic/imine and HMDS protons integrated. Selected resonances magnified for clarity.

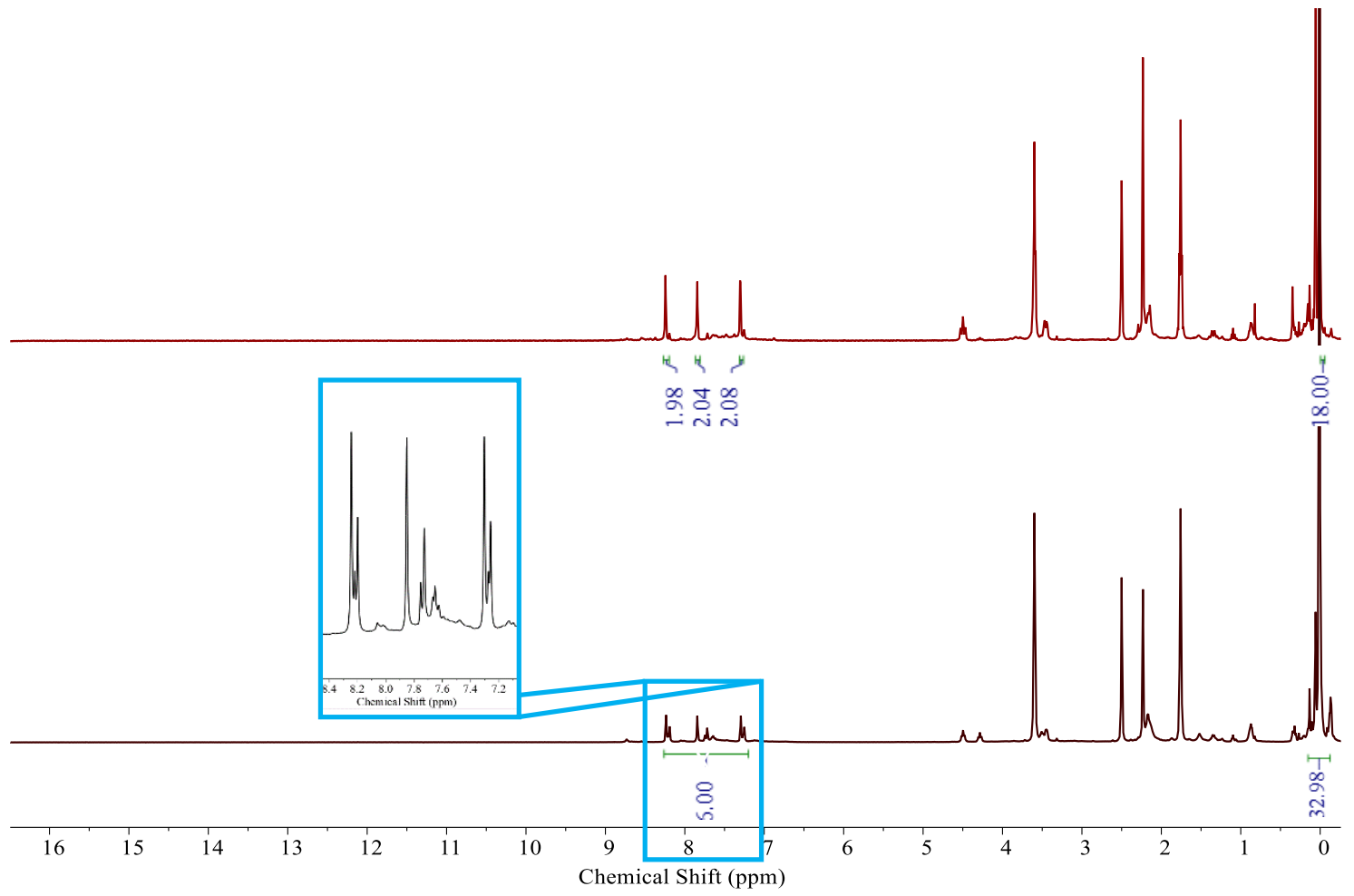

Figure $\mathbf{S 1 0}{ }^{1} \mathrm{H}$ NMR spectra ( $d_{6}$-DMSO) of the in situ reaction of complex $\mathbf{C 1}$ ligand +1 equivalent of $\mathrm{CaHMDS}_{2}$ (bottom), and the reaction with 0.5 equivalents of $\mathrm{CaHMDS}_{2}$ (top) at $303 \mathrm{~K}$. Aromatic/imine and HMDS protons integrated. Selected resonances magnified for clarity. 
$4 \quad{ }^{1} \mathrm{H}$ and ${ }^{13} \mathrm{C}$ NMR data of salen ligands and complexes

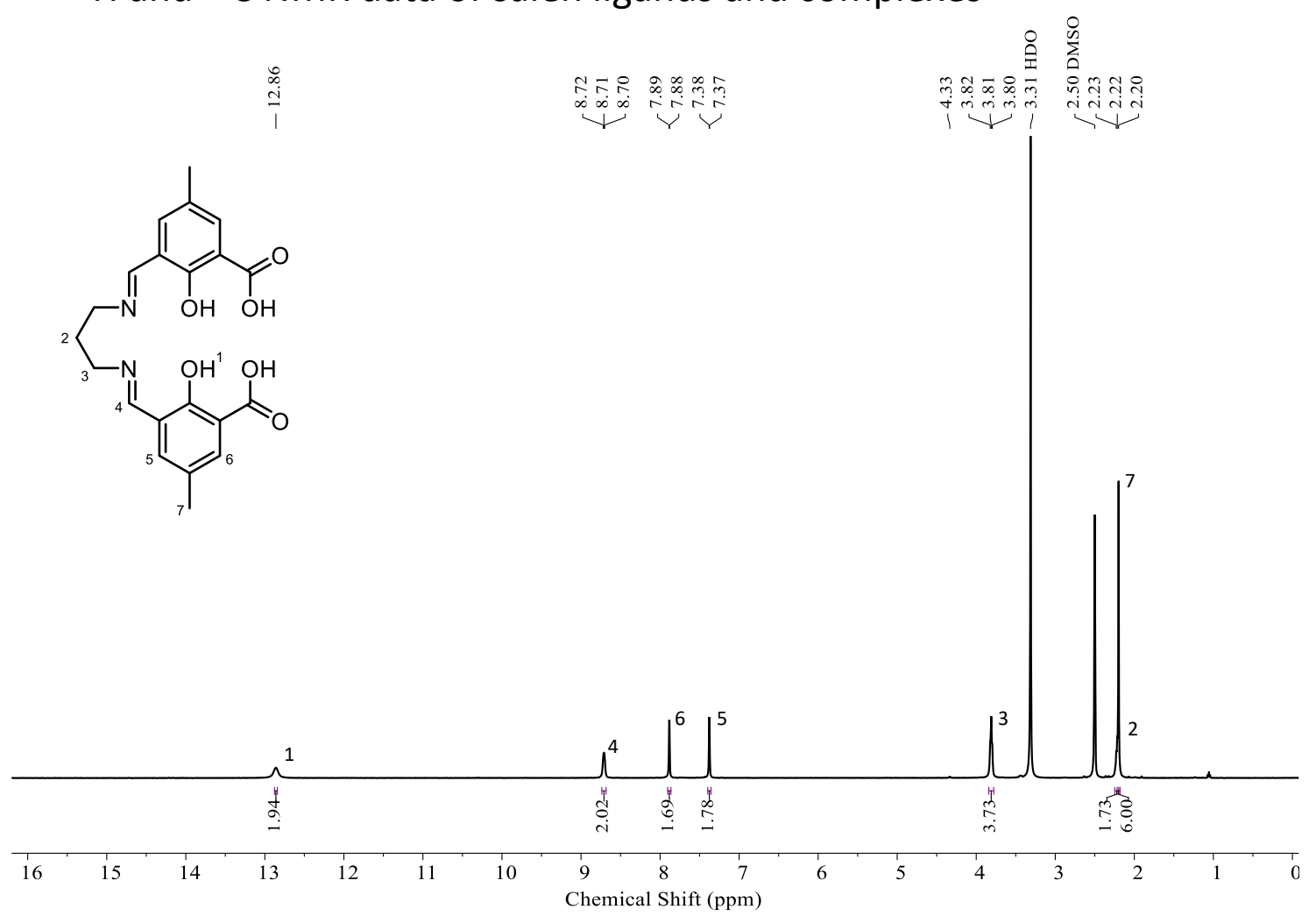

Figure $\mathbf{S} 11{ }^{1} \mathrm{H}$ NMR spectrum ( $d_{6}$-DMSO) of $\mathbf{L} 1$ at $303 \mathrm{~K}$.

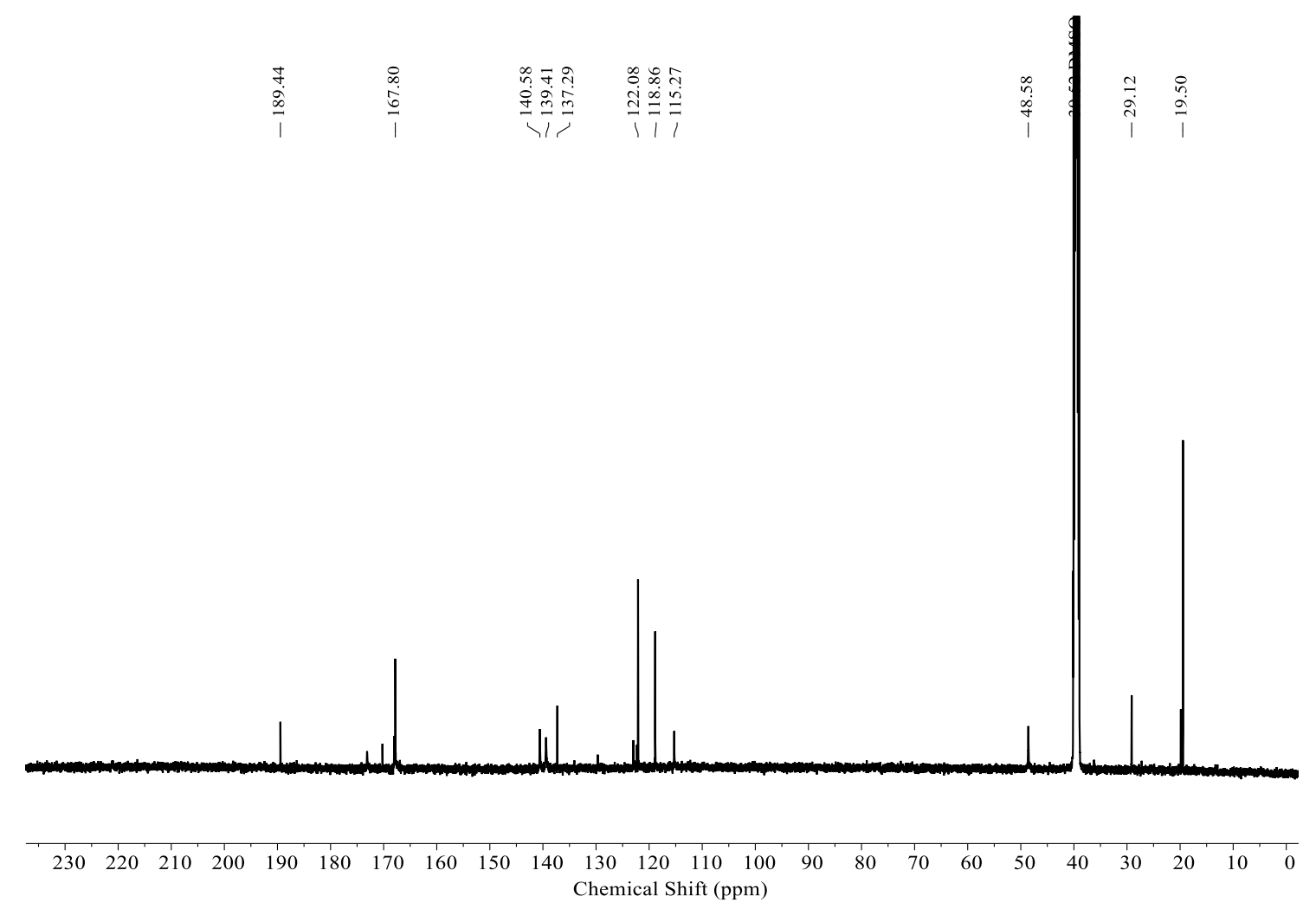

Figure $\mathbf{S 1 2}{ }^{13} \mathrm{C}$ NMR spectrum ( $d_{6}$-DMSO) of $\mathbf{L} 1$ at 303K. 


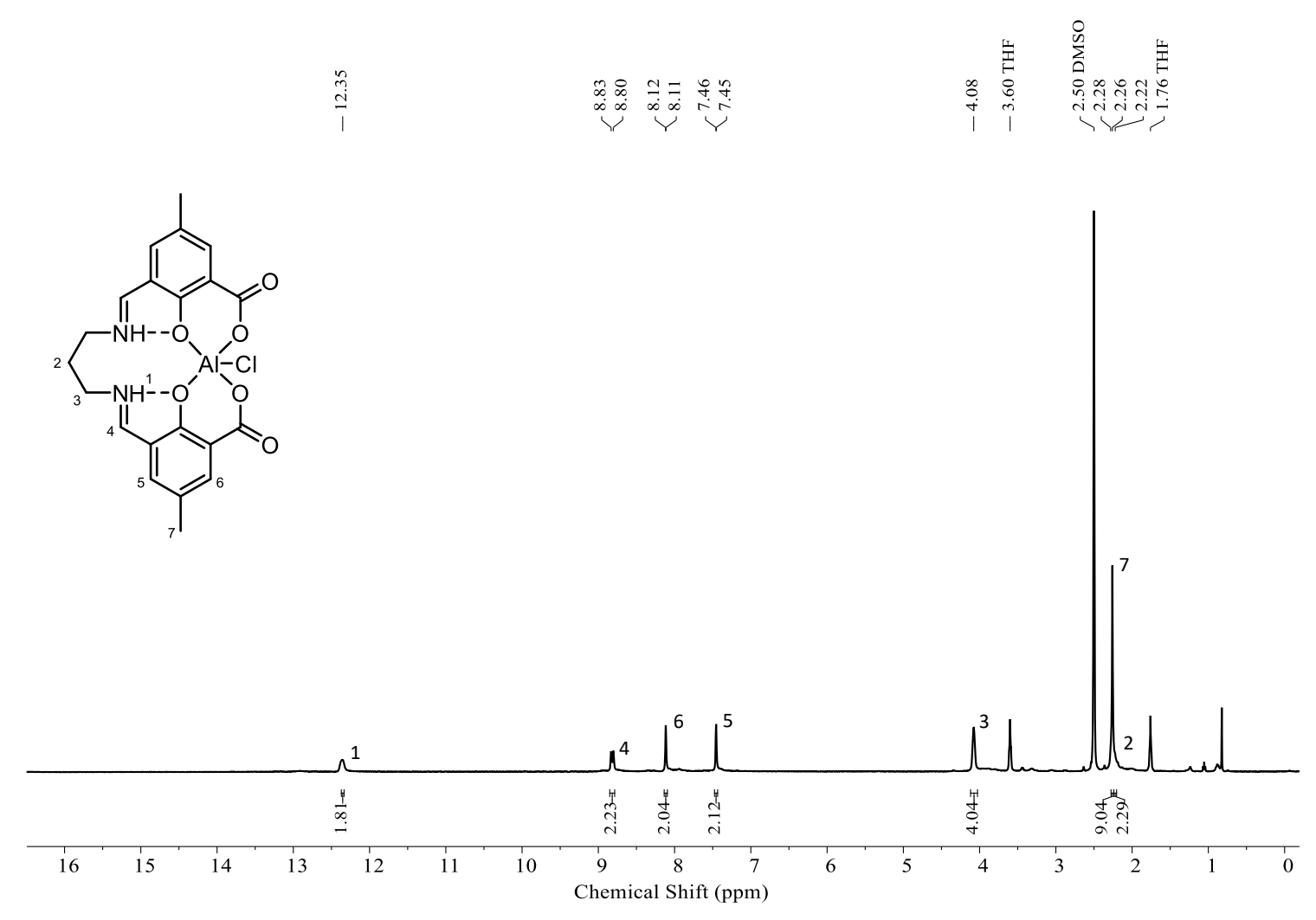

Figure $\mathrm{S} 13{ }^{1} \mathrm{H}$ NMR spectrum ( $d_{6}$-DMSO) of $\mathrm{C} 1$ at $303 \mathrm{~K}$.

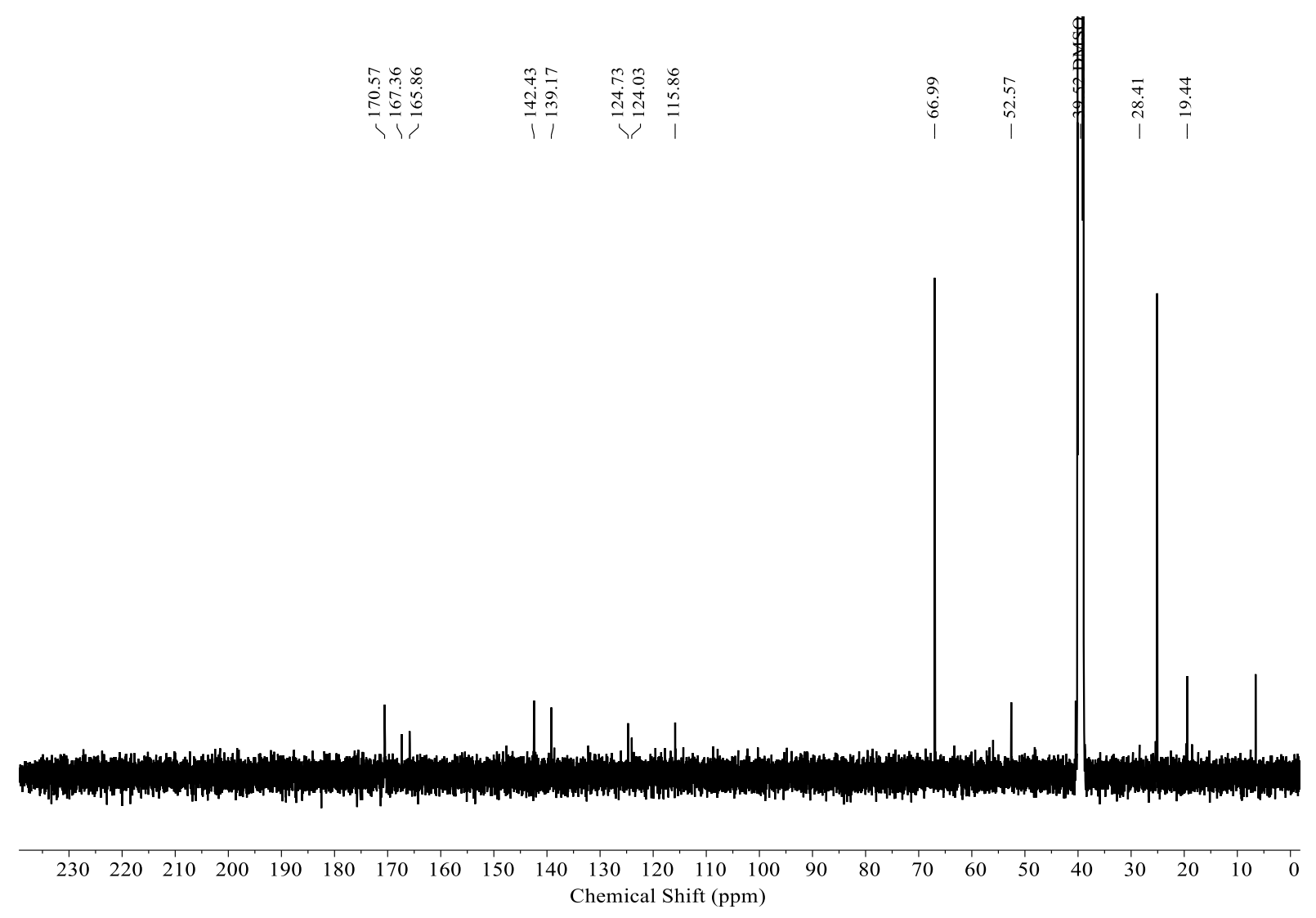

Figure $\mathbf{S 1 4}{ }^{13} \mathrm{C}$ NMR spectrum $\left(d_{6}\right.$-DMSO) of $\mathbf{C} 1$ at $303 \mathrm{~K}$. 


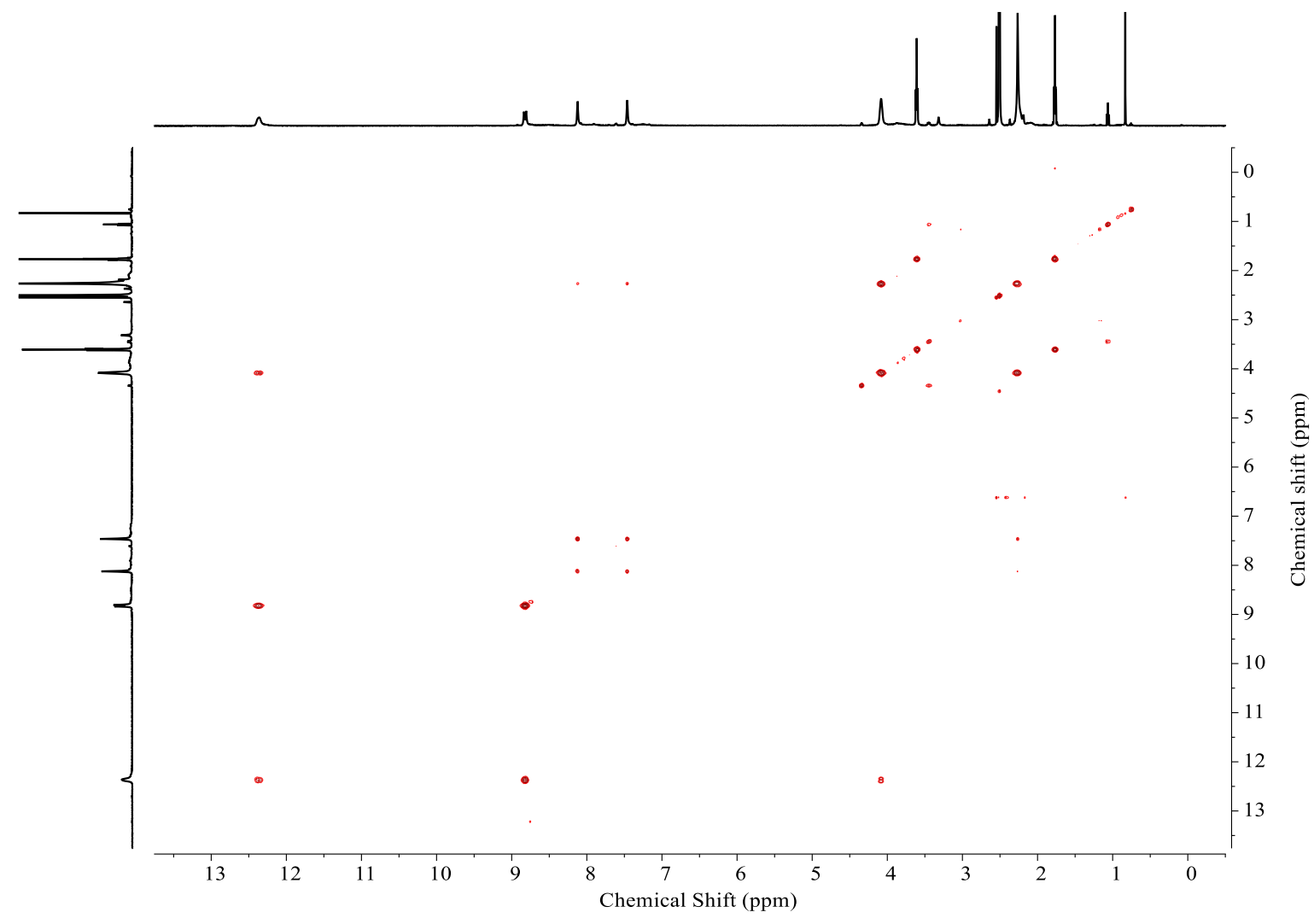

Figure $\mathbf{S 1 5}$ COSY NMR spectrum ( $d_{6}$-DMSO) of $\mathbf{C} 1$ at $303 \mathrm{~K}$.

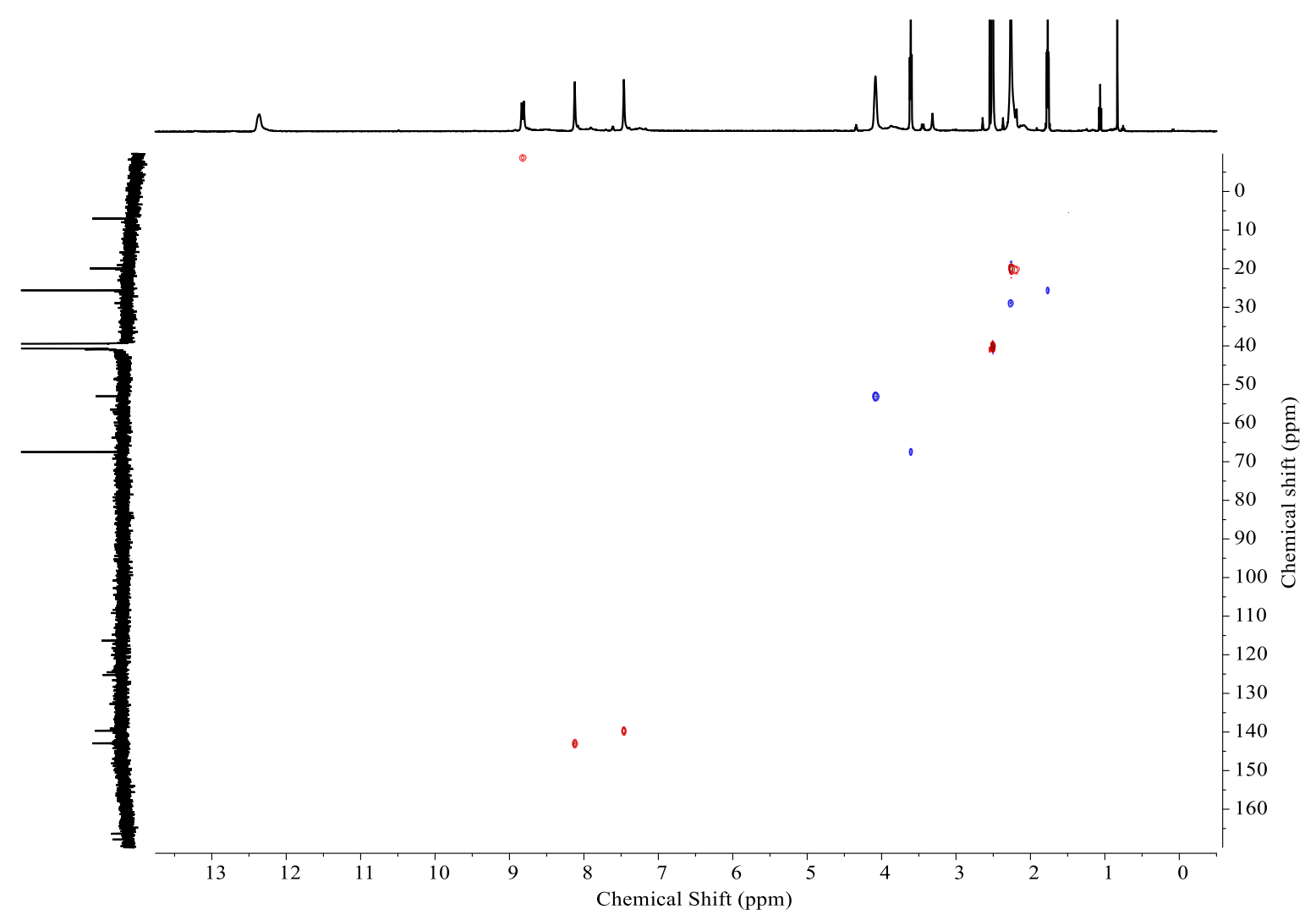

Figure S16 HSQC NMR spectrum ( $d_{6}$-DMSO) of $\mathbf{C 1}$ at 303K. 


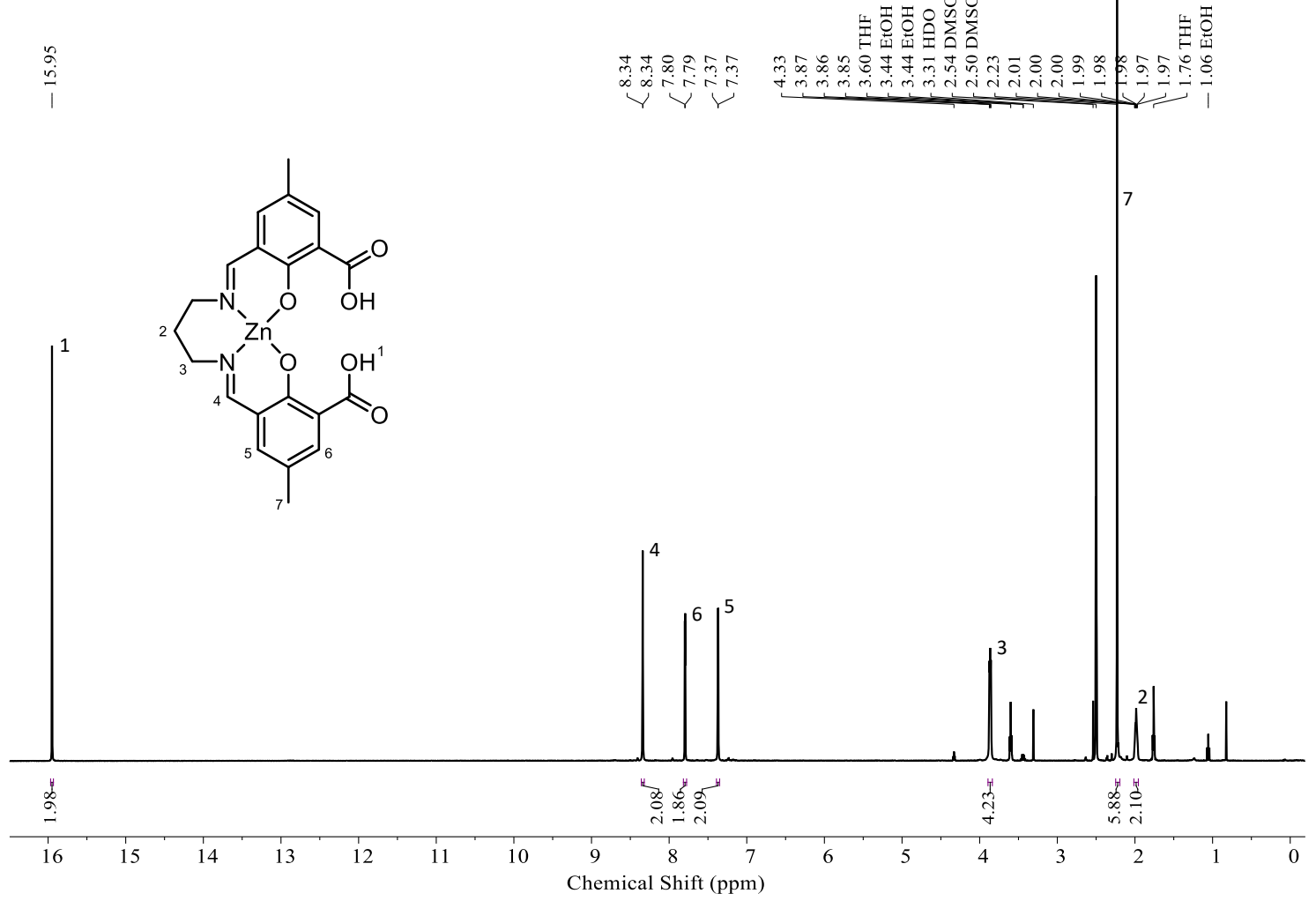

Figure $\mathbf{S 1 7}{ }^{1} \mathrm{H}$ NMR spectrum ( $d_{6}$-DMSO) of $\mathbf{C 2}$ at $303 \mathrm{~K}$.

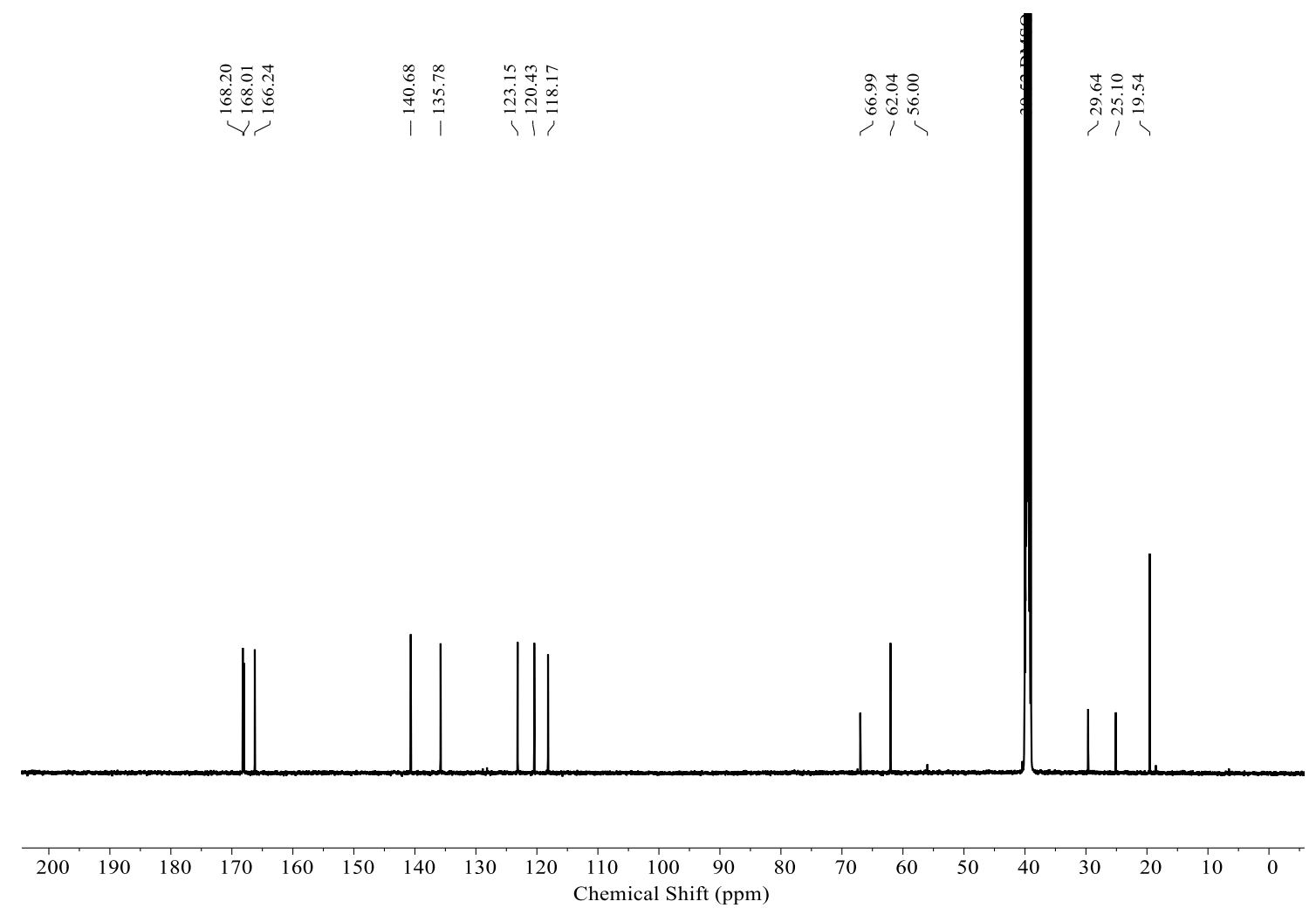

Figure $\mathbf{S 1 8}{ }^{13} \mathrm{C}$ NMR spectrum ( $d_{6}$-DMSO) of $\mathbf{C 2}$ at $303 \mathrm{~K}$. 


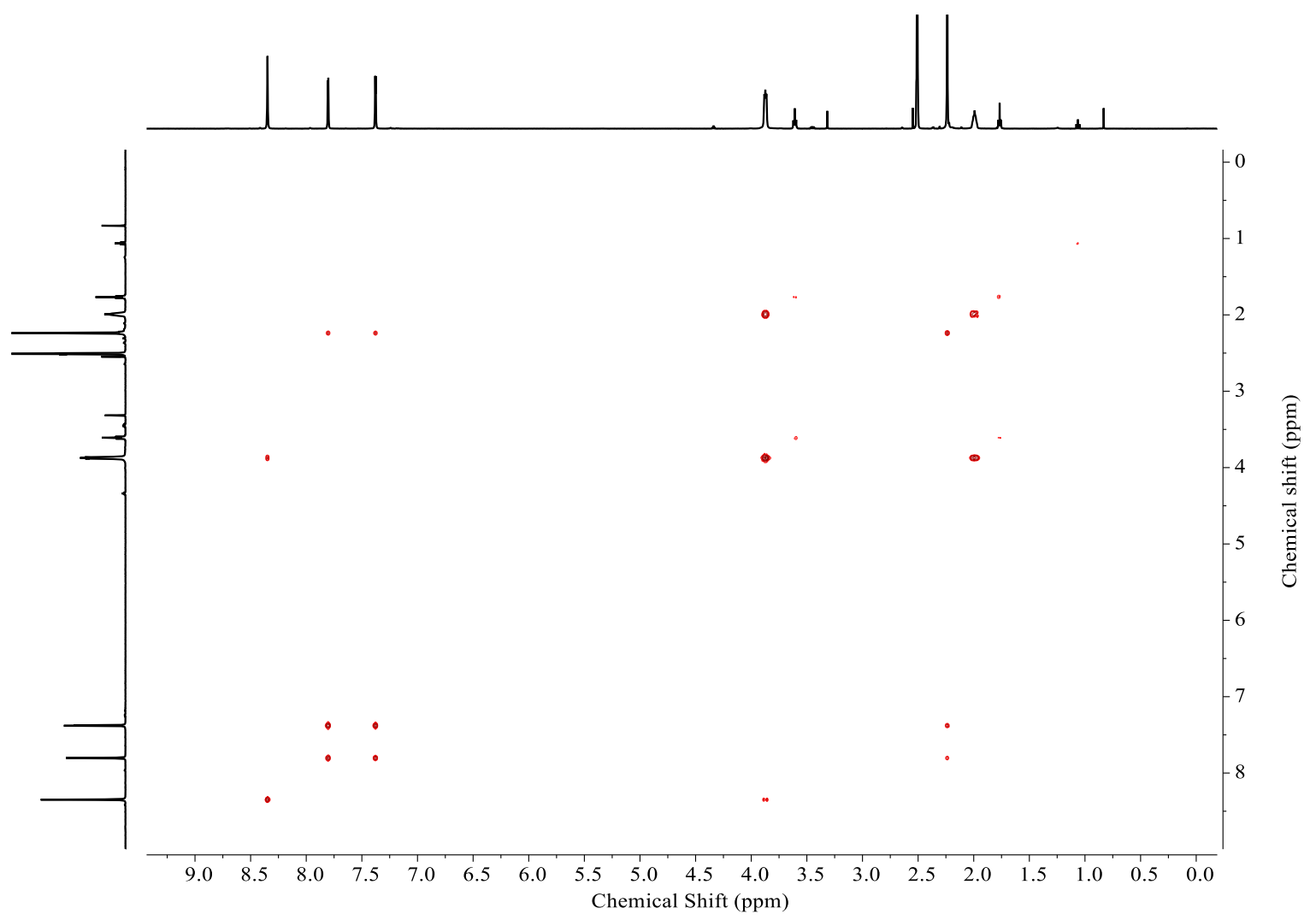

Figure S19 COSY NMR spectrum ( $d_{6}$-DMSO) of C2 at 303K.

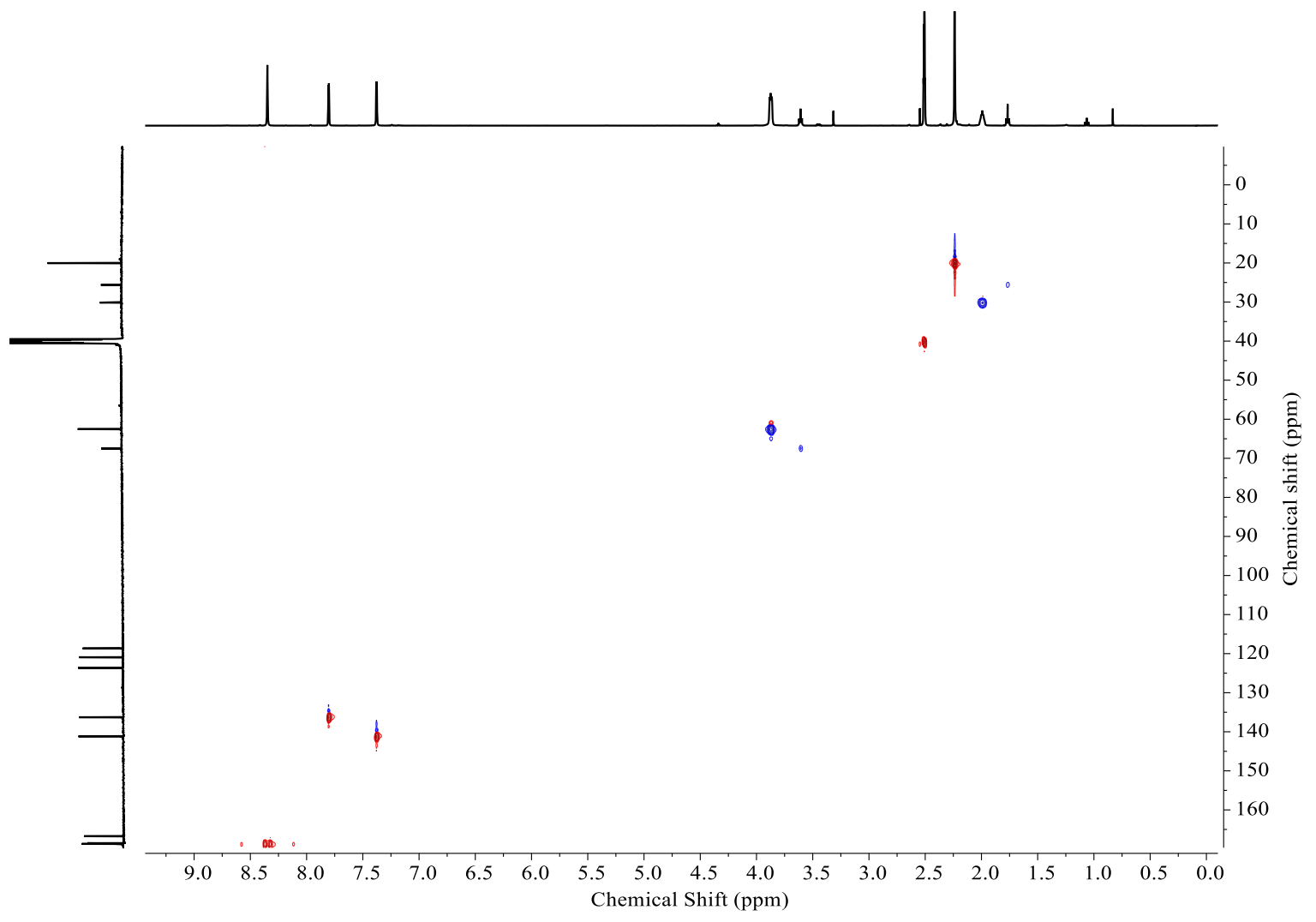

Figure S20 HSQC NMR spectrum ( $d_{6}$-DMSO) of C2 at 303K. 


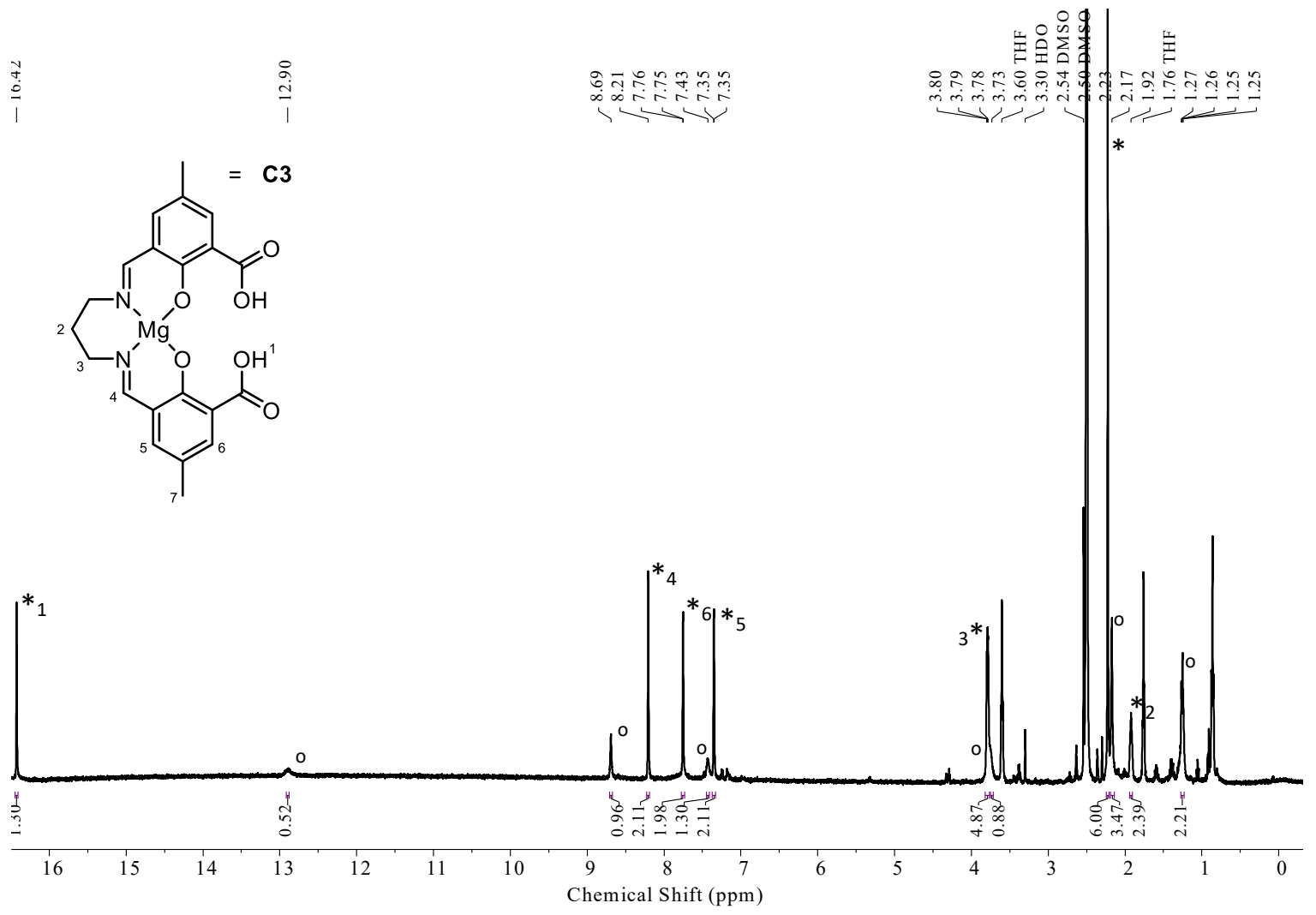

Figure S21 ${ }^{1} \mathrm{H}$ NMR spectrum ( $d_{6}$-DMSO) of a mixture of $\mathbf{C 3}\left({ }^{*}\right.$ attributed signals) and $\mathbf{C 3}^{\prime}\left({ }^{\circ}\right.$ attributed signals) at $303 \mathrm{~K}$.

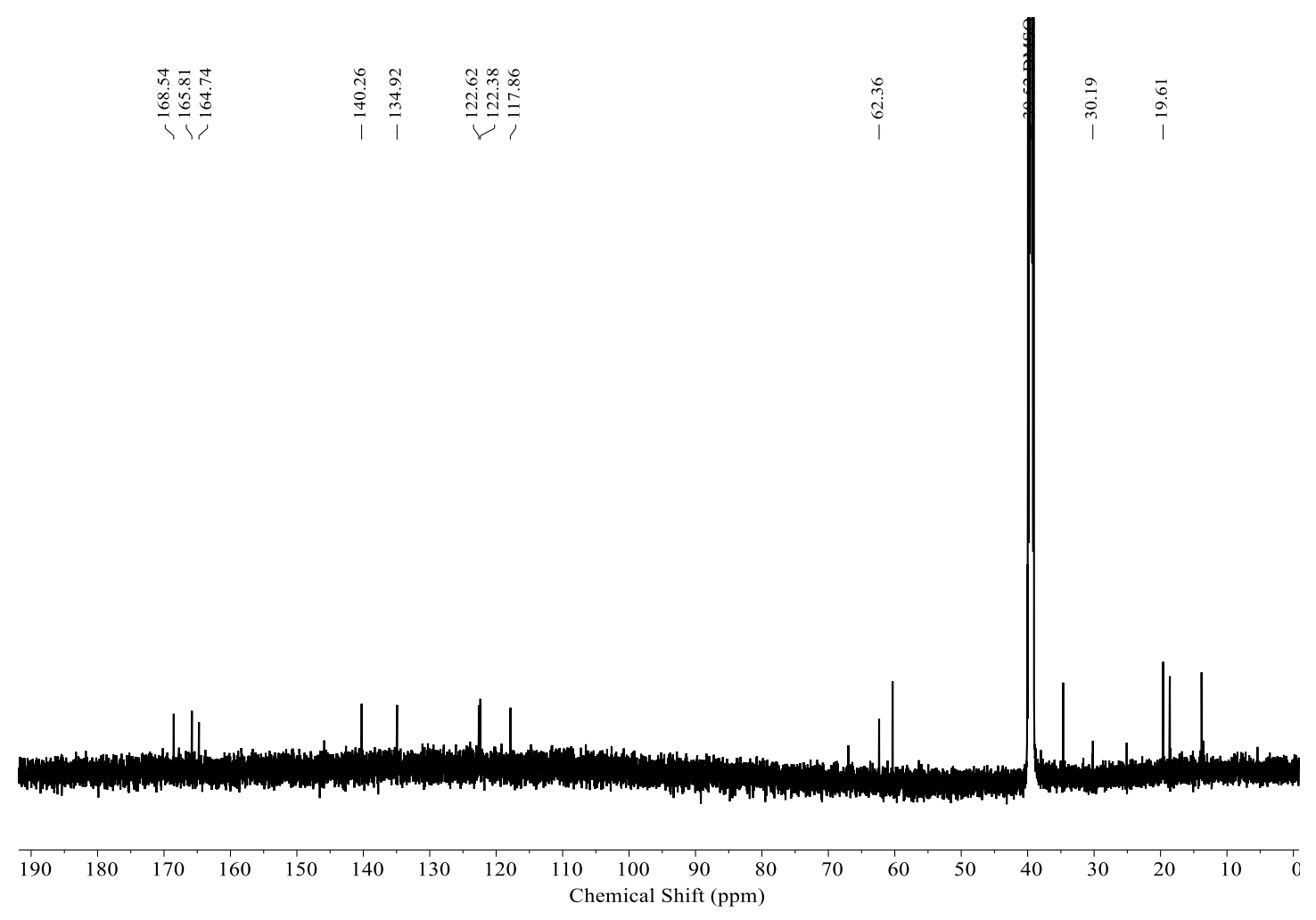

Figure S22 ${ }^{13} \mathrm{C}$ NMR spectrum ( $d_{6}$-DMSO) of a mixture of $\mathbf{C 3}$ and $\mathbf{C 3}^{\prime}$ at $303 \mathrm{~K}$. 


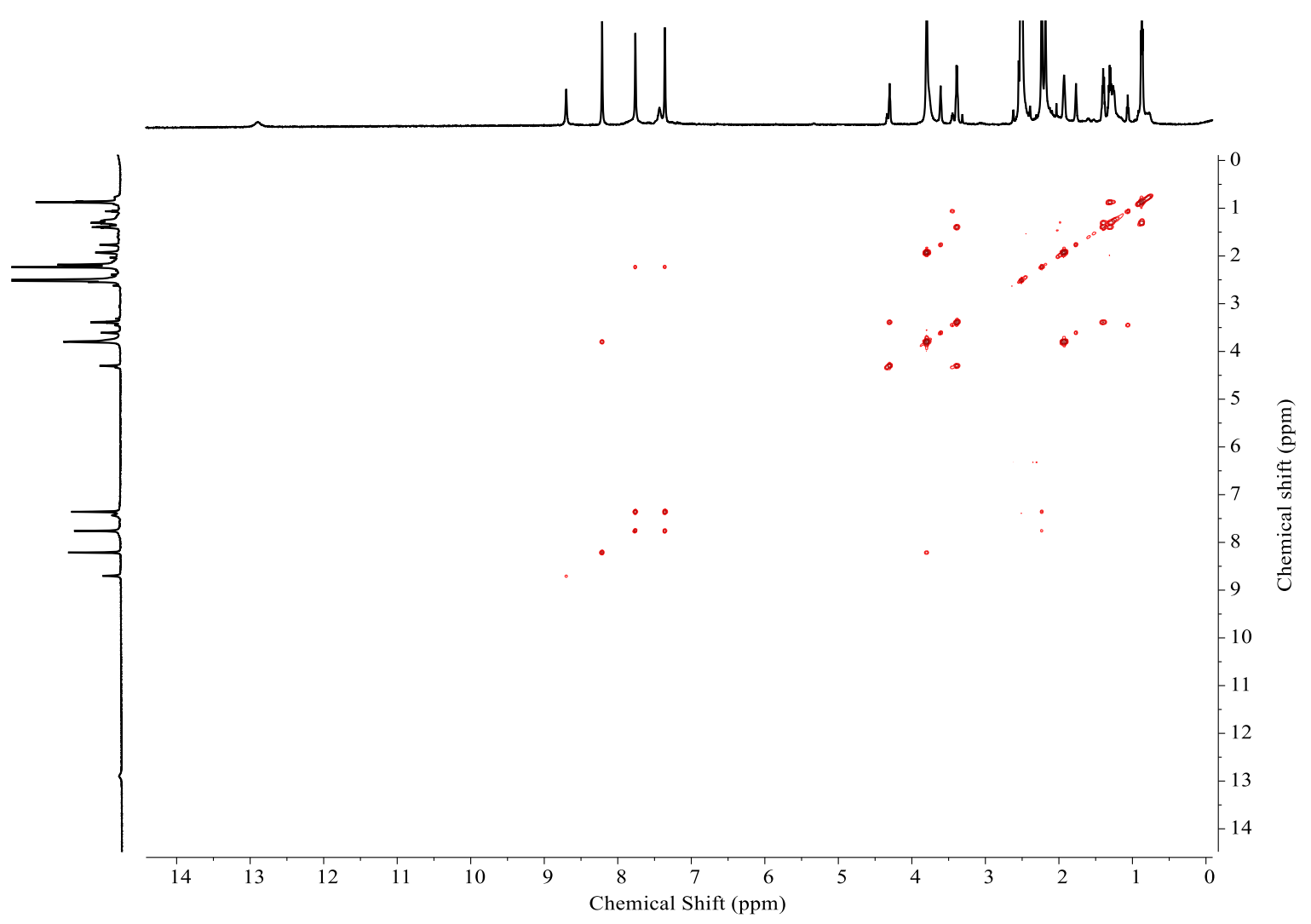

Figure S23 COSY NMR spectrum ( $d_{6}$-DMSO) of a mixture of C3 and $\mathbf{C 3}^{\prime}$ at 303K.

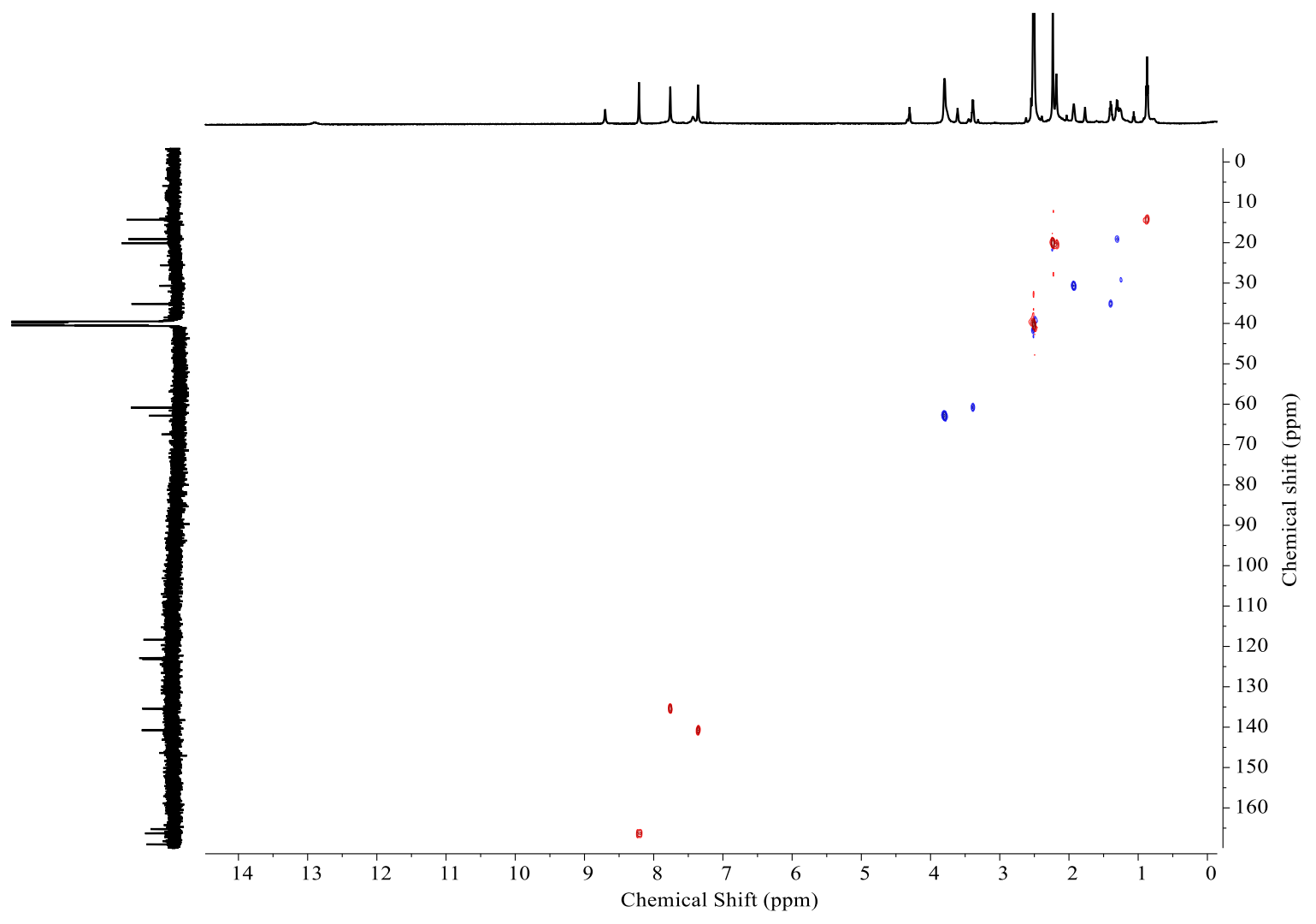

Figure S24 HSQC NMR spectrum ( $d_{6}$-DMSO) of a mixture of C3 and C3' at 303K. 


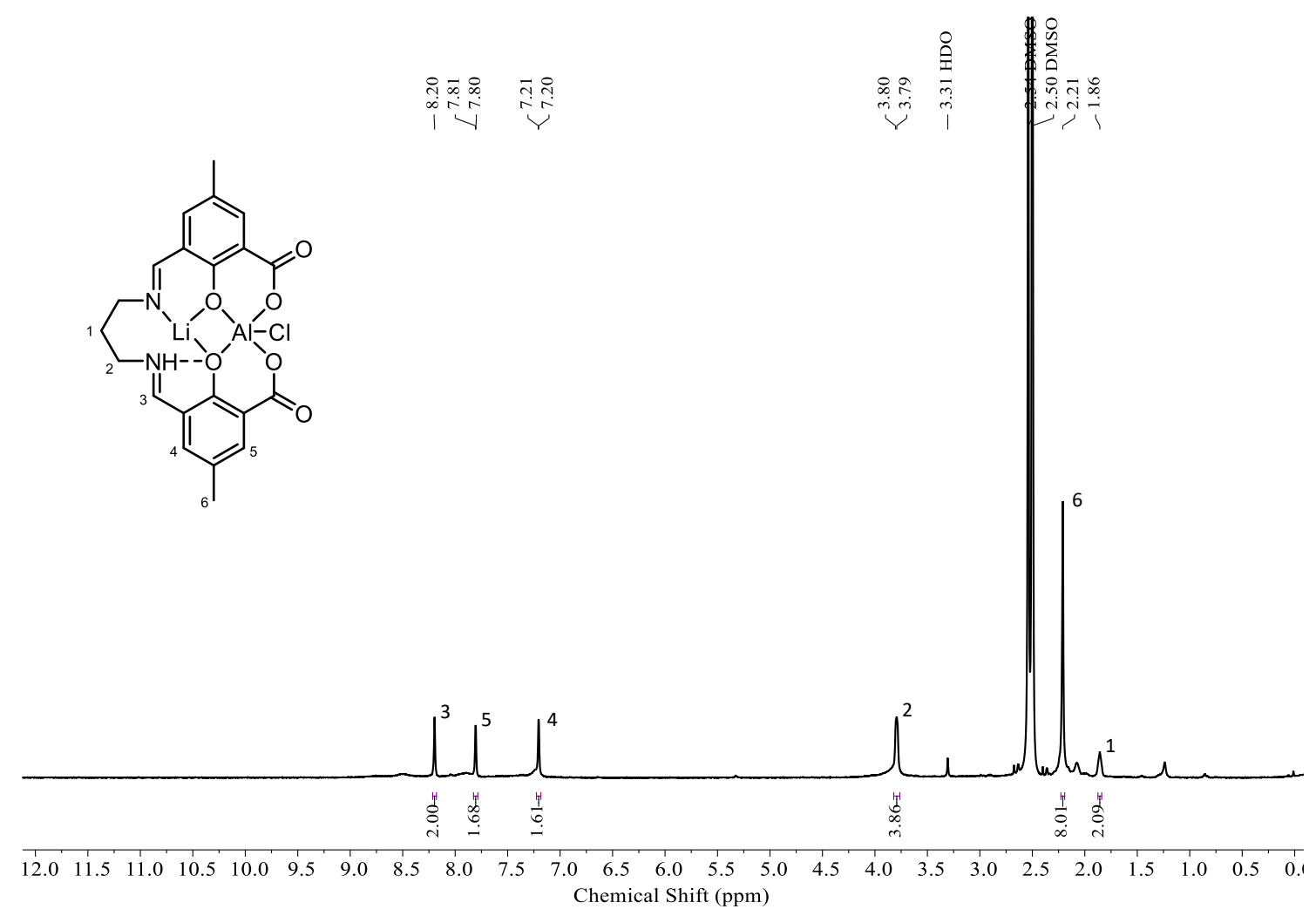

Figure $\mathbf{S 2 5}{ }^{1} \mathrm{H}$ NMR spectrum ( $d_{6}$-DMSO) of C1a at 303K.

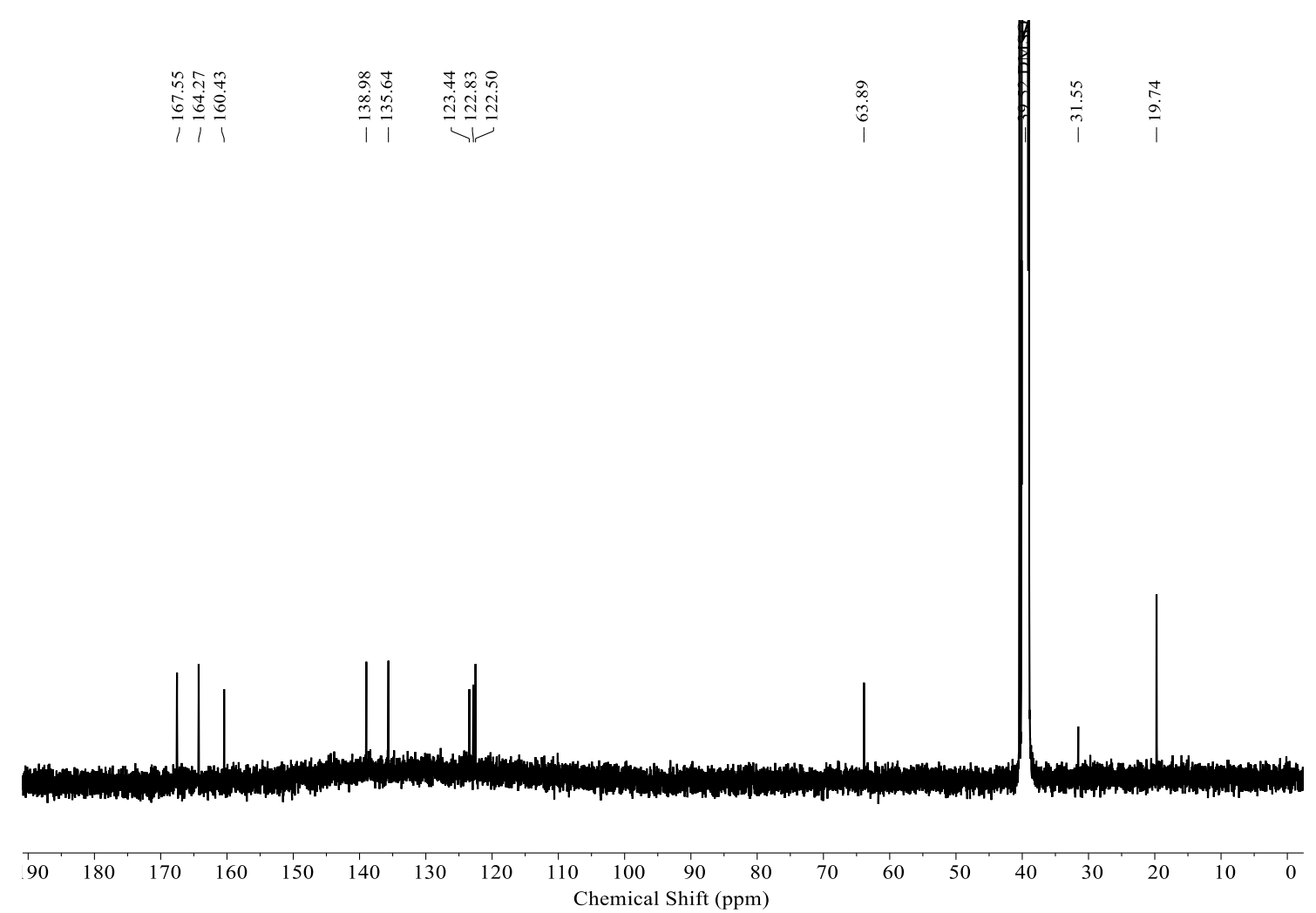

Figure $\mathrm{S} 26{ }^{13} \mathrm{C}$ NMR spectrum ( $d_{6}$-DMSO) of C1a at $303 \mathrm{~K}$. 


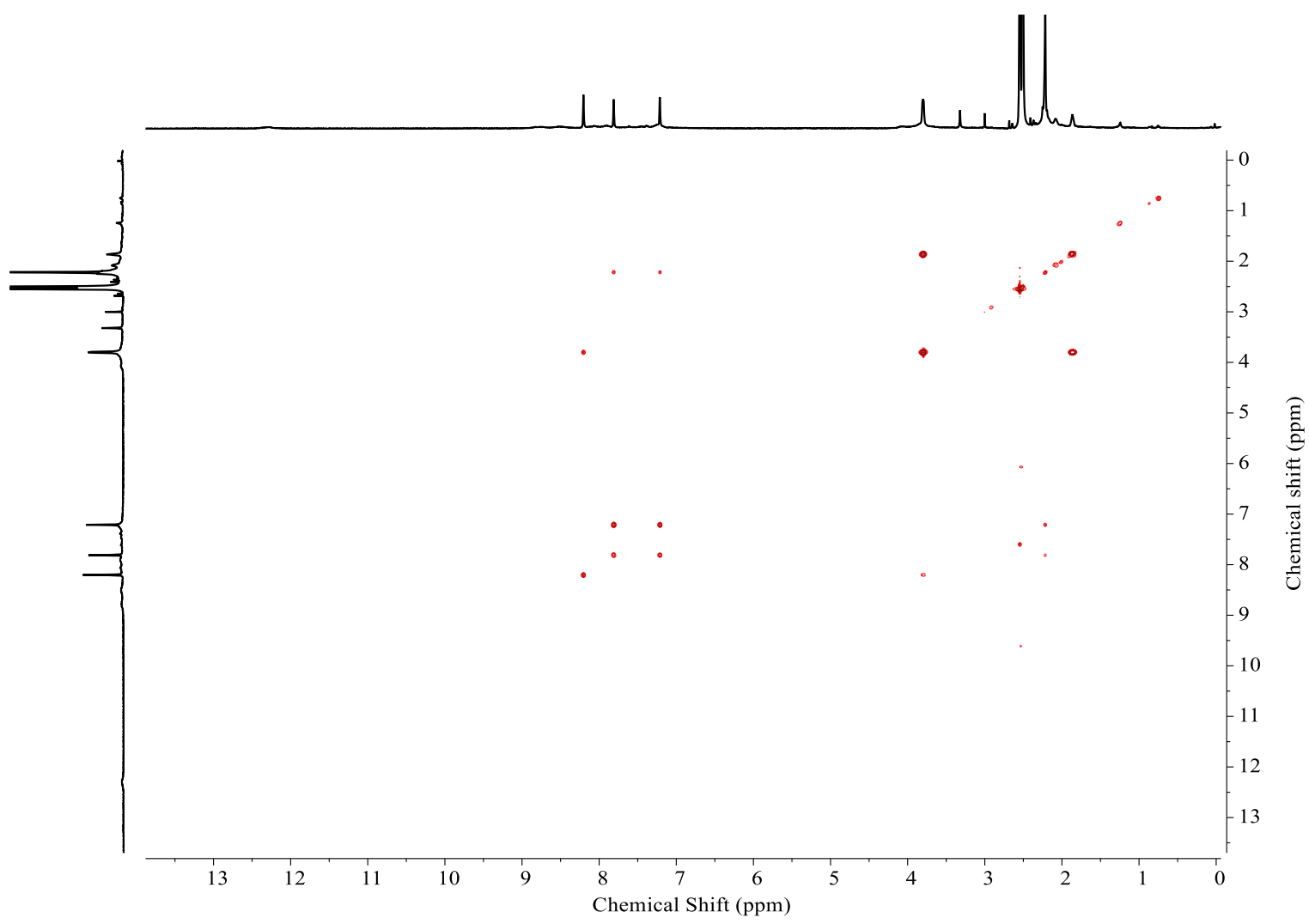

Figure S27 COSY NMR spectrum ( $d_{6}$-DMSO) of C1a at 303K.

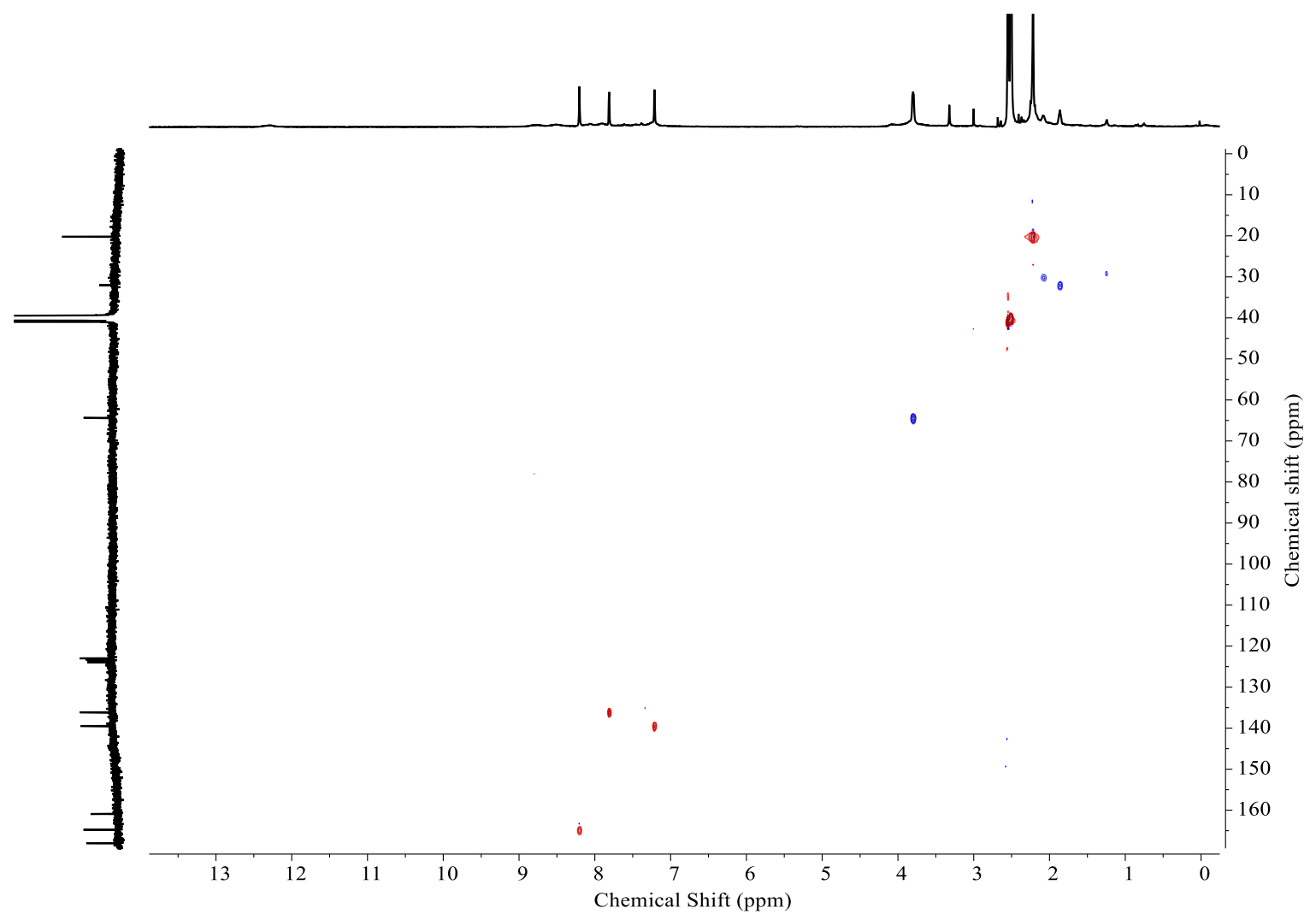

Figure S28 HSQC NMR spectrum ( $d_{6}$-DMSO) of C1a at 303K. 


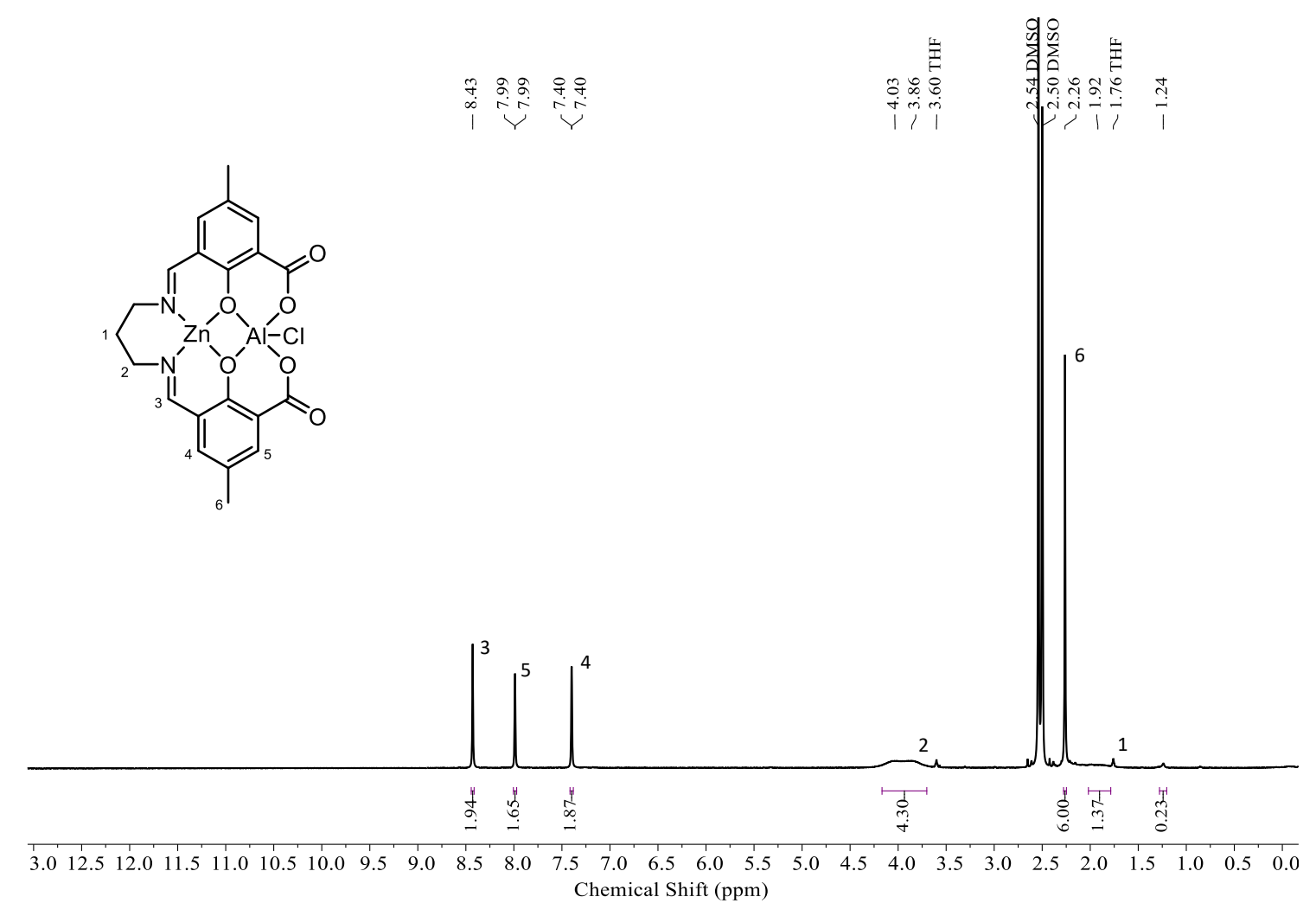

Figure $\mathbf{S 2 9}{ }^{1} \mathrm{H}$ NMR spectrum ( $d_{6}$-DMSO) of $\mathbf{C} 1 \mathrm{~b}$ at $303 \mathrm{~K}$.

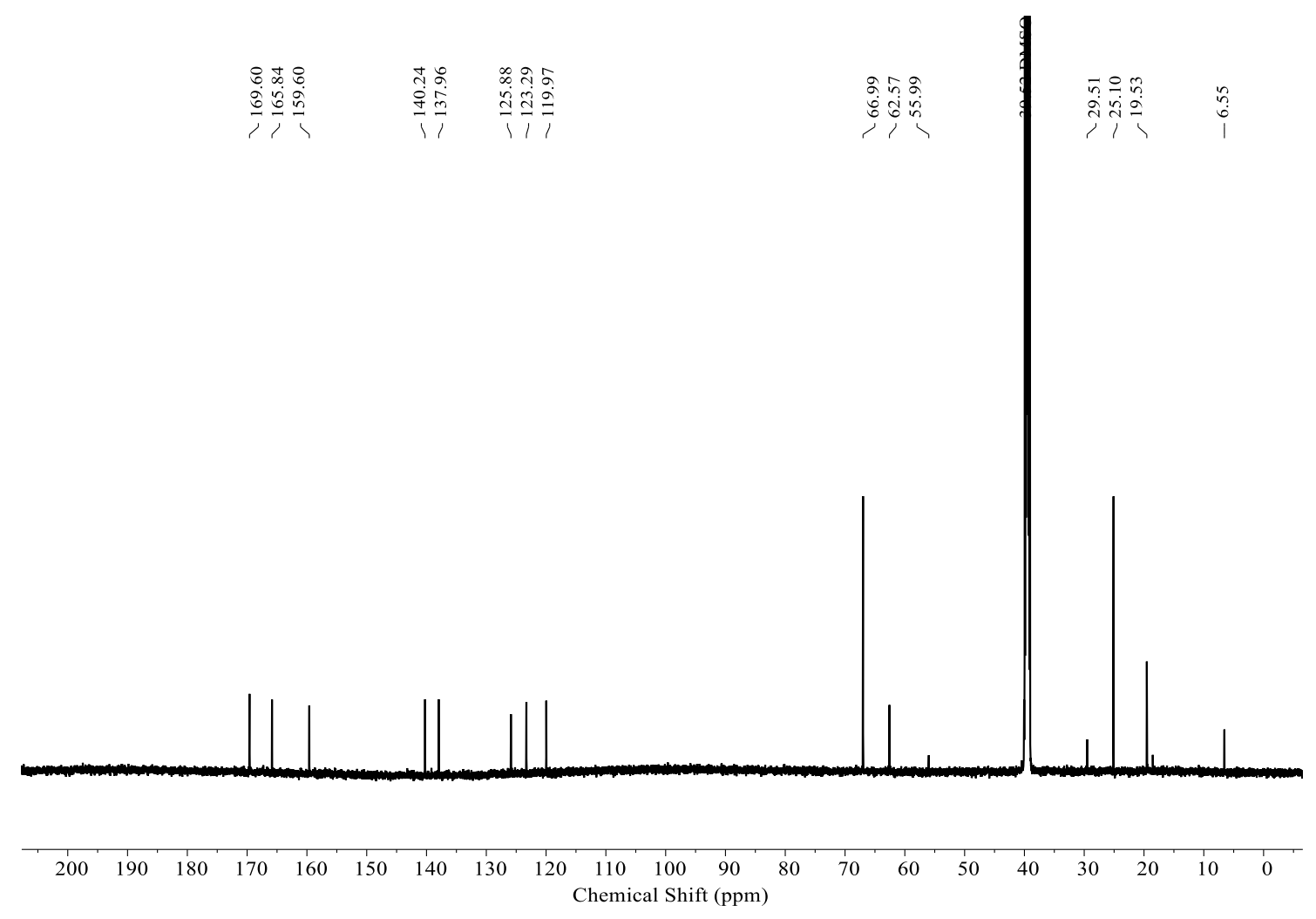

Figure $\mathbf{S} 30{ }^{13} \mathrm{C}$ NMR spectrum ( $d_{6}$-DMSO) of $\mathbf{C 1 b}$ at $303 \mathrm{~K}$. 


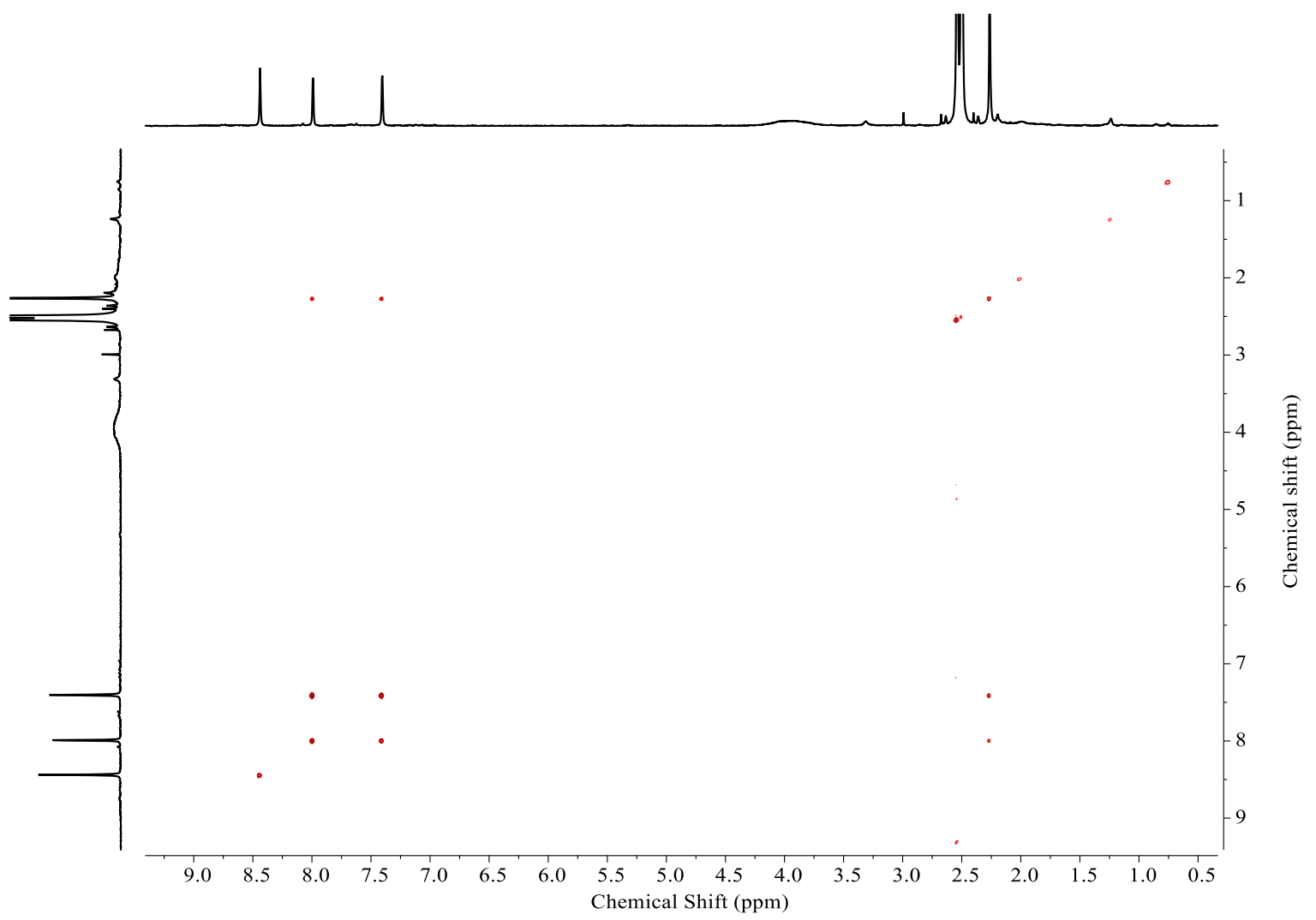

Figure S31 COSY NMR spectrum ( $d_{6}$-DMSO) of $\mathbf{C} 1 \mathbf{b}$ at $303 \mathrm{~K}$.

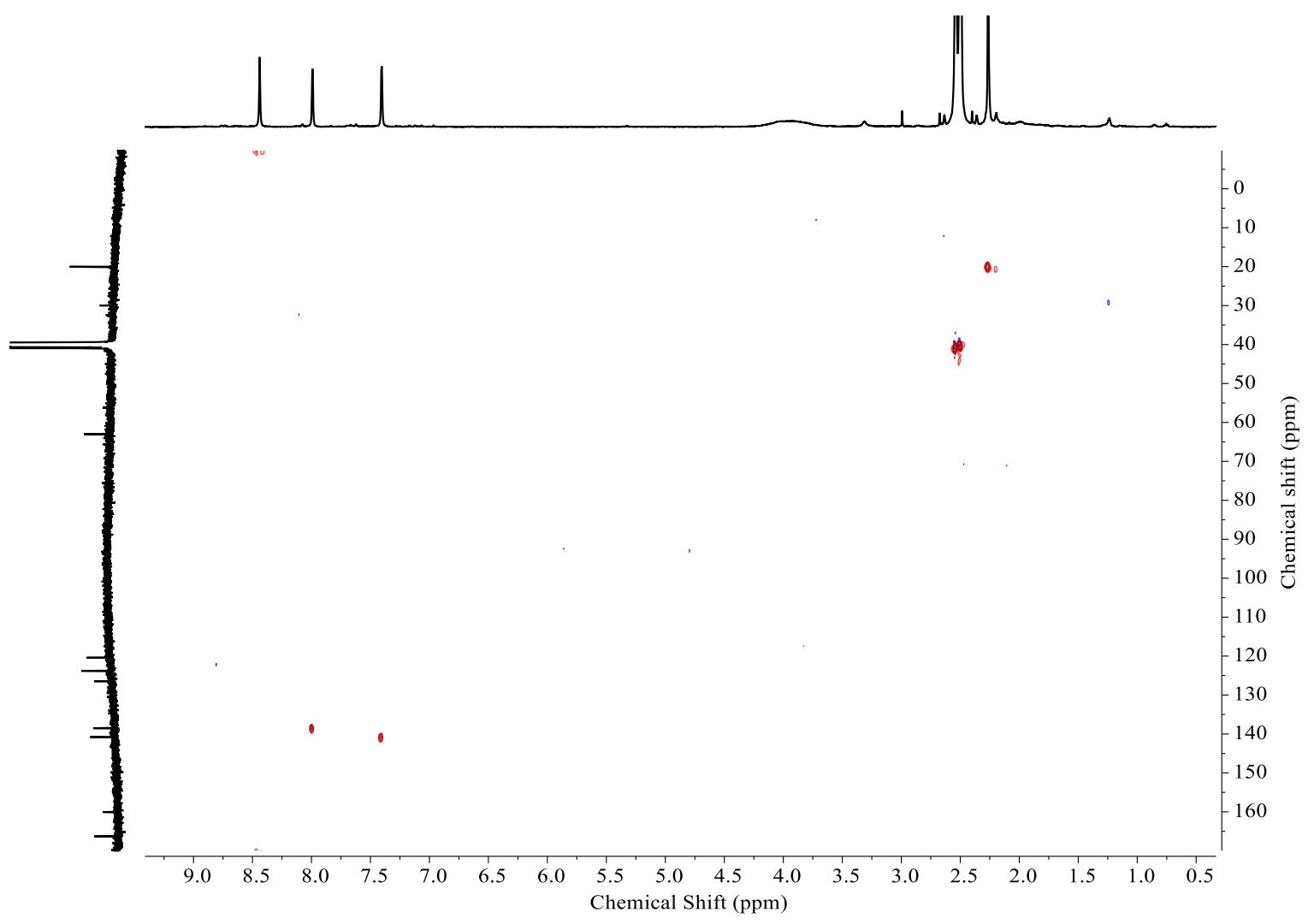

Figure S32 HSQC NMR spectrum ( $d_{6}$-DMSO) of C1b at 303K. 


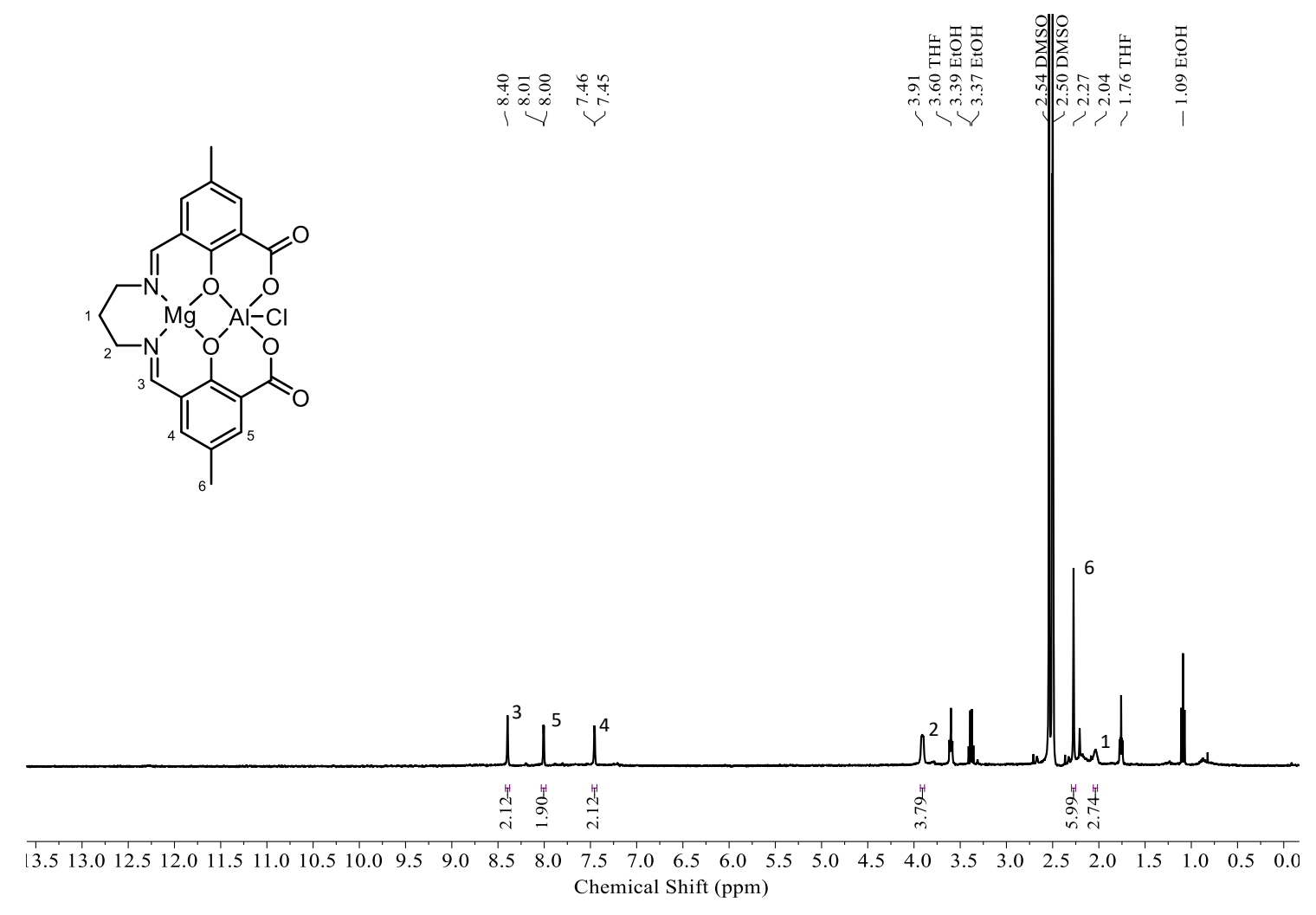

Figure $S 33{ }^{1} \mathrm{H}$ NMR spectrum $\left(d_{6}\right.$-DMSO) of $\mathrm{C} 1 \mathrm{c}$ at $303 \mathrm{~K}$.

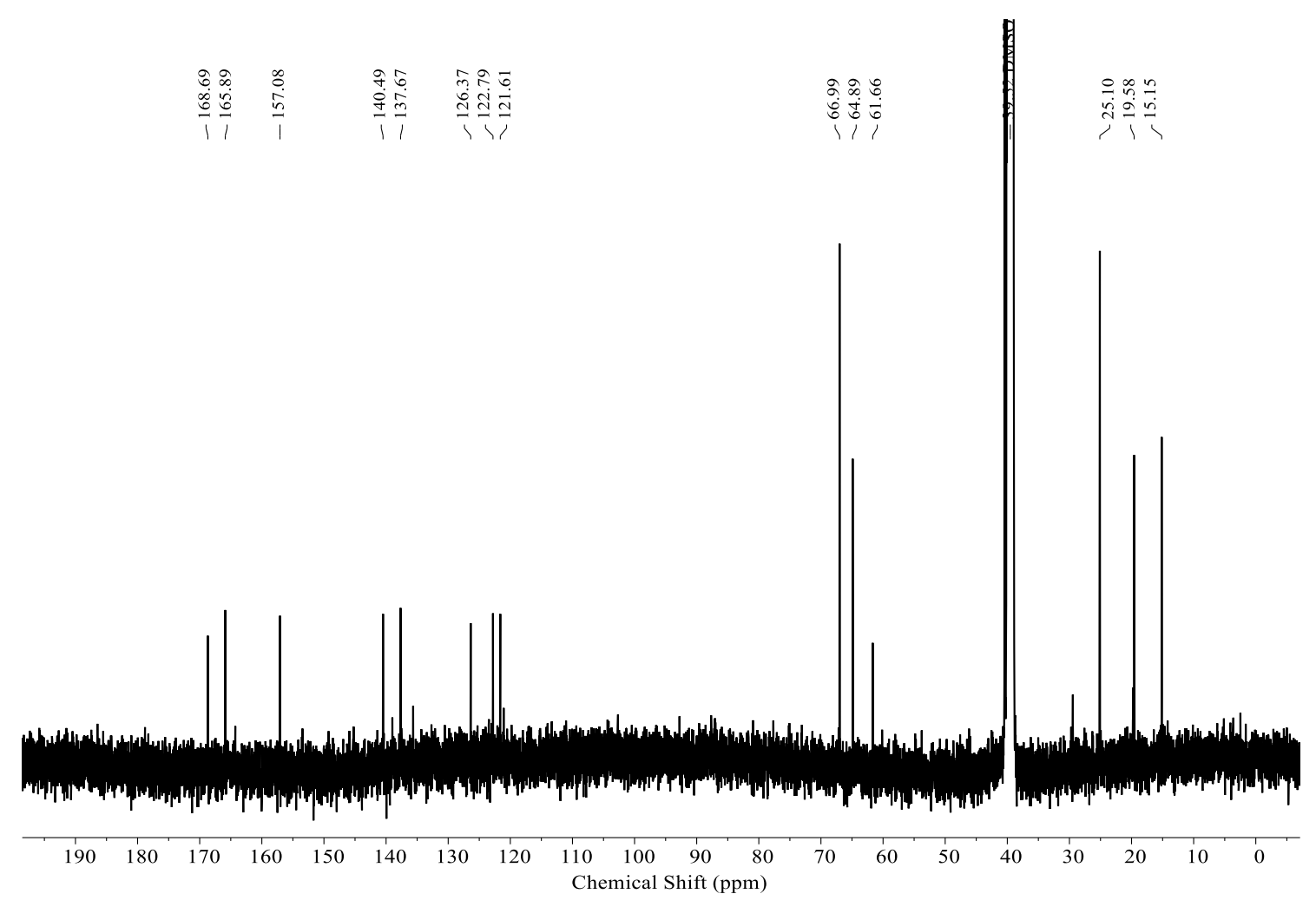

Figure $S 34{ }^{13} \mathrm{C}$ NMR spectrum ( $d_{6}$-DMSO) of C1c at 303K. 


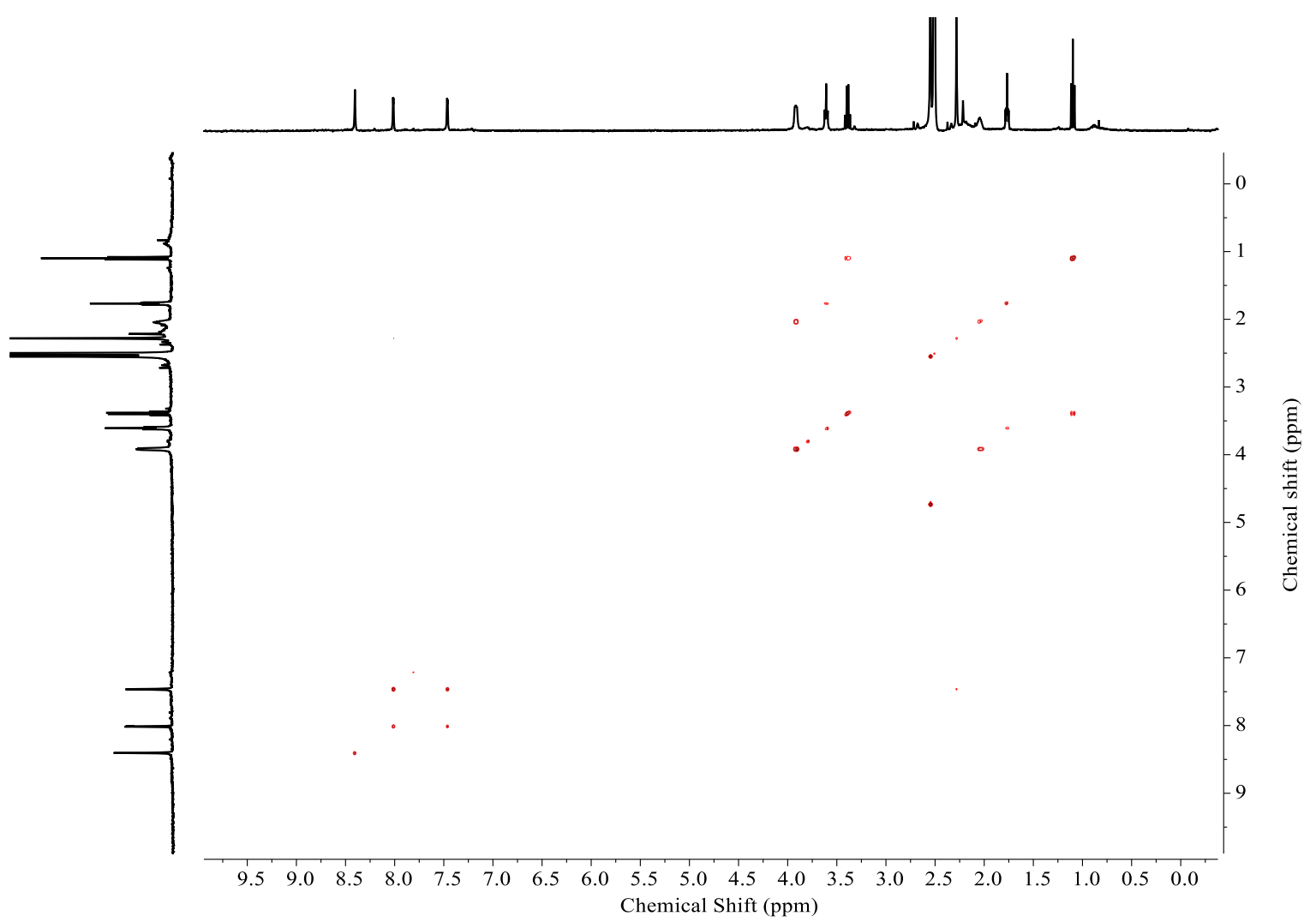

Figure S35 COSY NMR spectrum ( $d_{6}$-DMSO) of C1c at 303K.

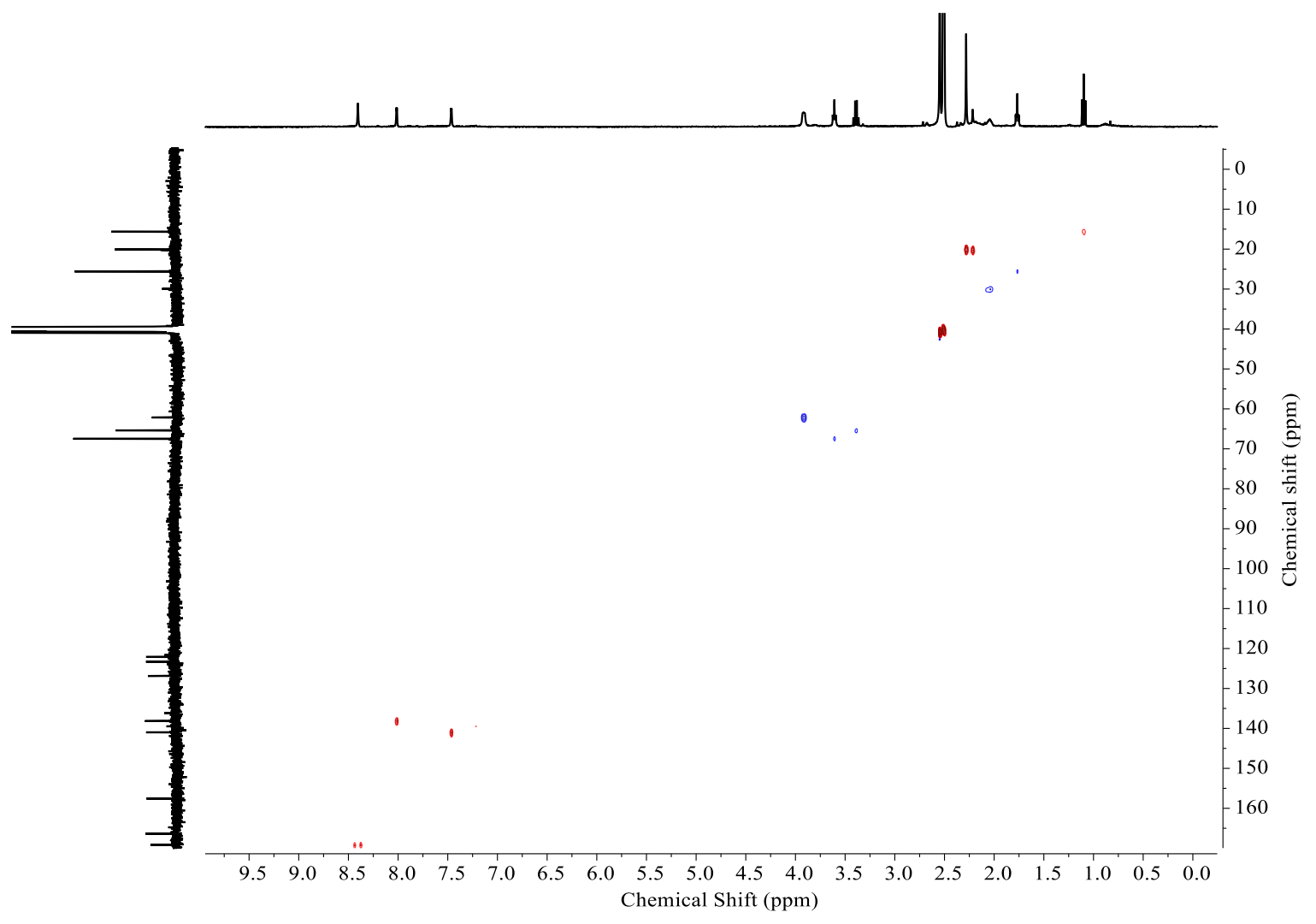

Figure S36 HSQC NMR spectrum ( $d_{6}$-DMSO) of C1c at 303K. 

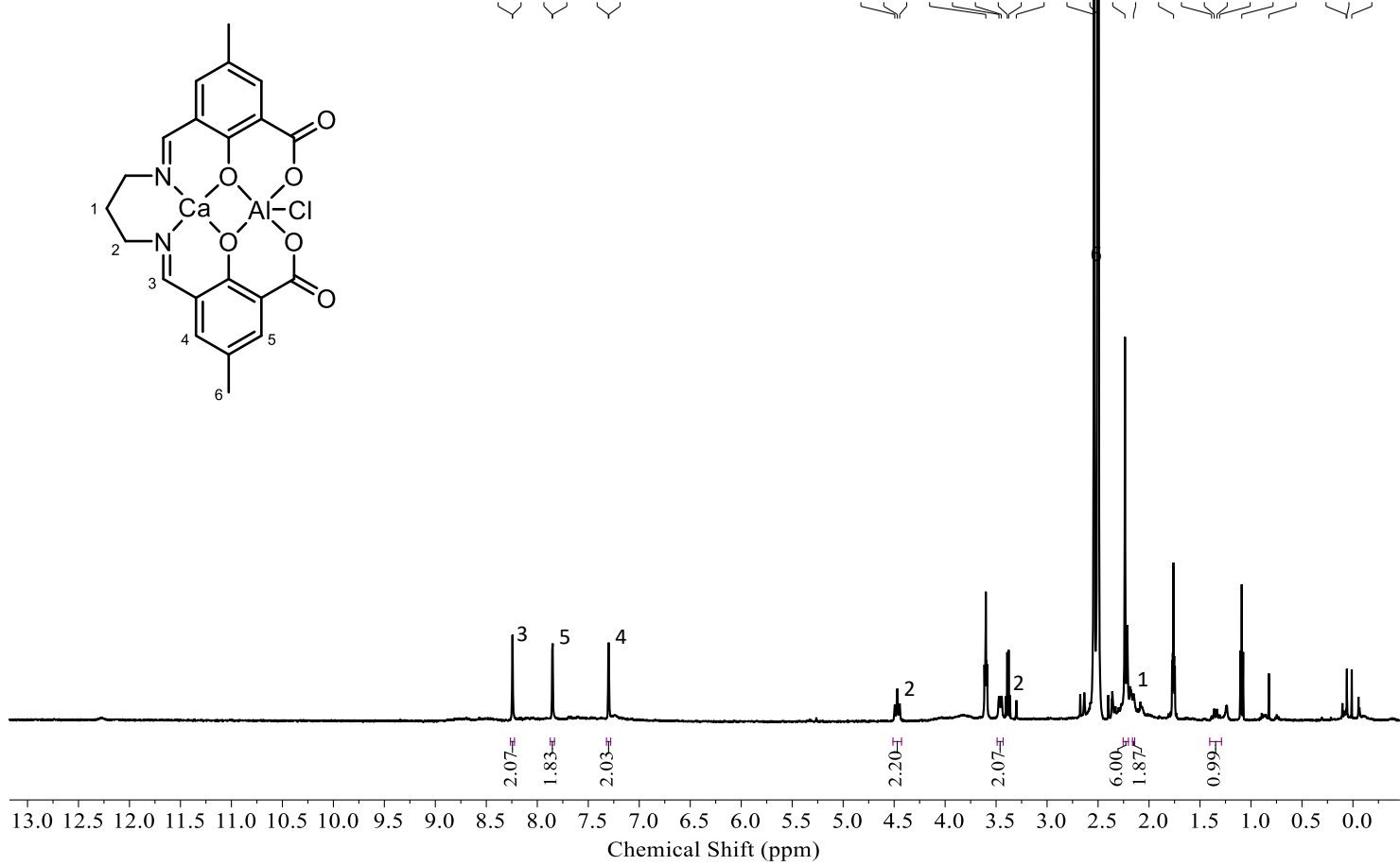

Figure $\mathbf{S} 37{ }^{1} \mathrm{H}$ NMR spectrum $\left(d_{6}\right.$-DMSO) of $\mathbf{C} 1 \mathrm{~d}$ at $303 \mathrm{~K}$.

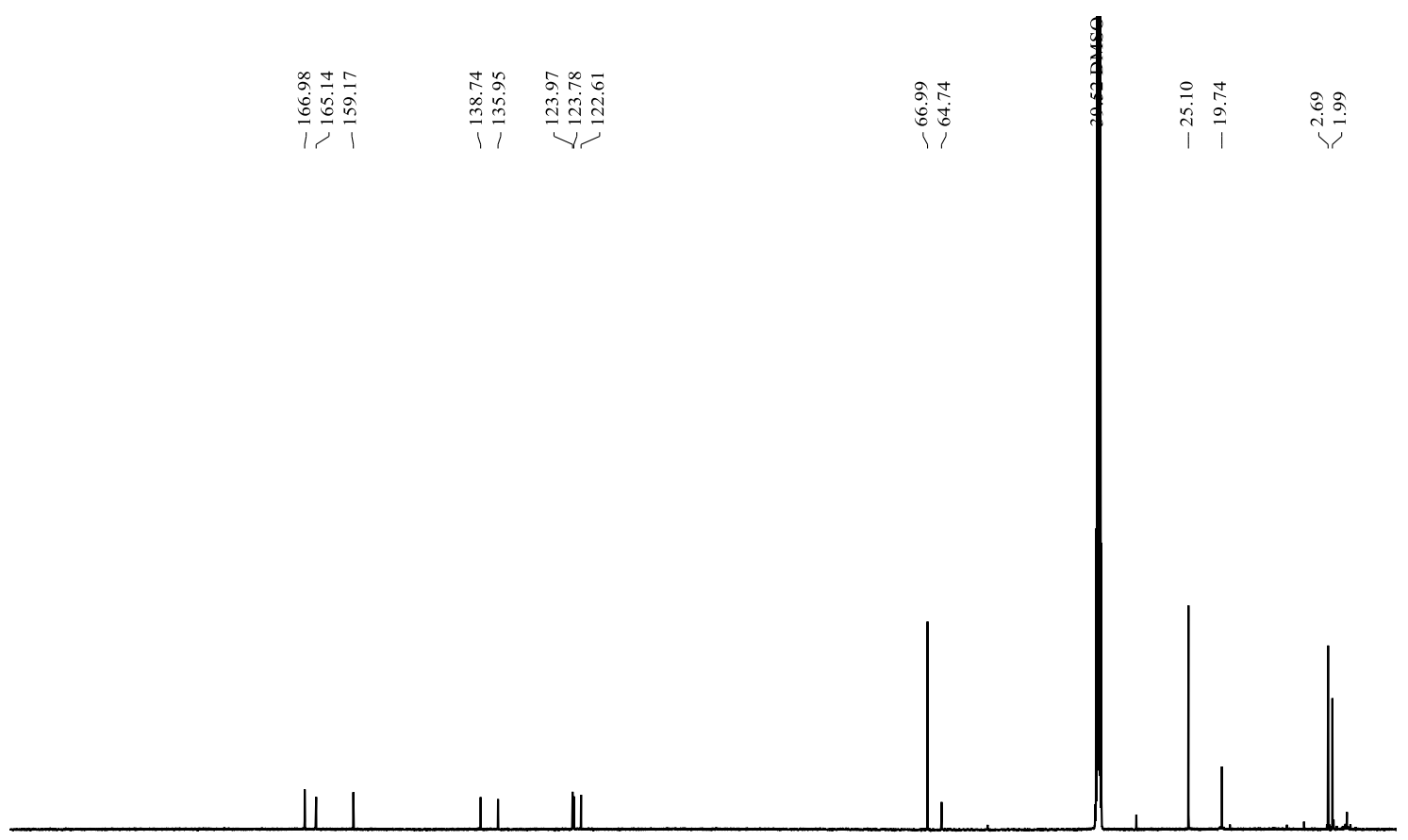

$\begin{array}{llllllllllllllllllllll}210 & 200 & 190 & 180 & 170 & 160 & 150 & 140 & 130 & 120 & 110 & 100 & 90 & 80 & 70 & 60 & 50 & 40 & 30 & 20 & 10 & 0\end{array}$ Chemical Shift (ppm)

Figure $\mathbf{S 3 8}{ }^{13} \mathrm{C}$ NMR spectrum $\left(d_{6}\right.$-DMSO) of $\mathbf{C} 1 \mathbf{d}$ at $303 \mathrm{~K}$. 


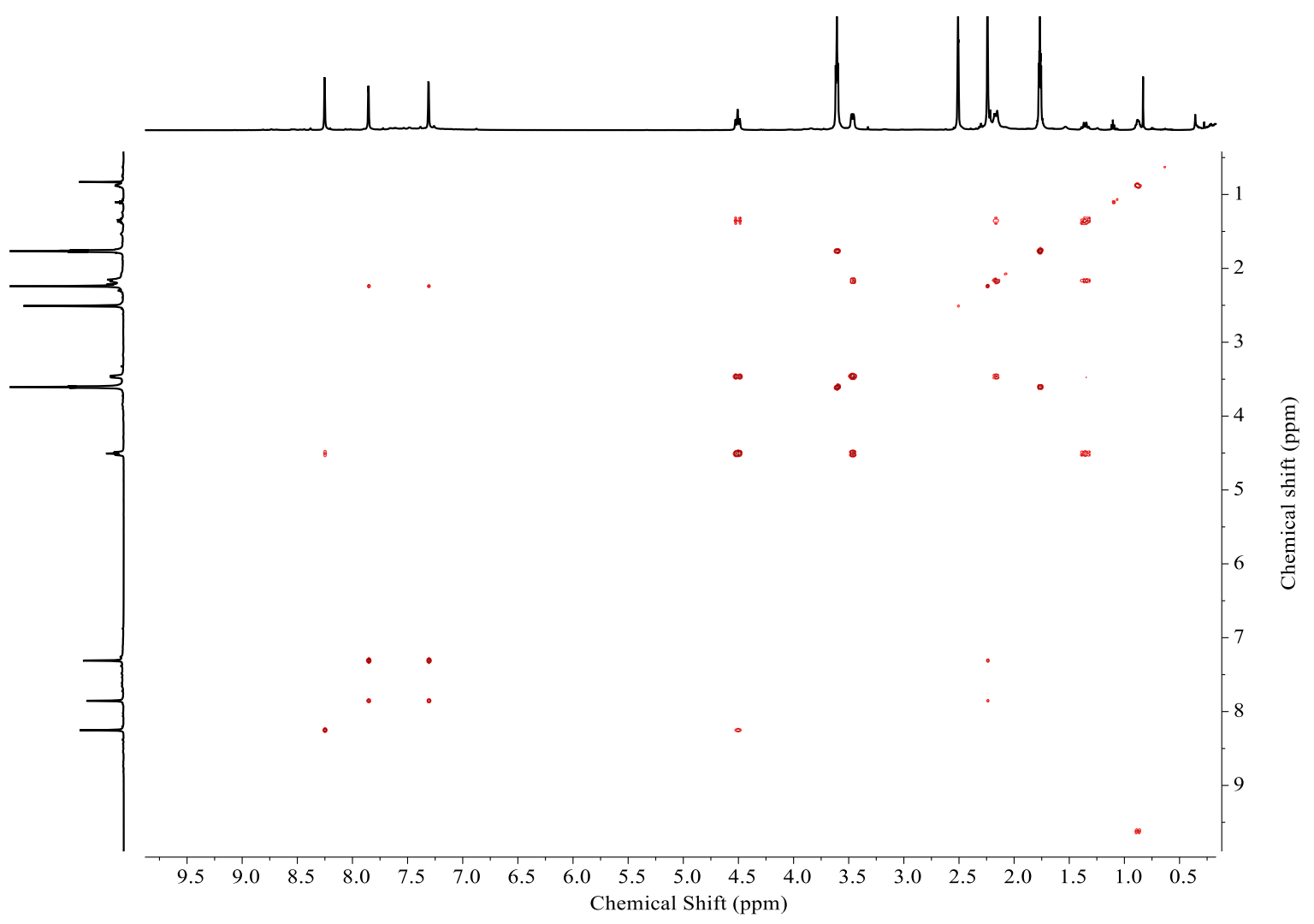

Figure S39 COSY NMR spectrum ( $d_{6}$-DMSO) of C1d at 303K.

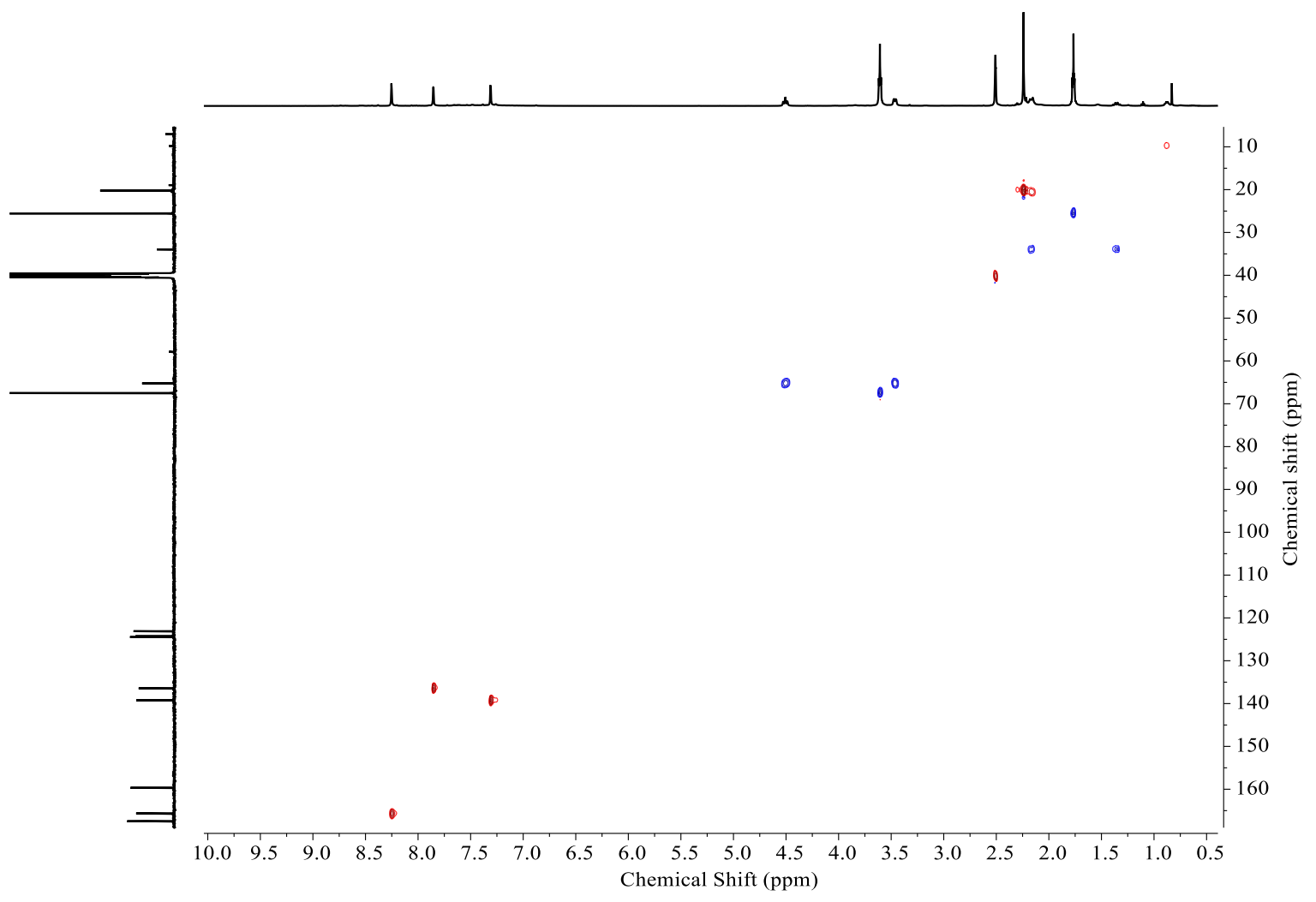

Figure $\mathbf{S 4 0}$ HSQC NMR spectrum ( $d_{6}$-DMSO) of C1d at 303K. 
$5 \quad$ Mass spectrometry data of salen ligands and complexes

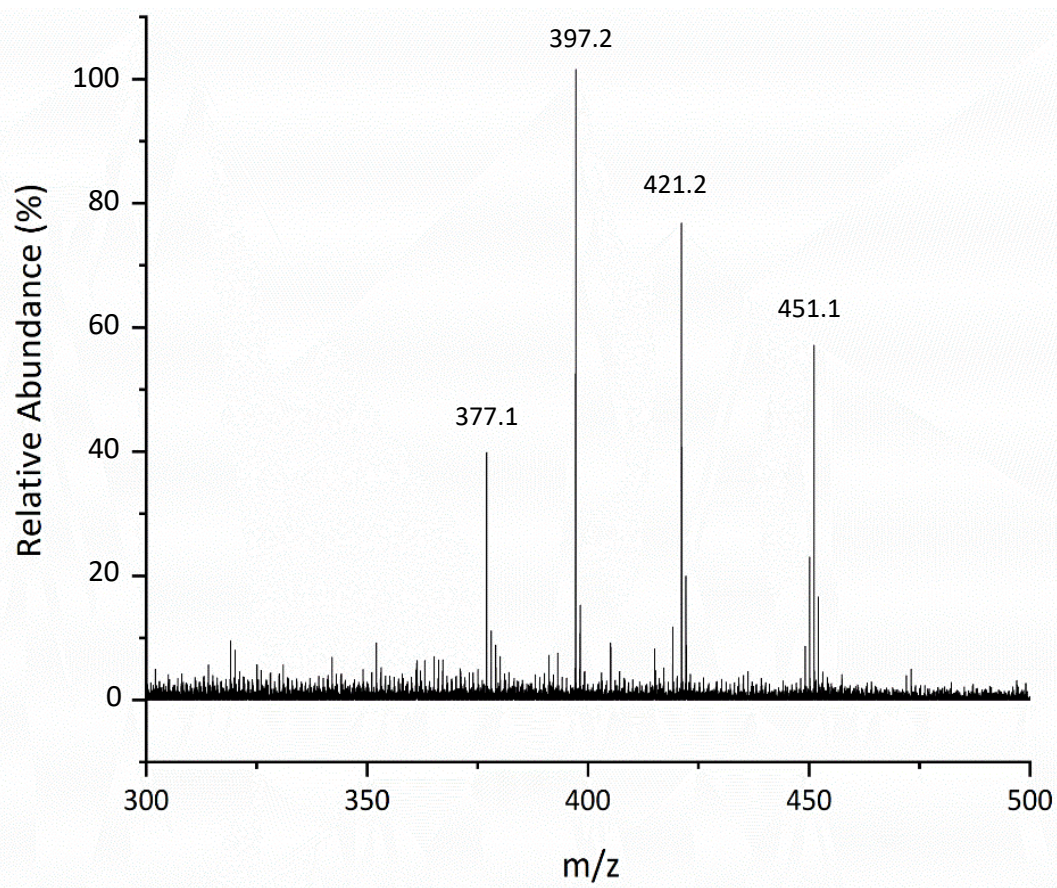

Figure S41 MALDI-ToF mass spectrum of L1, run in negative reflectron mode. The ion seen at $\mathrm{m} / \mathrm{z}$ 397.2 corresponds to fragment ion formula: $[\mathrm{M}-\mathrm{H}]^{-} \mathrm{C}_{21} \mathrm{H}_{21} \mathrm{~N}_{2} \mathrm{O}_{6}{ }^{-}$.

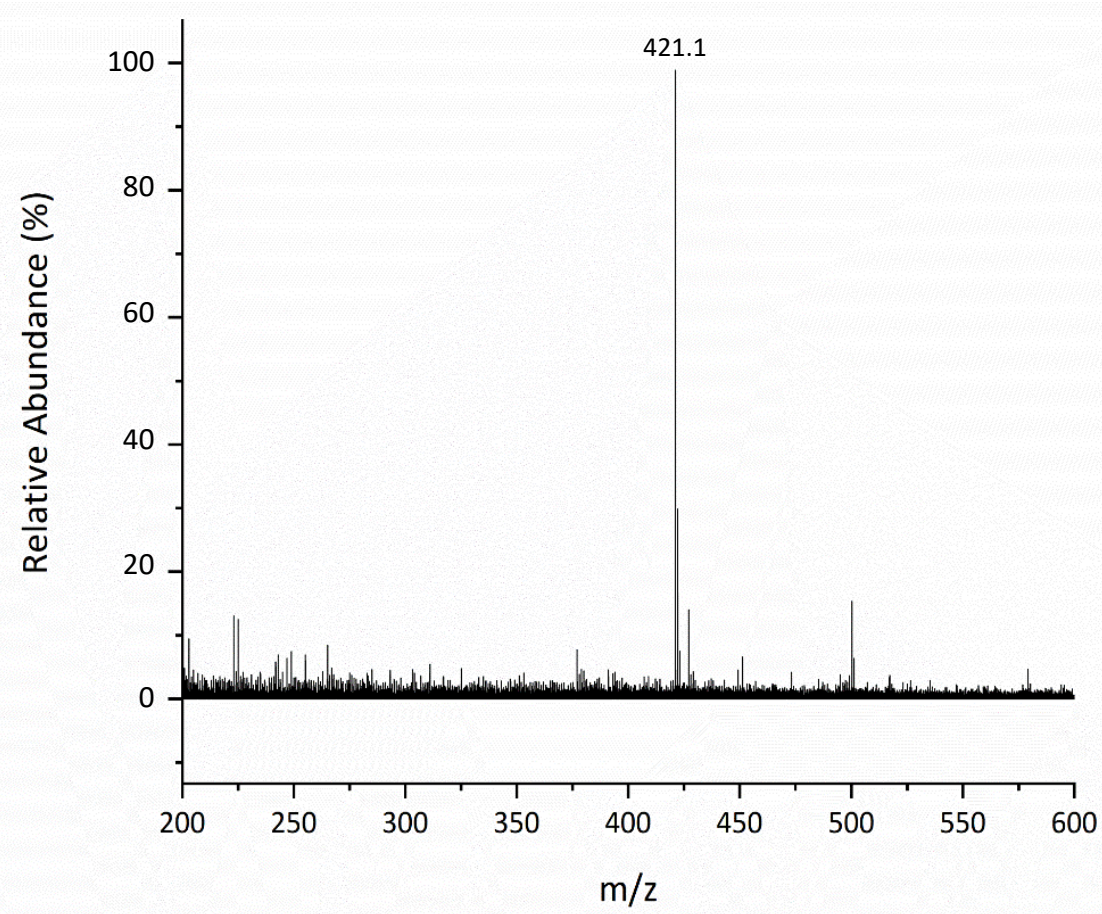

Figure $\mathbf{5 4 2}$ MALDI-ToF mass spectrum of $\mathbf{C 1}$, run in negative reflectron mode. The ion seen at $\mathrm{m} / \mathrm{z}$ 421.1 corresponds to fragment ion formula: $\left[\mathrm{M}-2 \mathrm{H}^{+}-\mathrm{Cl}-\right]^{-} \mathrm{C}_{21} \mathrm{H}_{18} \mathrm{AlN}_{2} \mathrm{O}_{6}{ }^{-}$. 


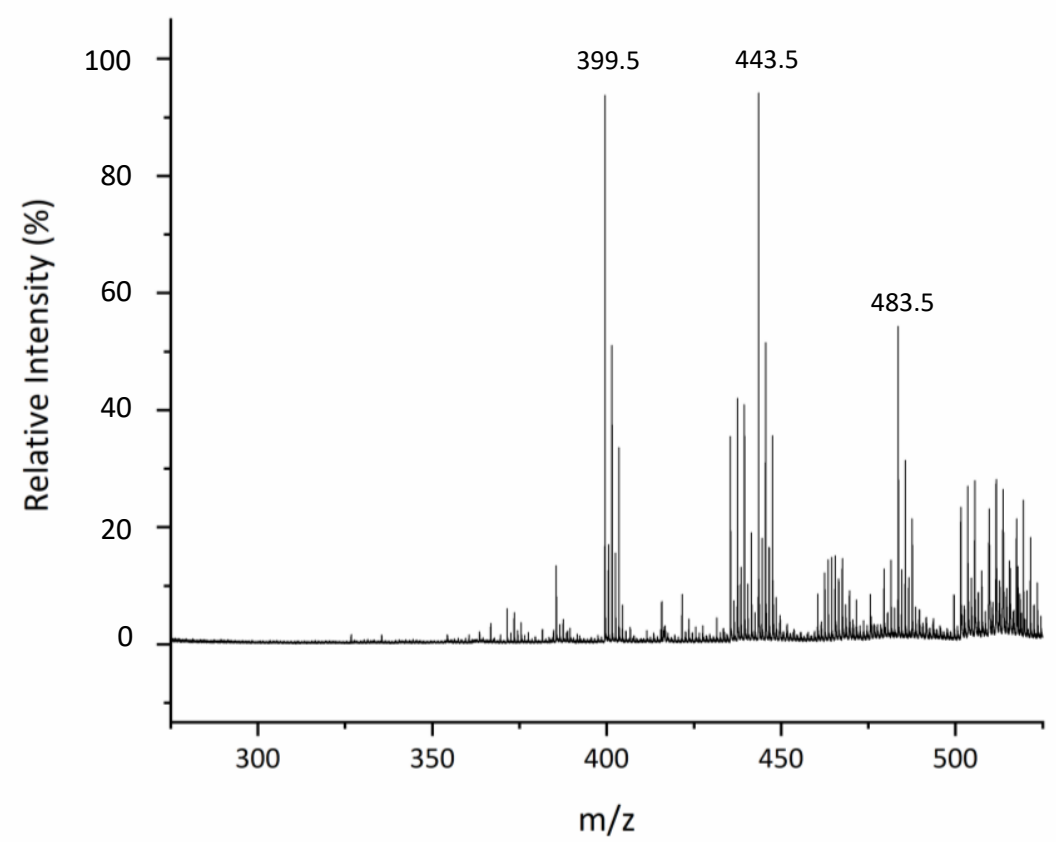

Figure S43 APPI mass spectrum of C2, run in reflectron positive mode. The ion seen at $m / z 483.5$ corresponds to fragment ion formula: $[\mathrm{M}+\mathrm{Na}]^{+} \mathrm{C}_{21} \mathrm{H}_{20} \mathrm{ZnNaN}_{2} \mathrm{O}_{6}$.

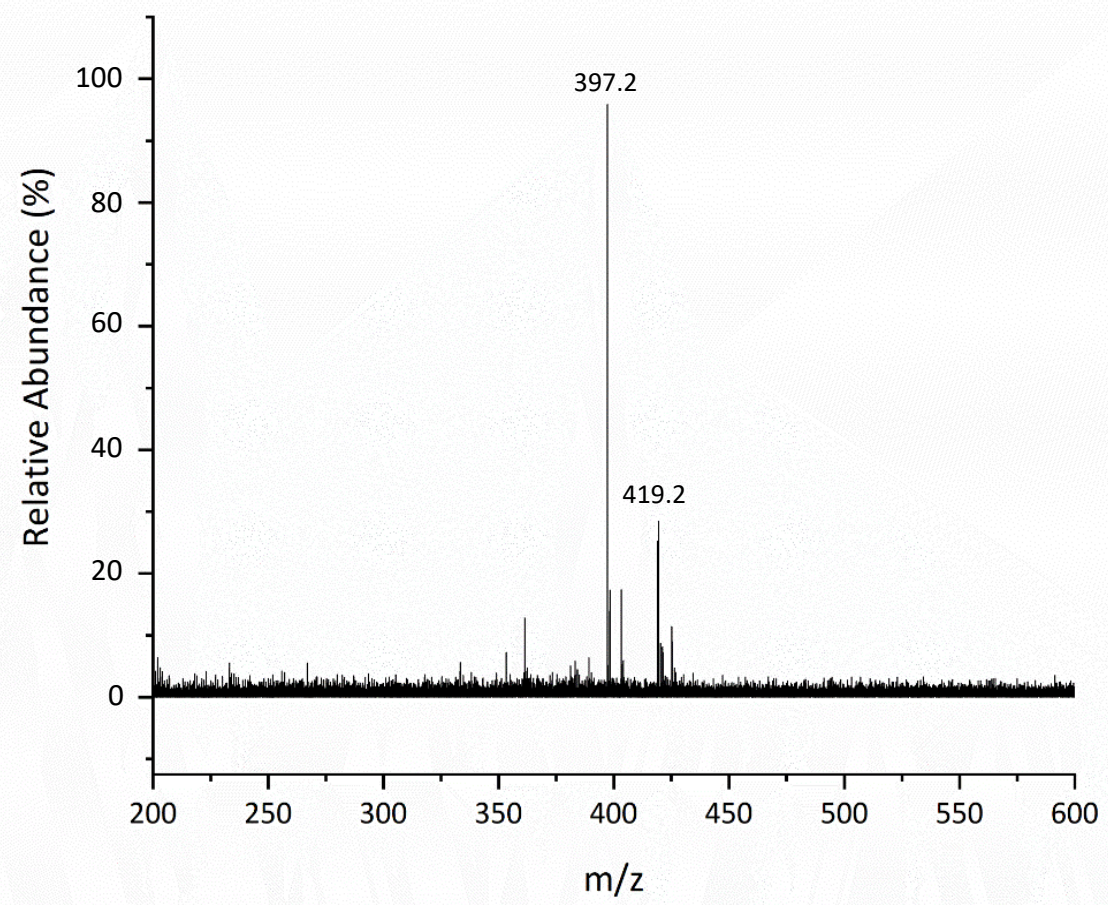

Figure S44 MALDI-ToF mass spectrum of C3, run in negative reflectron mode. The ion seen at $\mathrm{m} / \mathbf{z}$ 419.2 corresponds to fragment ion formula: $[\mathrm{M}-\mathrm{H}]^{-} \mathrm{C}_{21} \mathrm{H}_{19} \mathrm{MgN}_{2} \mathrm{O}_{6}{ }^{-}$. 


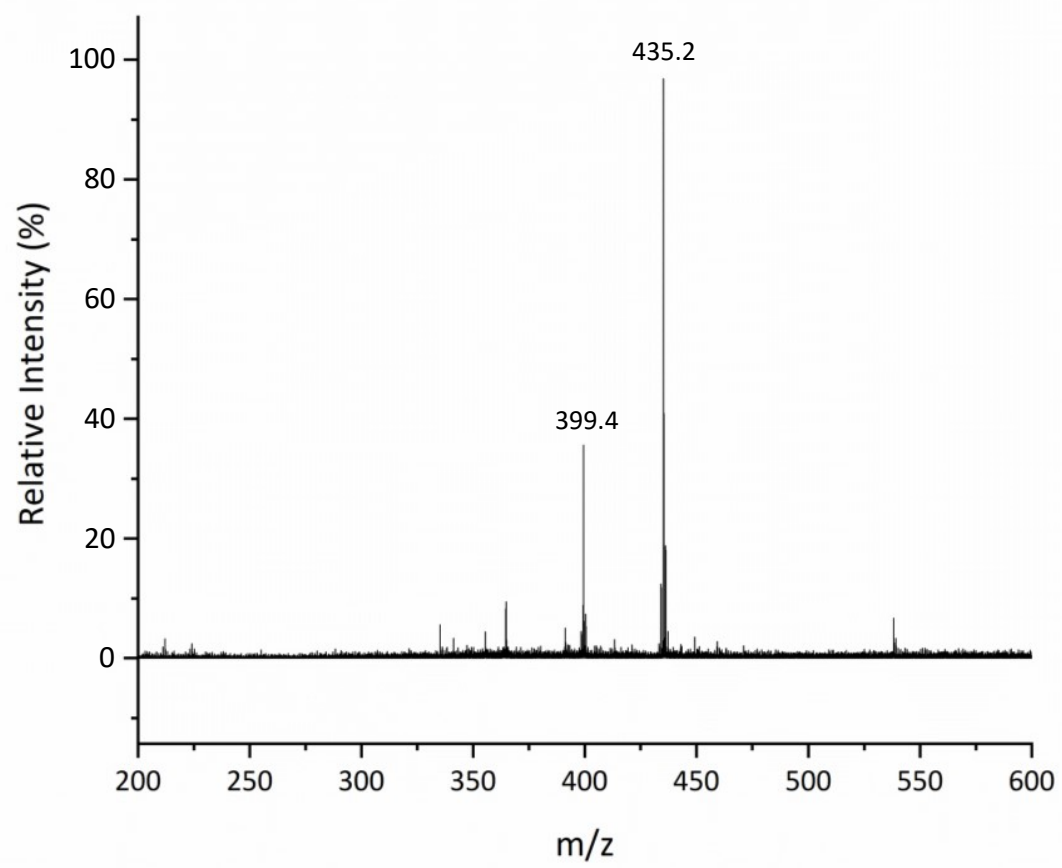

Figure S45 MALDI-ToF mass spectrum of C1a, run in positive reflectron mode. The ion seen at $m / z$ 435.2 corresponds to fragment ion formula: $[\mathrm{M}-\mathrm{HCl}+\mathrm{Li}]^{+} \mathrm{C}_{21} \mathrm{H}_{18} \mathrm{AlLi}_{2} \mathrm{~N}_{2} \mathrm{O}_{6}{ }^{+}$.

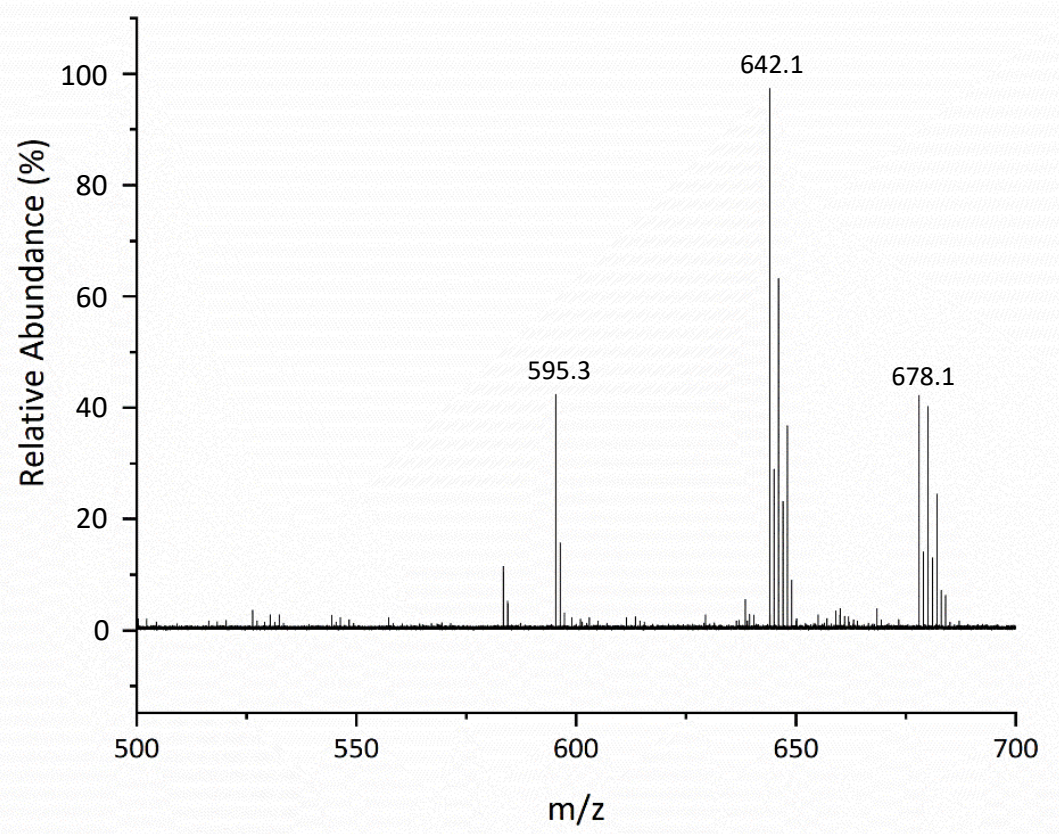

Figure S46 APPI mass spectrum of C1b, run in positive reflectron mode. The ion seen at $m / z 678.1$ corresponds to combined fragments with ion formula: $[\mathrm{M}+\mathrm{H}]^{+} \mathrm{C}_{21} \mathrm{H}_{19} \mathrm{AlClZnN}_{2} \mathrm{O}_{6}{ }^{+} \cdot \mathrm{C}_{5} \mathrm{H}_{5} \mathrm{~N}$ (pyridine) . $\mathrm{C}_{2} \mathrm{H}_{6} \mathrm{SO}$ (DMSO). 


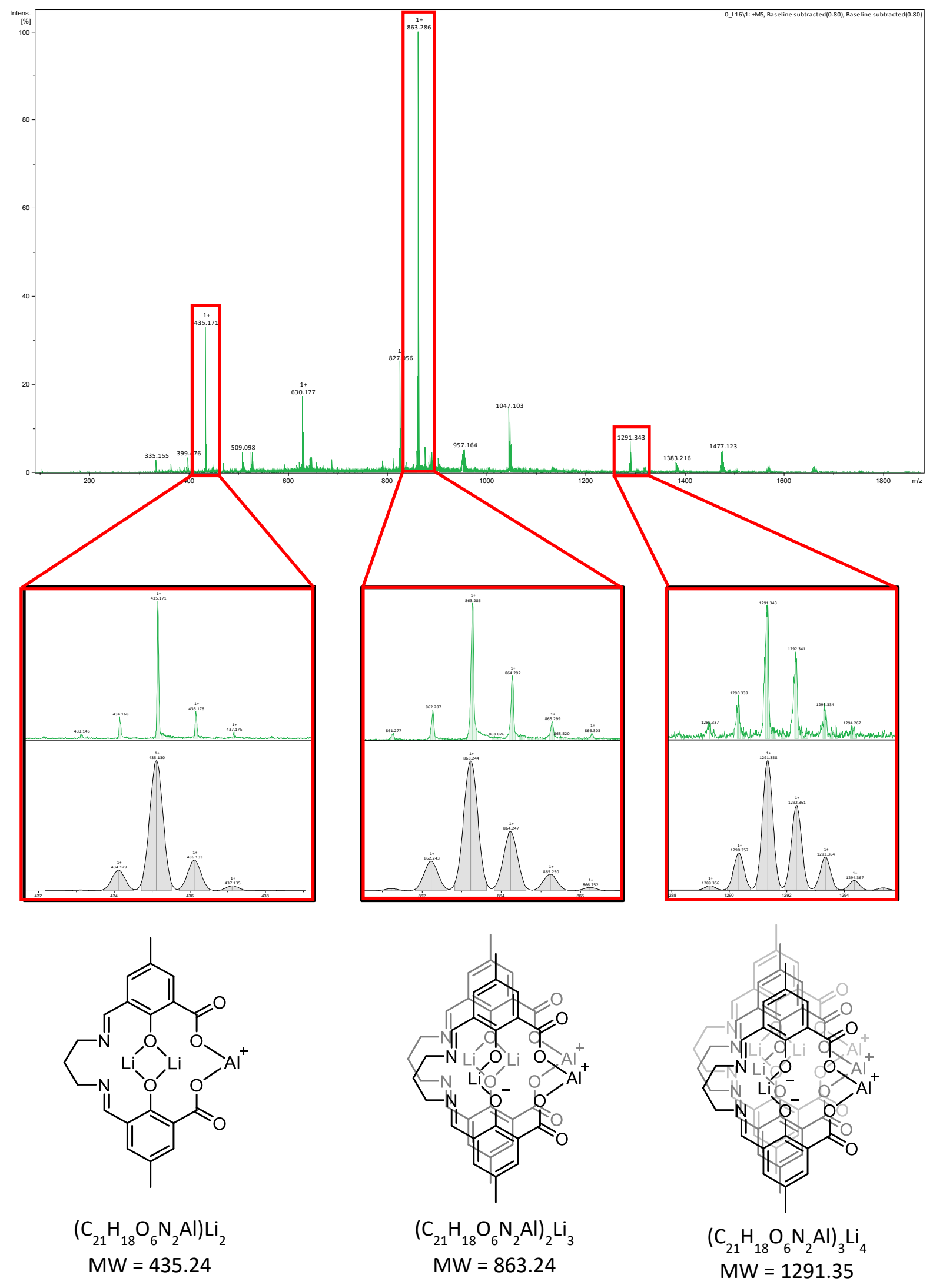

Figure S47 MALDI-ToF mass spectrometry run in positive reflectron mode of complex $\mathbf{C} \mathbf{1 b}$, formed by the reaction of complex $\mathrm{Cla}_{\mathrm{a}}$ with $\mathrm{ZnCl}_{2}$ (top). Comparison of magnified mass spectrum with predicted spectrum of the shown structures, with molecular formula and weight shown (bottom). 


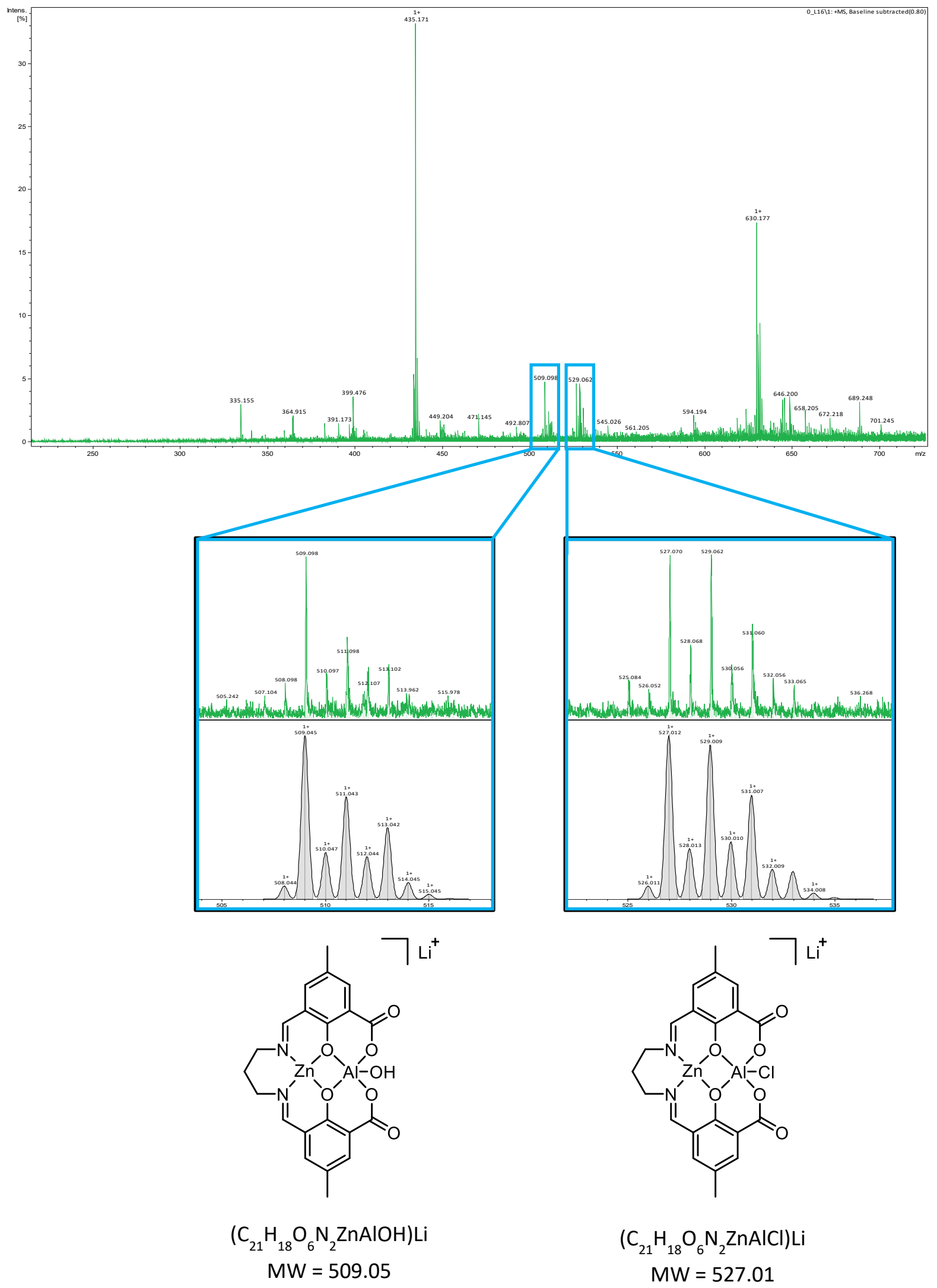

Figure S48 MALDI-ToF mass spectrometry run in positive reflectron mode of complex C1b, formed by the reaction of complex $\mathbf{C 1 a}$ with $\mathrm{ZnCl}_{2}$ (top). Comparison of magnified mass spectrum with predicted spectrum of the shown structures, with molecular formula and weight shown (bottom). Note, hydrolysis of AICl occurs upon exposure to air during MALDI-ToF analysis. 


\section{General procedure for the ring opening polymerization of rac-lactide}

In the glove box under an argon atmosphere 100 equivalents of rac-lactide $(0.306 \mathrm{~g}, 2.12 \mathrm{mmol}), 1$ equivalent of complex $(0.0212 \mathrm{mmol})$ and toluene $(2.12 \mathrm{~mL})$ were added into an air-tight vial equipped with a magnetic stirrer bar. 50 equivalents of propylene oxide $(74.4 \mu \mathrm{L}, 1.06 \mathrm{mmol})$ were added, the vial was sealed tightly and transferred from the glove box to the fume hood. The reaction was then heated to $120^{\circ} \mathrm{C}$ using an oil bath whilst stirring. After the appropriate reaction time, the reaction was then removed from the oil bath, cooled in a water bath and quenched with hexane. The hexane was then removed using compressed air, the product dissolved in $\mathrm{CDCl}_{3}$, and subsequently analyzed using ${ }^{1} \mathrm{H}$ NMR spectroscopy. ${ }^{1} \mathrm{H}$ NMR spectroscopy was used to calculate the polymer conversion through the relative integrations of the lactide monomer at $5.04 \mathrm{ppm}$ and PLA multiplet at $5.20 \mathrm{ppm}$ (figure S44). Tacticity was determined using a decoupled ${ }^{1} \mathrm{H}\left\{{ }^{1} \mathrm{H}\right\}$ NMR spectrum (figure $\mathrm{S} 50$ ).

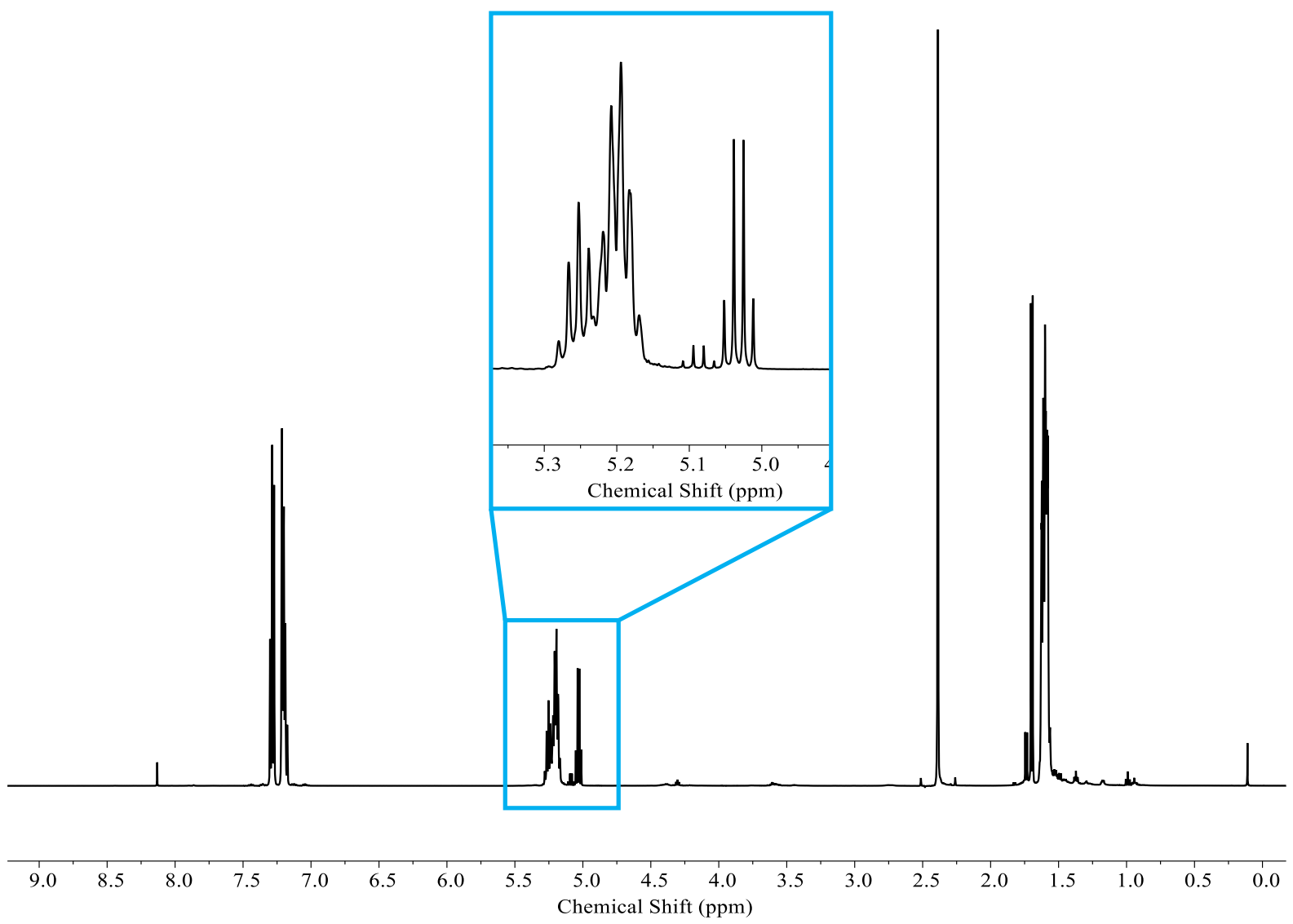

Figure $549{ }^{1} \mathrm{H}$ NMR spectrum $\left(\mathrm{CDCl}_{3}\right)$ of PLA generated by $\mathrm{C} 1(40 \mathrm{~min})$ at $303 \mathrm{~K}$. PLA and lactide resonances magnified for clarity. 


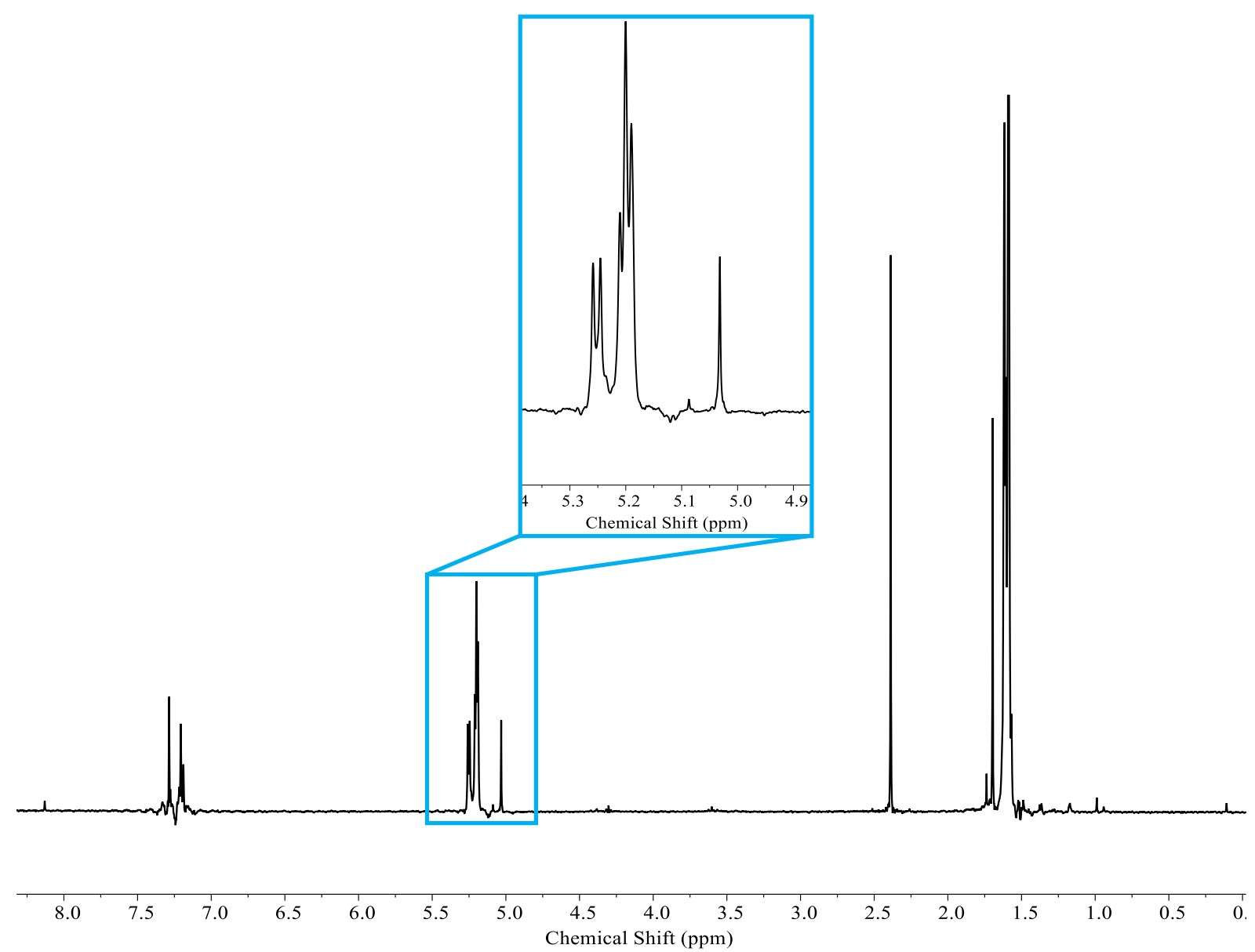

Figure S50 Pureshift decoupled ${ }^{1} \mathrm{H}\left\{{ }^{1} \mathrm{H}\right\}$ NMR spectrum $\left(\mathrm{CDCl}_{3}\right)$ of PLA generated by $\mathrm{C} 1$ (40 min) at 303K. PLA and lactide resonances magnified for clarity. Tacticity calculated using the method proposed by Coates and Ovitt. ${ }^{2}$ 
7 SEC traces of PLA catalyzed by complexes $\mathbf{C} \mathbf{1}$ and $\mathbf{C 1 a}-\mathbf{C} \mathbf{C}$

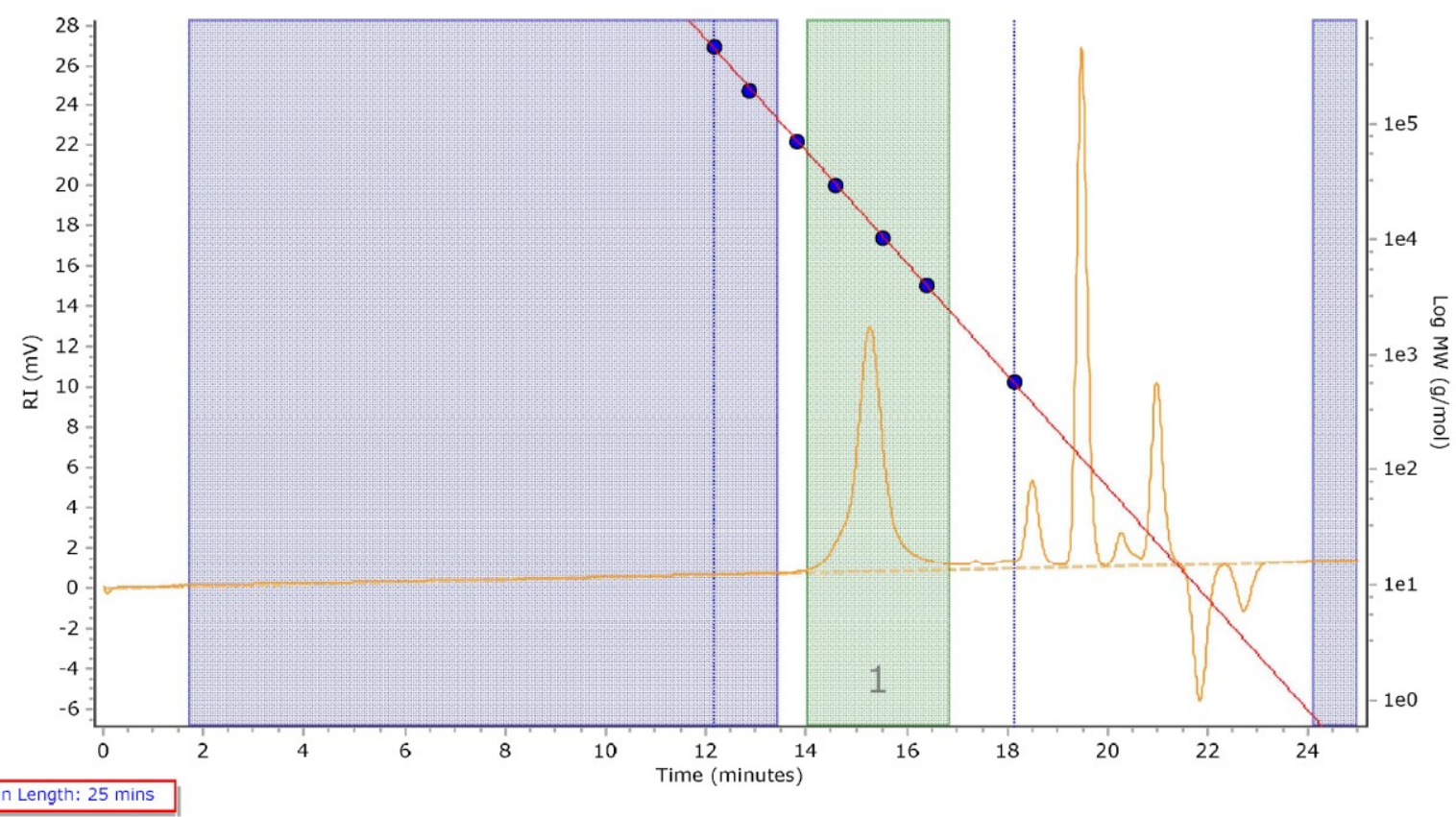

Figure S51 GPC trace of PLA generated by C1 ( $30 \mathrm{~min}$ ) after a $25 \mathrm{~min}$ sample run length.

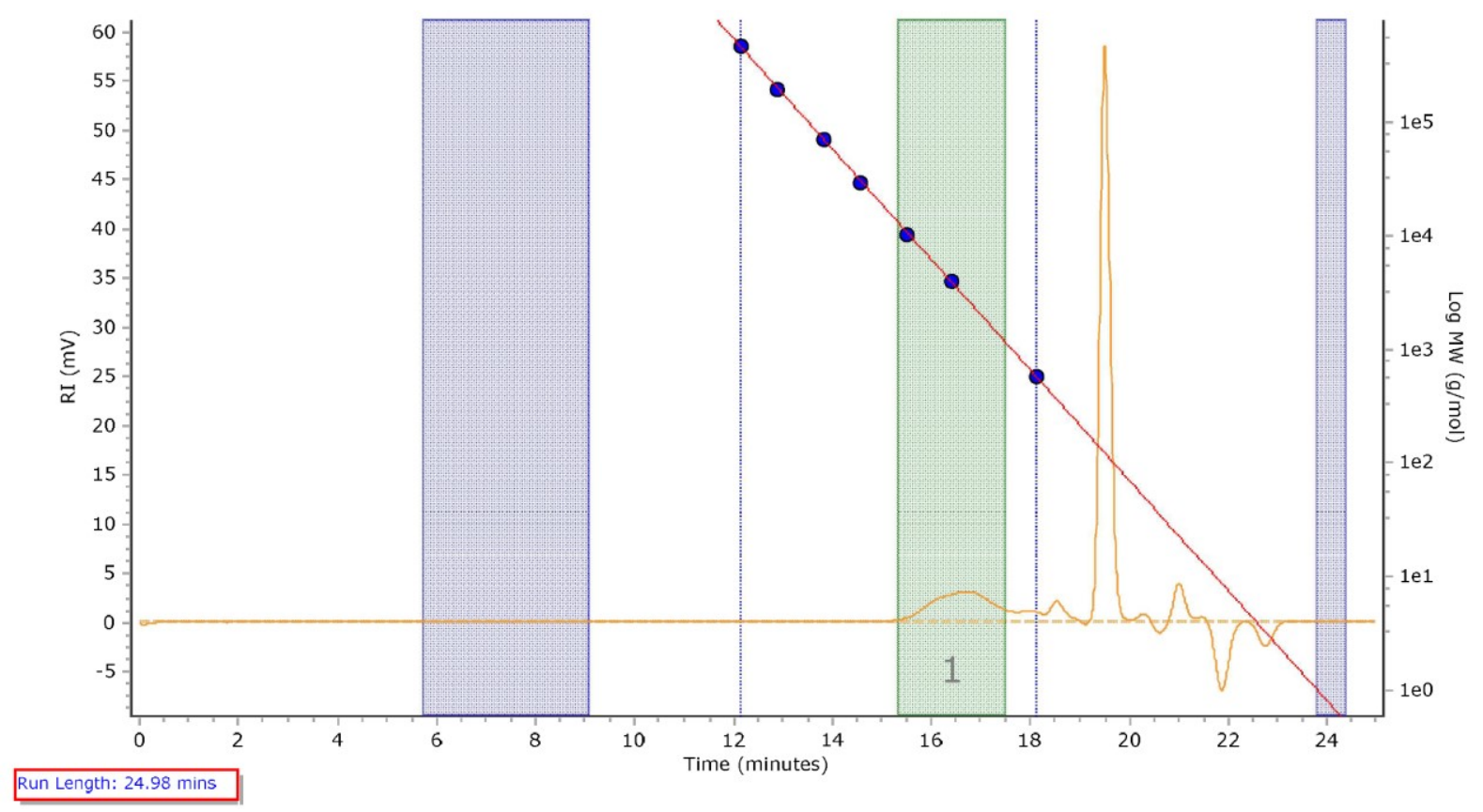

Figure S52 GPC trace of PLA generated by C1a (30 min) after a 25 min sample run length. 


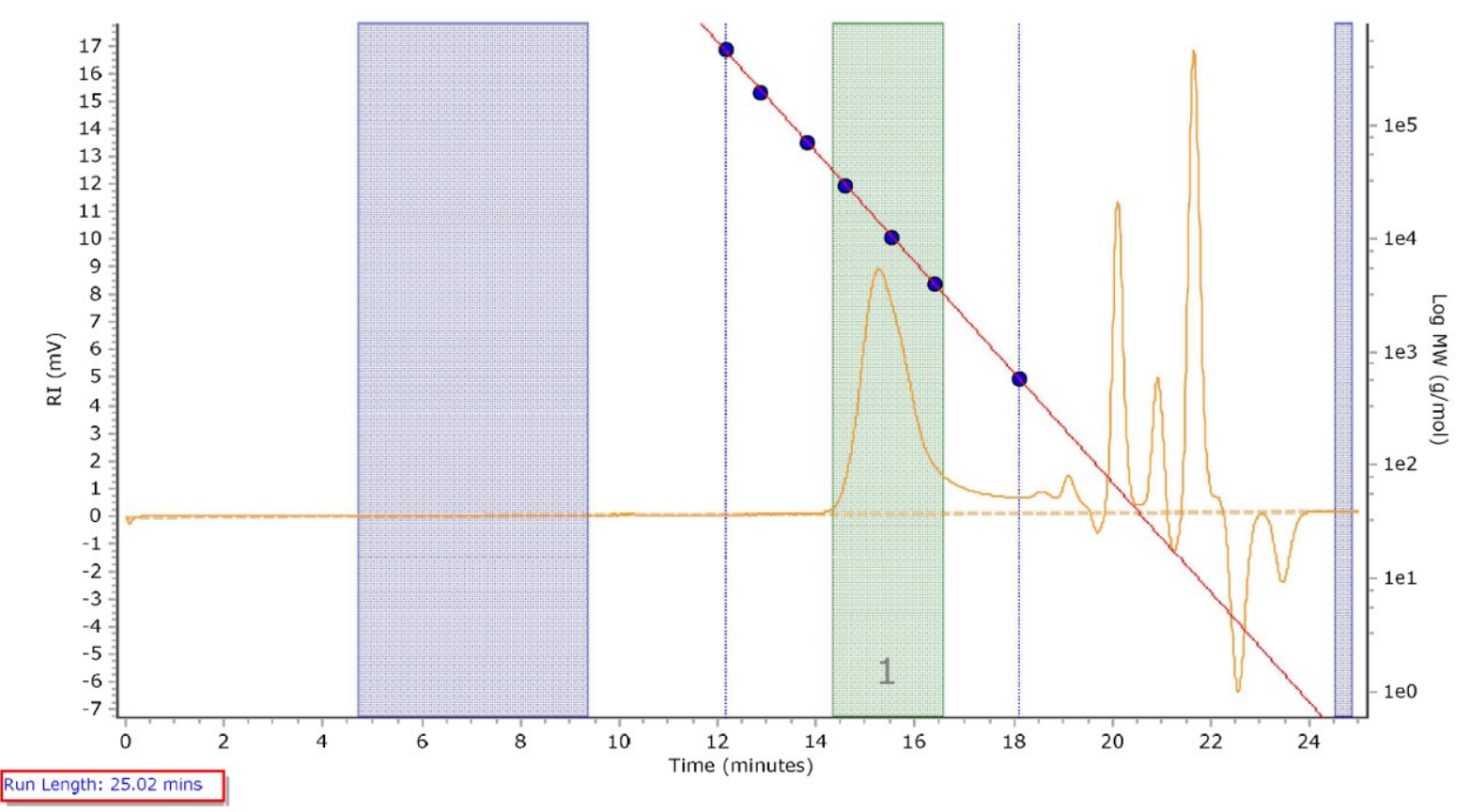

Figure S53 GPC trace of PLA generated by C1b (15 min) after a 25 min sample run length.

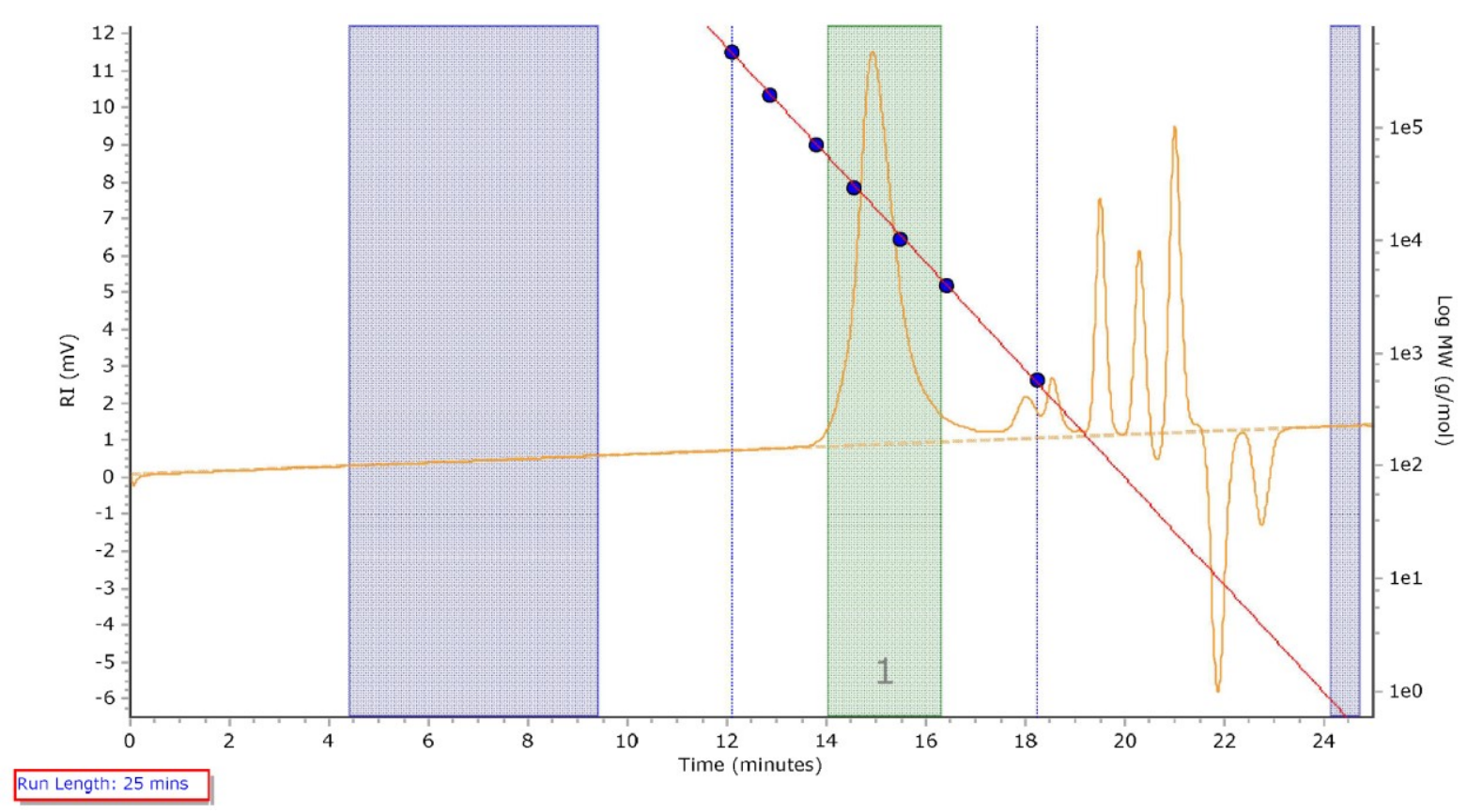

Figure S54 GPC trace of PLA generated by C1c (5 min) after a 25 min sample run length. 


\section{ROP of rac-lactide mediated by catalysts $\mathbf{C} \mathbf{1}-\mathbf{C} 3$ and $\mathbf{C 1 a}-\mathbf{C 1 d}$}

Table S1 Rac-lactide ROP mediated by catalysts C1 - C3 and C1a - C1d. ${ }^{[a]}$

\begin{tabular}{|c|c|c|c|c|c|c|}
\hline Entry & Catalyst & Time (min) & $\%$ Conversion ${ }^{[b]}$ & $M_{n, \text { calc }} / \mathrm{Da}^{[c]}$ & $M_{\mathrm{n}, \mathrm{obs}} / \mathrm{Da}^{[\mathrm{d}]}$ & $\bigoplus^{[\mathrm{d}]}$ \\
\hline 1 & \multirow{6}{*}{ C1 } & 5 & 9 & 1275 & 810 & 1.25 \\
\hline 2 & & 10 & 24 & 3490 & 2710 & 1.10 \\
\hline 3 & & 20 & 55 & 7985 & 5480 & 1.13 \\
\hline 4 & & 30 & 75 & 10730 & 6975 & 1.24 \\
\hline 5 & & 40 & 83 & 11915 & 7640 & 1.21 \\
\hline $6^{[e]}$ & & 30 & - & - & - & - \\
\hline 7 & \multirow{4}{*}{ C1a } & 5 & 3 & 400 & 390 & 1.02 \\
\hline 8 & & 10 & 7 & 960 & 750 & 1.36 \\
\hline 9 & & 20 & 14 & 1950 & 1140 & 1.30 \\
\hline 10 & & 30 & 24 & 3490 & 1600 & 1.35 \\
\hline 11 & \multirow{14}{*}{ C1b } & 3 & 1 & 200 & 670 & - \\
\hline 12 & & 5 & 6 & 900 & 670 & 1.10 \\
\hline 13 & & 7 & 23 & 3285 & 3910 & 1.18 \\
\hline 14 & & 10 & 46 & 6615 & 3380 & 1.24 \\
\hline 15 & & 15 & 79 & 11410 & 5750 & 1.29 \\
\hline 16 & & 20 & 86 & 12440 & 5950 & 1.38 \\
\hline 17 & & 30 & 94 & 13500 & 5610 & 1.63 \\
\hline 18 & & 40 & 95 & 13620 & 5530 & 1.60 \\
\hline $19^{[\mathrm{e}]}$ & & 15 & - & - & - & - \\
\hline $20^{[f]}$ & & 20 & 9 & 1310 & 3130 & 1.21 \\
\hline $21^{[g-300]}$ & & 20 & 23 & 9830 & 9560 & 1.20 \\
\hline $22^{[g-500]}$ & & 20 & 11 & 8230 & 7430 & 1.28 \\
\hline $23^{[g-1000]}$ & & 20 & 4 & 5750 & 5100 & 1.30 \\
\hline $24^{[\mathrm{h}]}$ & & 20 & 6 & 841 & - & - \\
\hline 25 & \multirow{8}{*}{ C1c } & 1 & 6 & 810 & 1980 & 1.11 \\
\hline 26 & & 2 & 48 & 6980 & 7190 & 1.14 \\
\hline 27 & & 3 & 74 & 10710 & 7900 & 1.20 \\
\hline 28 & & 5 & 80 & 11545 & 8930 & 1.22 \\
\hline 29 & & 7 & 90 & 12980 & 10610 & 1.23 \\
\hline 30 & & 10 & 90 & 13020 & 10140 & 1.25 \\
\hline 31 & & 20 & 93 & 13320 & 9480 & 1.28 \\
\hline $32^{[\mathrm{e}]}$ & & 15 & - & - & - & - \\
\hline 33 & \multirow{3}{*}{ C1d } & 5 & 3 & 460 & - & - \\
\hline 34 & & 10 & 5 & 700 & - & - \\
\hline 35 & & 15 & 7 & 1040 & - & - \\
\hline 36 & C2 & 15 & - & - & - & - \\
\hline 37 & C3 & 15 & - & - & - & - \\
\hline
\end{tabular}

[a] Reaction conditions: [catalyst]/[PO]/[rac-LA]/ = 1:50:100, $[\mathrm{rac}-\mathrm{LA}]=1 \mathrm{M}$ in toluene, $120^{\circ} \mathrm{C}$. [b] Determined by ${ }^{1} \mathrm{H}$ NMR spectroscopy. [c] Calculated as ([rac-LA]/[catalyst]) $\times(\%$ conversion/100) $\times \mathrm{MW}$ of lactide, assuming that only one chain grows per catalyst system. [d] Determined by size-exclusion chromatography (SEC) in THF, universal calibration relative to polystyrene standard, $M_{\mathrm{n}}$ was calculated considering Mark-Houwink's corrections for $M_{n}\left(M_{n}(\right.$ calc $\left.)=0.58\left[M_{n}(S E C)\right]\right) .^{3}$ [e] No PO added. [f] 1 equivalent of PO added. [g-X] X = equivalents of rac-LA. [h] polymerization ran at $90^{\circ} \mathrm{C}$. 
8.1 Rate comparison to analogous AlCl-salen complexes

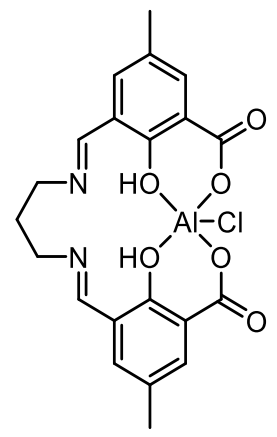

C1

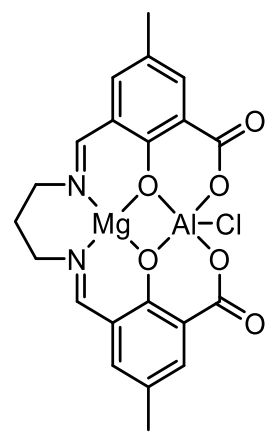

C1c

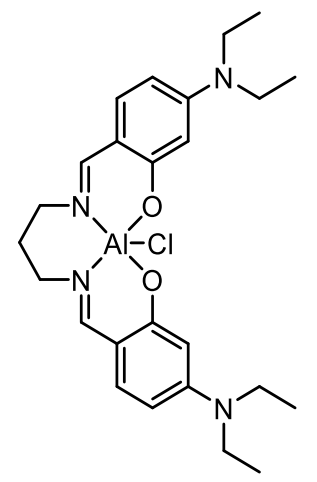

1

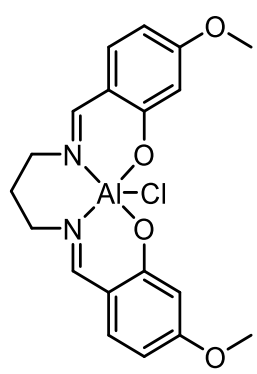

2

Figure S55 The structures of comparable complexes, C1 and C1c (this study), $\mathbf{1}$ (Gaston et al.) ${ }^{4}$ and $\mathbf{2}$ (Rae et al. $)^{5}$.

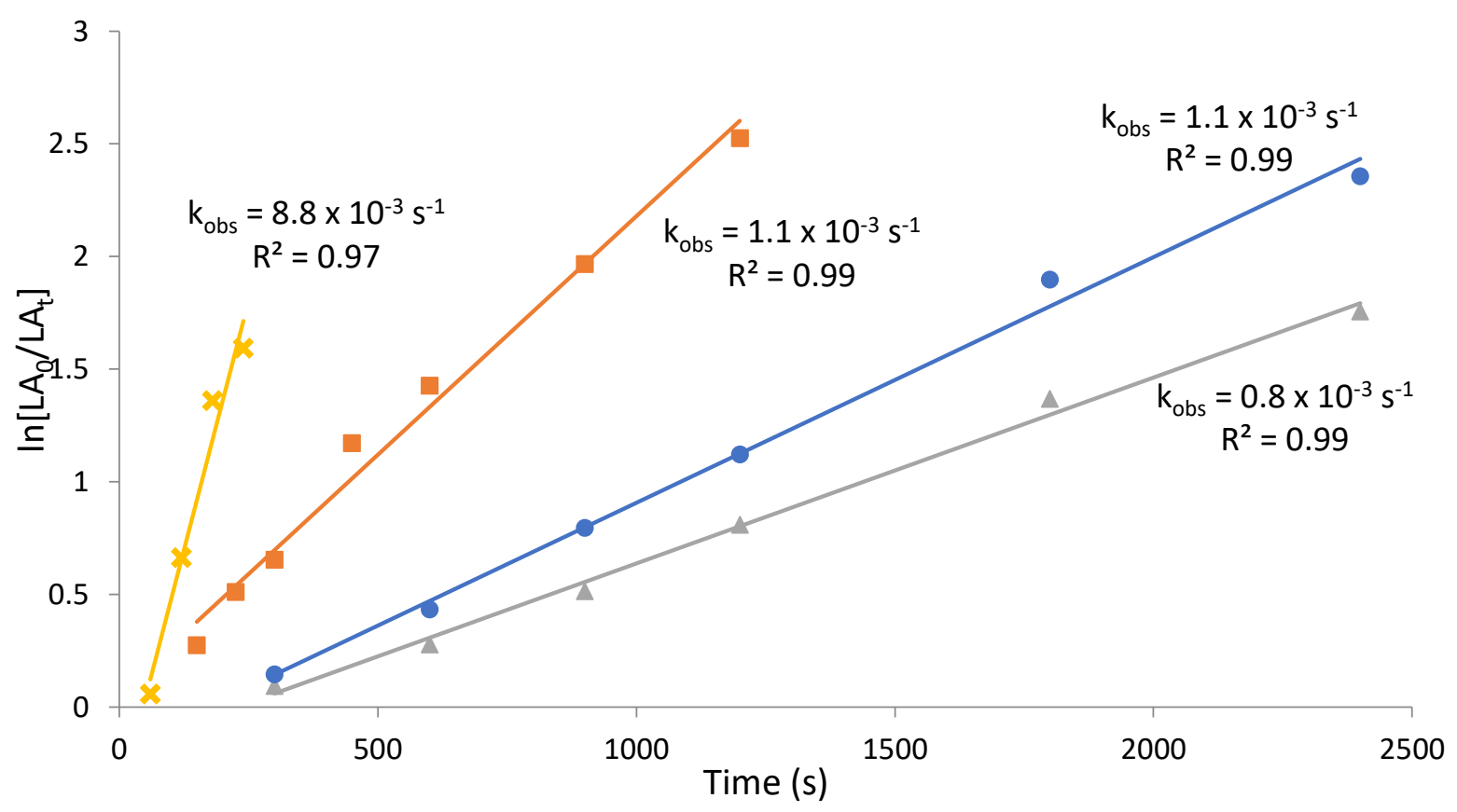

Figure S56 Kinetic plot of $\ln [\mathrm{LA}]_{0} / \ln [\mathrm{LA}]_{\mathrm{t}}$ versus time for the ROP of rac-LA catalyzed by complexes C1c (X), C1 (A) and comparative monometallic AICl-salen complexes, $\mathbf{1}(\mathbf{O})$ and $\mathbf{2}(\mathbf{\square})$. Reaction conditions: $[$ catalyst $] /[\mathrm{PO}] /[$ rac-LA $]=1: 50: 100,[$ rac-LA $]=1 \mathrm{M}$ in toluene, $120^{\circ} \mathrm{C}$. 


\subsection{MALDI-ToF mass spectrometry of PLA}

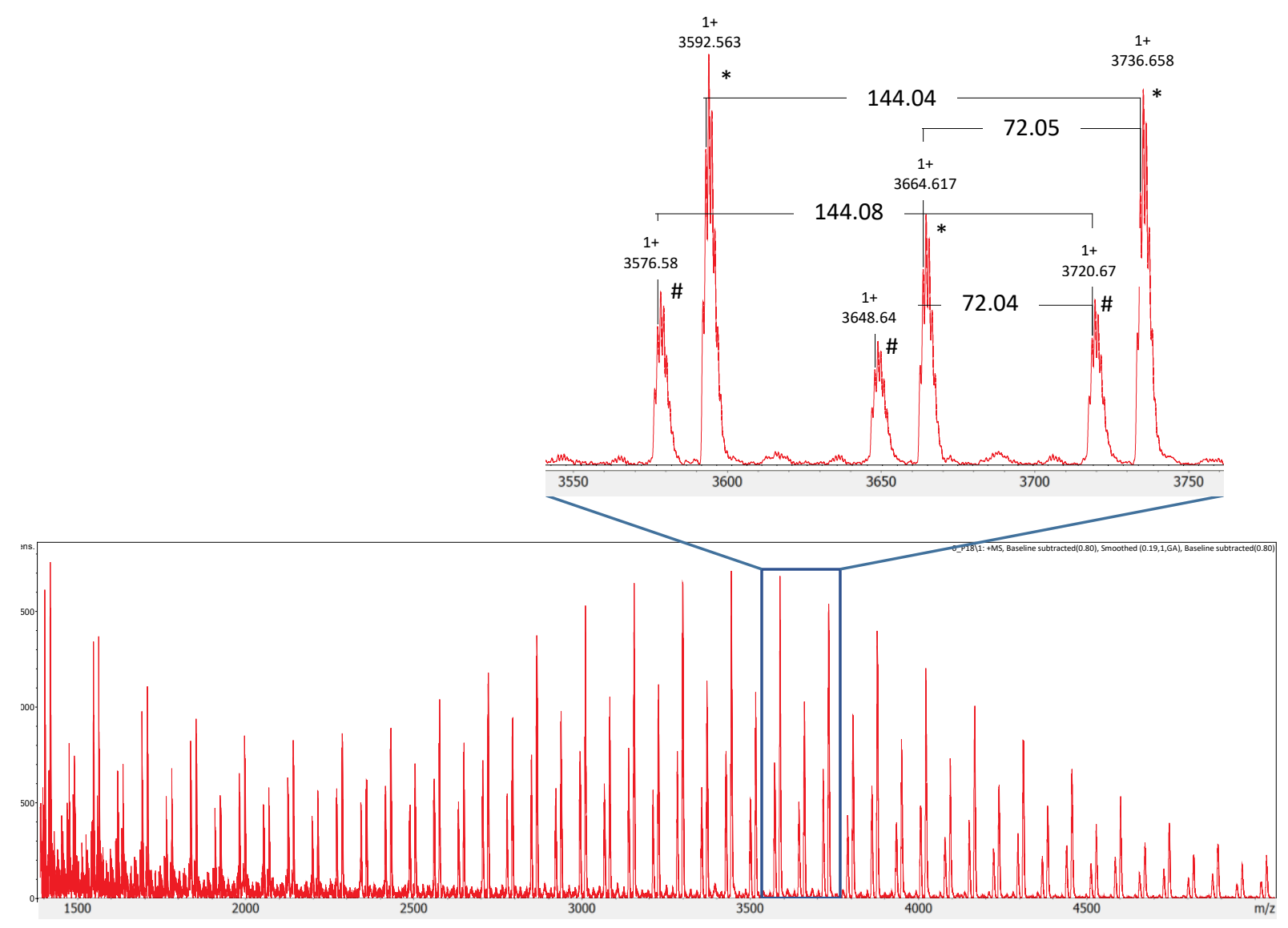

$$
\begin{gathered}
\frac{3592.563}{144.14=\mathrm{MW} \mathrm{LA}}=24.924=24 \text { LA units }+0.924 \\
0.924 \times 144.14=\mathrm{MW} \text { of end group }+\mathrm{K}^{+} \text {ion }=133.19
\end{gathered}
$$

$133.19-38.96=\mathrm{MW}$ of end group $=94.225 \approx 94.018=\mathrm{MW}$ chloropropoxyl $+\mathrm{H}$<smiles>CC(CO)OC(=O)C(C)OC(=O)C(C)OC(=O)C(C)OC(=O)C(C)OC(C)C(=O)OC(C)C[18OH]</smiles>

Figure S57 Example MALDI-ToF mass spectrum of PLA produced by complex C1, reaction time 10 minutes. Polymer end groups highlighted, $\alpha$-chloropropoxyl, $\omega$-hydroxyl (left), propylene diol (right). Example polymer end group calculation included to verify presence of $\alpha$-chloropropoxyl, $\omega$-hydroxyl

PLA.

Propylene diol end-capped PLA in the MALDI-ToF spectrum may indicate the presence of chain transfer and transesterification reactions. Propylene diol, often present in trace quantities due to hydrolysis of $\mathrm{PO}$, has been shown to act as a mono- or bi-functional chain transfer agent in $\mathrm{CO}_{2}$ /epoxide ring-opening copolymerization. ${ }^{6}$ 


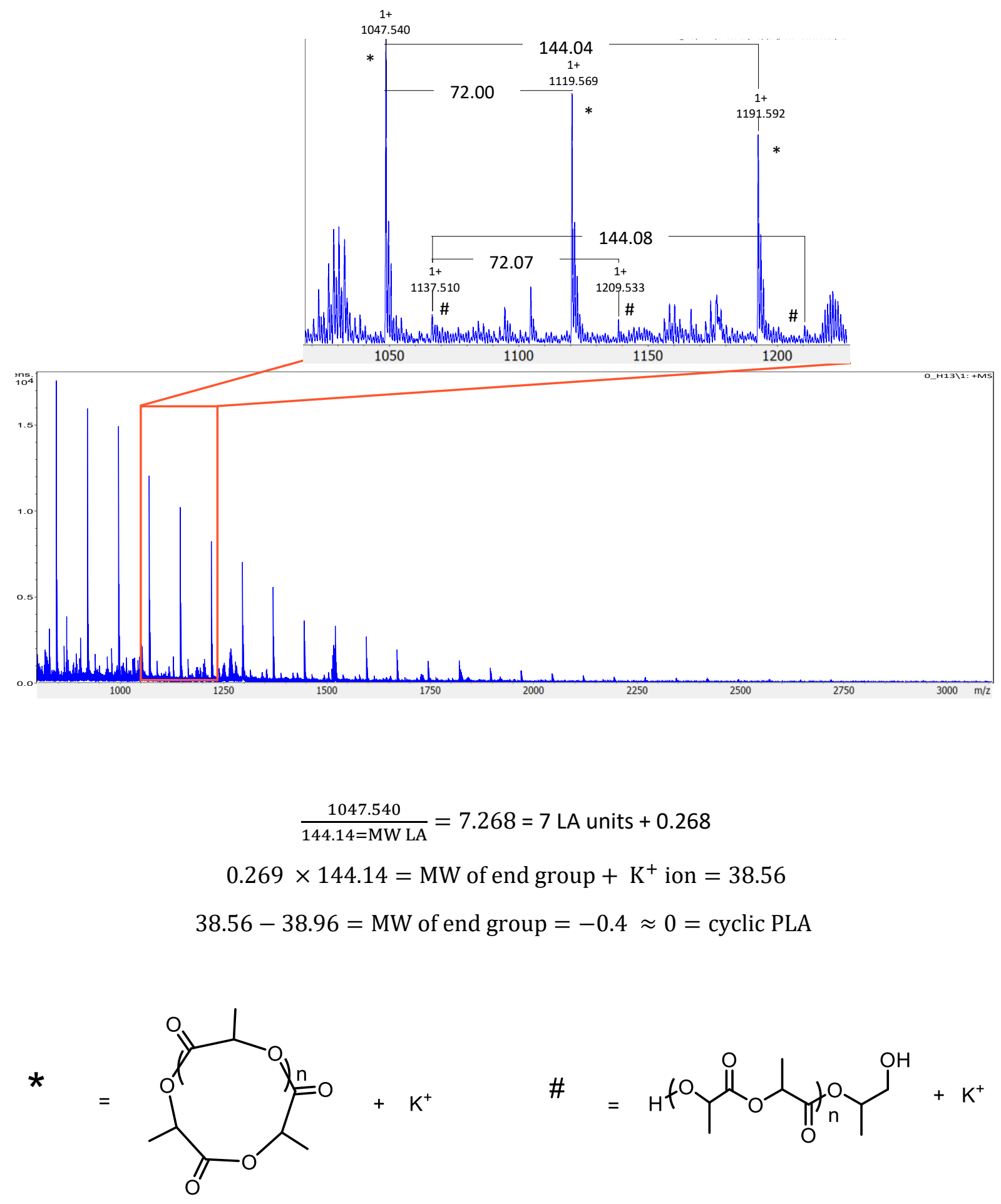

Figure S58 Example MALDI-ToF mass spectrum of cyclic PLA produced by complex $\mathbf{C 1 b}$, reaction time 20 minutes. Polymer end groups highlighted, cyclic PLA (left), propylene diol (right). Example polymer end group calculation included to verify presence cyclic PLA. 


\section{Computational modelling}

Ab initio molecular orbital calculations: A series of geometry optimization calculations were performed for C1 and C1a-c, using Gaussian $16^{7}$ and the B3LYP/6-311G* model chemistry. All stationary points obtained were confirmed as minima by vibrational frequency analysis (all real numbers) and recast as free energies following computation of thermochemical energy corrections. Ligand strain energies were derived via single point energy calculation of the corresponding optimized geometry, stripped of the cavity occupation and capped with freely optimizing hydrogen atoms.

Ab initio molecular dynamics (AIMD) simulations: All ab initio (Born-Oppenheimer) MD calculations were performed using the Quickstep module of the CP2K (version 4.1) simulation package using the PBE exchange-correlation throughout. ${ }^{8,9}$ Energies and forces were calculated utilizing the Gaussian plane-wave scheme wherein a linear combination of Gaussian-type orbitals is used to describe the Kohn-Sham molecular orbitals while the electron density is described by an auxiliary plane-wave basis set (expressed at an energy cut-off of 450 Ry). The double-zeta quality MOLOPT basis sets was used for all elements, ${ }^{10}$ in conjunction with the relativistic, norm-conserving Goedecker-Teter Hutter pseudopotentials, optimized for use against the PBE functional. During each SCF cycle, the electronic structure was explicitly minimized to a tolerance of $10^{-7}$ Hartree. The equations of motion were integrated using a time step of $0.55 \mathrm{fs}$.

The optimized geometries obtained from the ab initio $\mathrm{MO}$ calculations were used as starting models, with the coordinates of each structure deposited into a $20 \AA \AA$ cubic periodic boundary condition box. The electronic structure in the resulting compact $1^{\text {st }}$ Brillouin zone was sampled at the $\Gamma$-point only. Simulations were run under NVT conditions for ca. $6 \mathrm{ps}$, with the temperature set to $300 \mathrm{~K}$ and controlled by a chain of Nosé-Hoover thermostats. The output trajectories were then corrected to remove the effects of molecular translation and rotation around the $x-, y$ - and $z$-axes, in order that a consistent framework was presented to evaluate the extent of vibrational motion only at the given temperature. The resulting trajectories were then analyzed numerically to determine the timeaveraged mean atomic positions and to calculate the atomic probability density functions. This last step is accomplished by a numerical calculation of the variances and co-variances of each atom, using methods described previously. ${ }^{11,12}$ The output presents the trajectory data in an analogous manner to the thermal ellipsoid model used in crystallographic refinements, and are displayed at the standard 50\% probability level using Mercury CSD 4.3.1. ${ }^{13}$ 

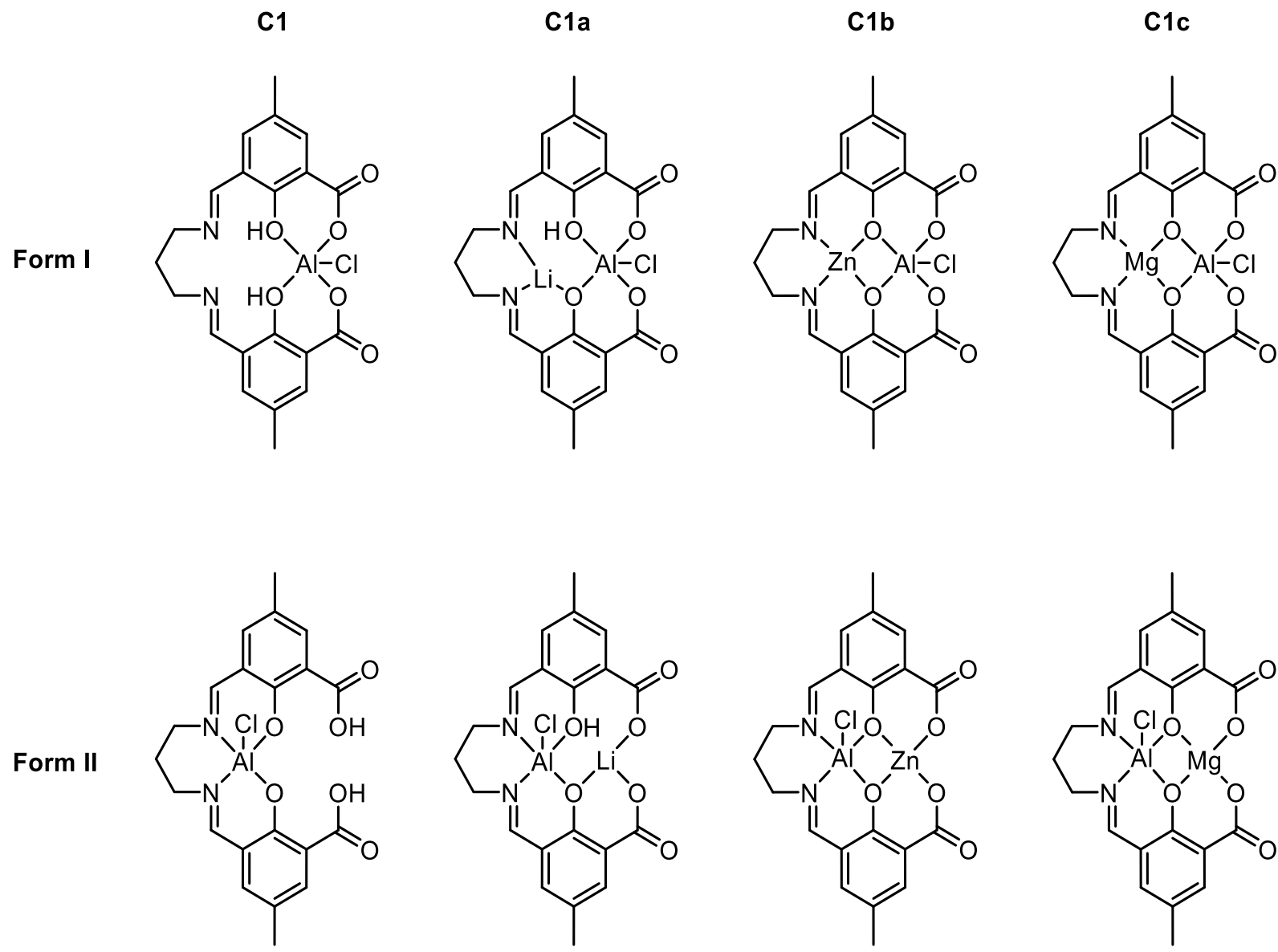

Figure S59 Comparison of form I and form II structures for complexes C1 and C1a - C1C.

Table S2 Energy comparison of each form of complexes C1 and C1a - C1c.

\begin{tabular}{cccc}
\hline Complex & Free energy (Hartrees) & $\Delta \mathrm{G}\left(\mathrm{kJmol}^{-1}\right)$ & $\Delta \mathrm{G}_{\text {strain }}\left(\mathrm{kJmol}^{-1}\right)$ \\
\hline C1-I & -2076.090417 & +9.2 & 82.5 \\
C1-II & -2076.093977 & 0 & 120.4 \\
C1a-I & -2083.133050 & 0 & 159.9 \\
C1a-II & -2083.117433 & +41.0 & 152.1 \\
\hline C1b-I & -3854.307120 & 0 & 188.0 \\
C1b-II & -3854.279968 & +71.3 & 166.5 \\
\hline C1c-I & -2275.168603 & 0 & 197.2 \\
C1c-II & -2275.160113 & +22.3 & 170.2 \\
\hline
\end{tabular}

Table S2 compares the internal and free energies of each form of complexes $\mathbf{C 1}, \mathbf{C 1 a}-\mathbf{C 1} \mathbf{c}$ and the Gibbs free energy relative to the lowest energy configuration. Form I denotes the metal arrangement 
as predicted by NMR analysis, while form II denotes a reversal of the $\mathrm{Al}(\mathrm{Cl})$ and metal $(\mathrm{Zn}, \mathrm{Mg}$ or $\mathrm{Li}(\mathrm{H}))$ positions (Figure S59). Images of all optimized structures are given in Figure S37. G values are presented relative to the lowest energy configuration. $\Delta \mathrm{G}_{\text {strain }}$ values are single point energy calculations of the ligand in the corresponding optimized geometry, stripped of cavity occupation and capped with freely optimizing hydrogen atoms.

Form II ligand conformation causes the propylene salen backbone to be more twisted, relative to form I, in order to accommodate the Al cation. This twist is reflected in the overall structure causing an Sshape to the form II complex, whereas form I complexes adopt a bowl type shape (Figure S60). Ligand strain energy calculations (table S2) determined that while C1-I $\left(82.5 \mathrm{kJmol}^{-1}\right)$ gives reduced ligand strain compared to C1-II (120.4 $\left.\mathrm{kJmol}^{-1}\right)$, form II is more stable for complexes C1a - C1c. These calculations suggest that internal ligand strain is not the only factor that determines isomeric form stability, and a reduced heterometal - aluminum distance and the presence of the bridging chloride may also have an effect.

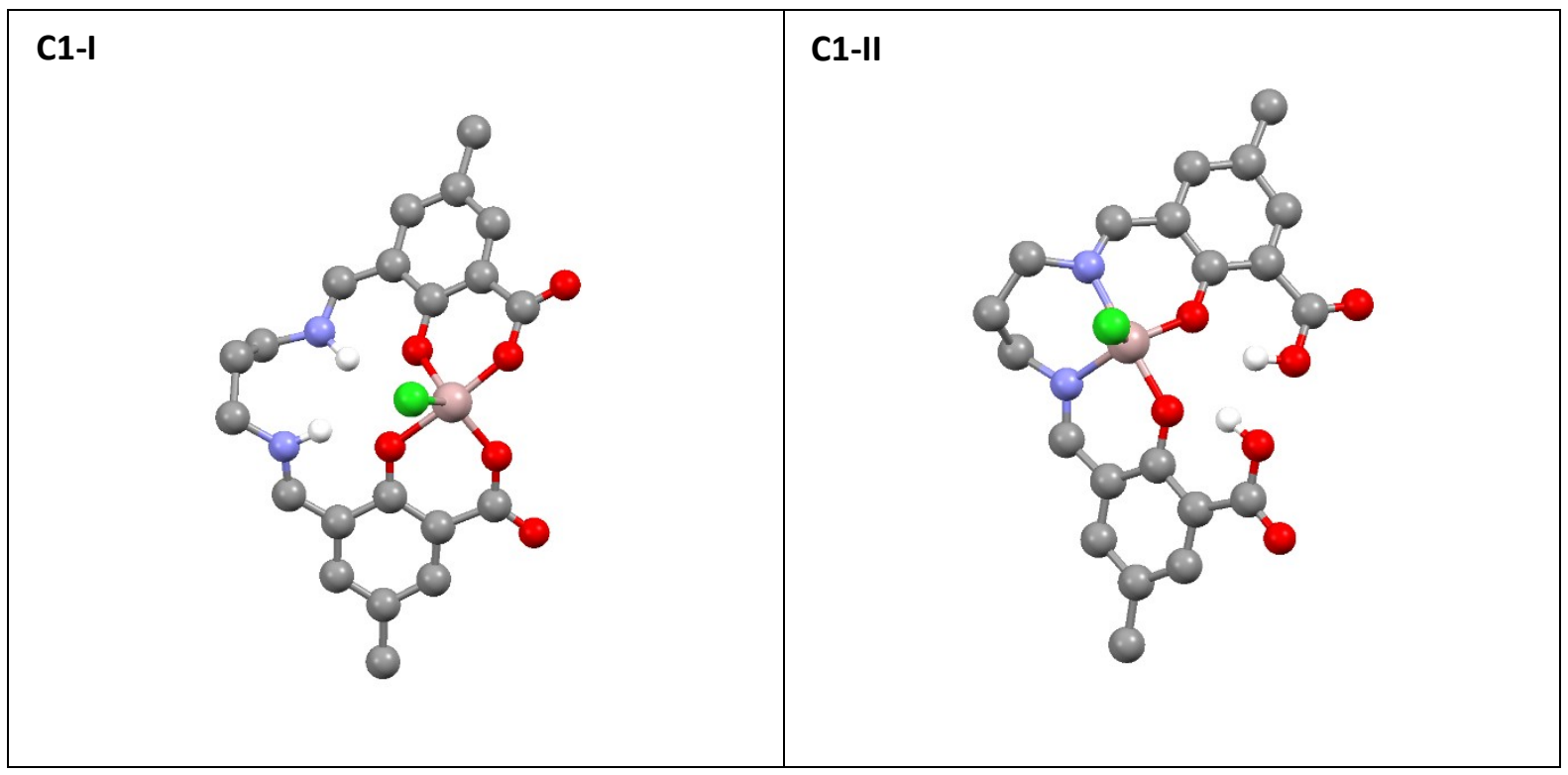




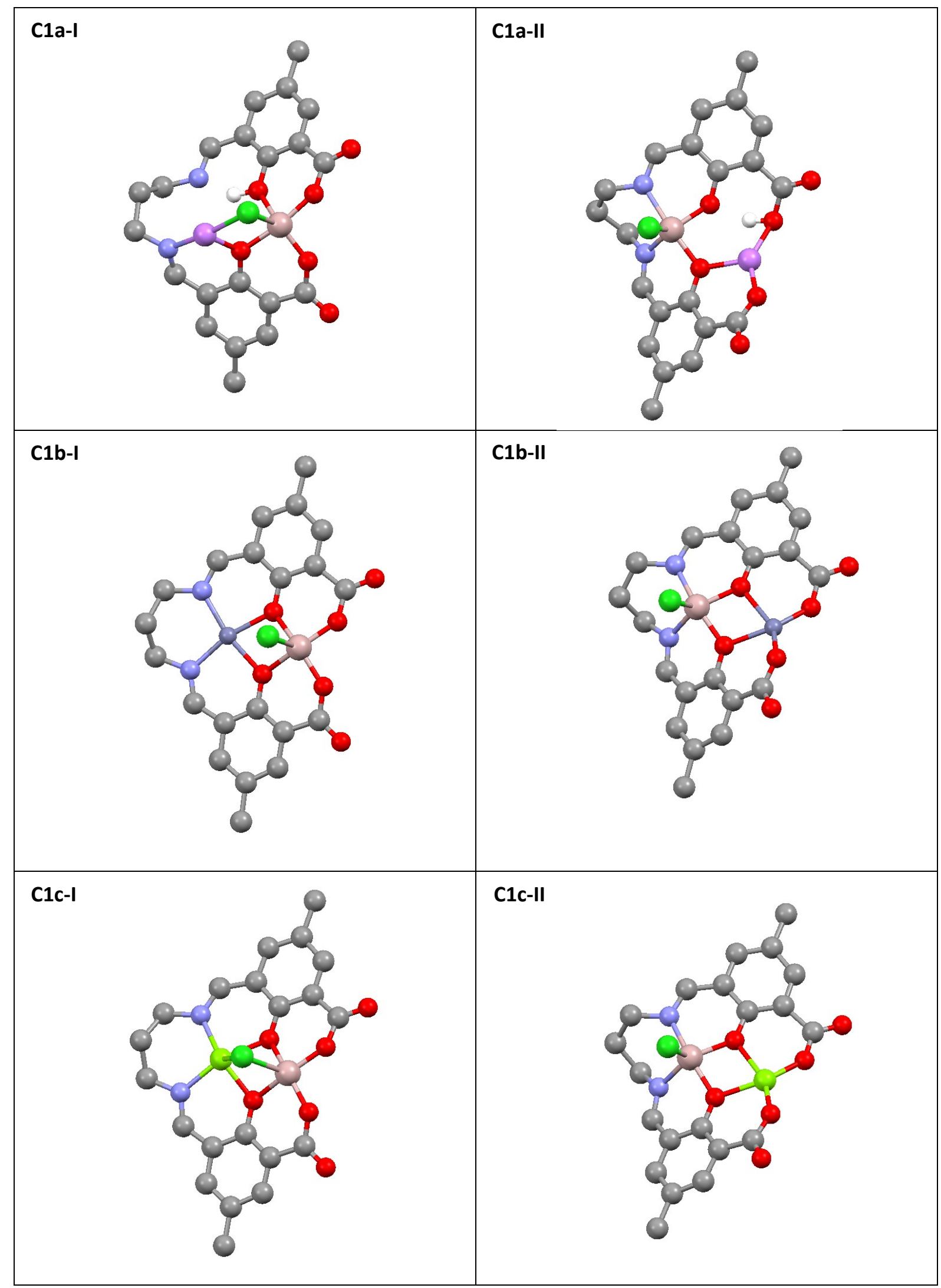

Figure $\mathbf{S 6 0}$ (top to bottom) Geometry optimized complexes of form I (left) and form II (right) of complexes $\mathbf{C 1}, \mathbf{C 1} \mathbf{a}, \mathbf{C} \mathbf{1} \mathbf{b}$ and $\mathbf{C 1}$ c respectively. Color scheme: grey $=\mathbf{C}$, light blue $=\mathrm{N}$, red $=\mathbf{O}$, pink $=$ $\mathrm{Al}$, purple $=\mathrm{Li}$, dark blue $=\mathrm{Zn}$, yellow $/$ green $=\mathrm{Mg}$, green $=\mathrm{Cl}$. 


\section{C1c-II}
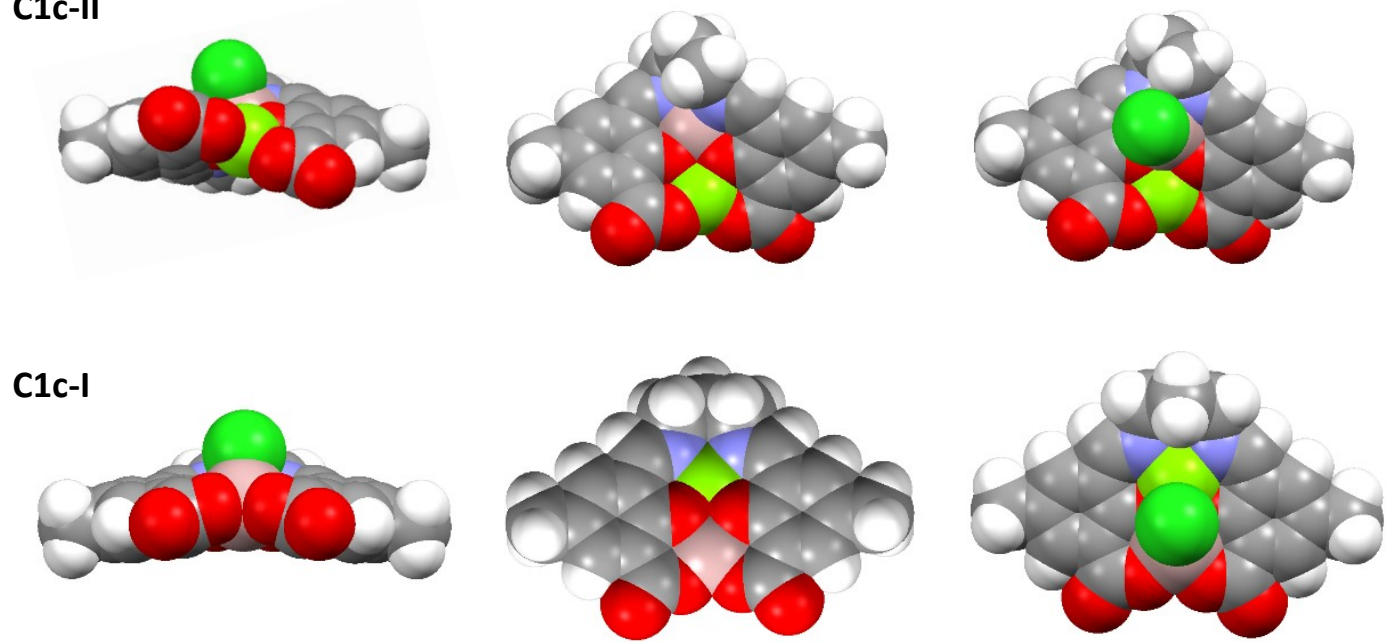

C1b-II
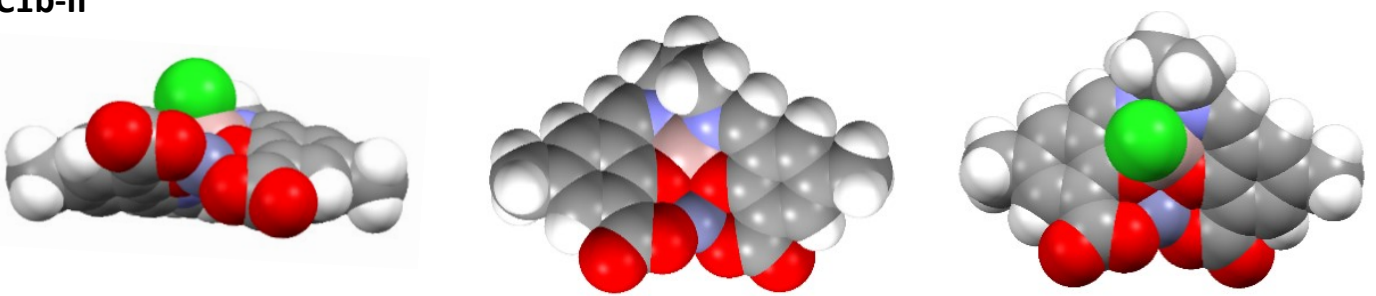

C1b-I
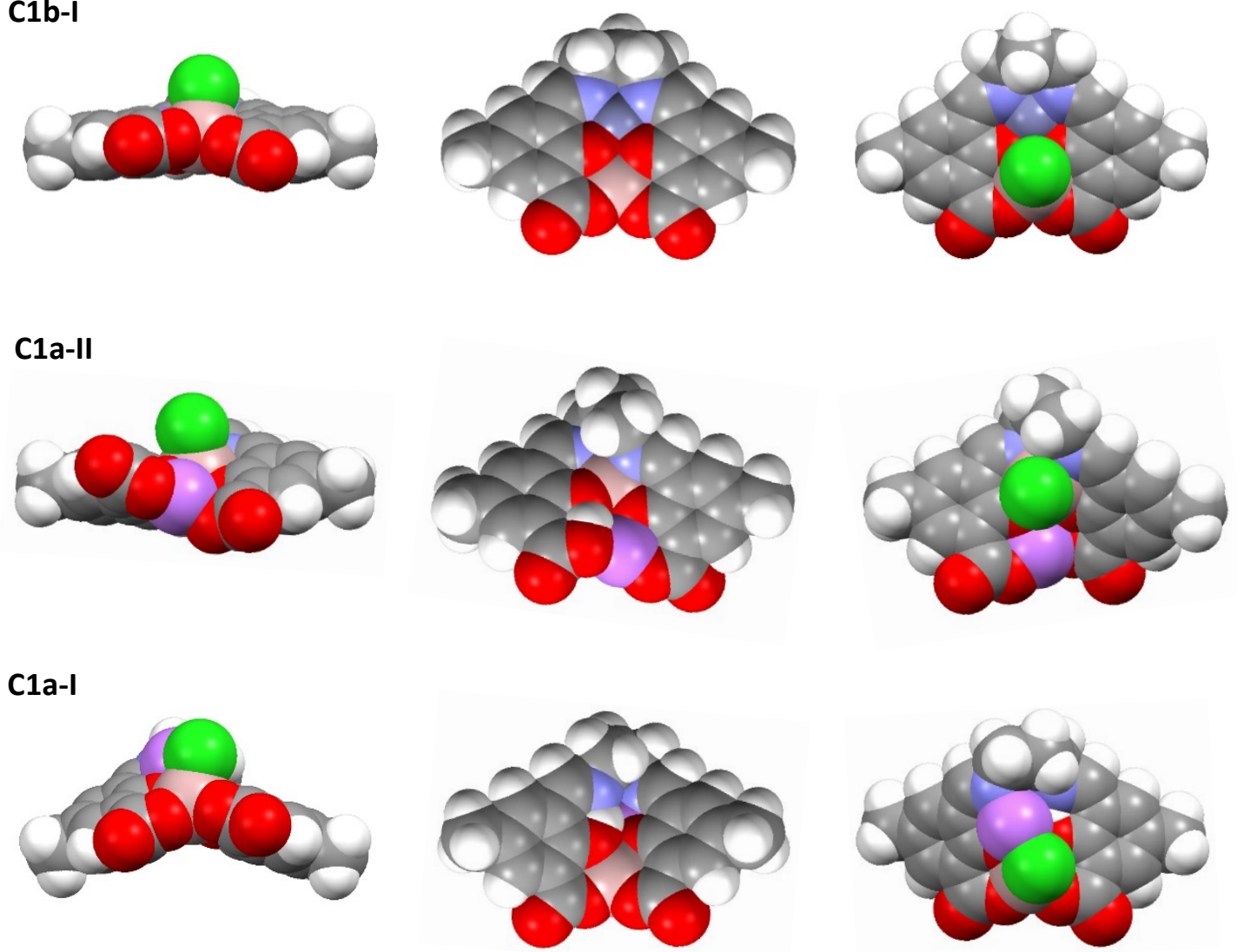


\section{C1-II}
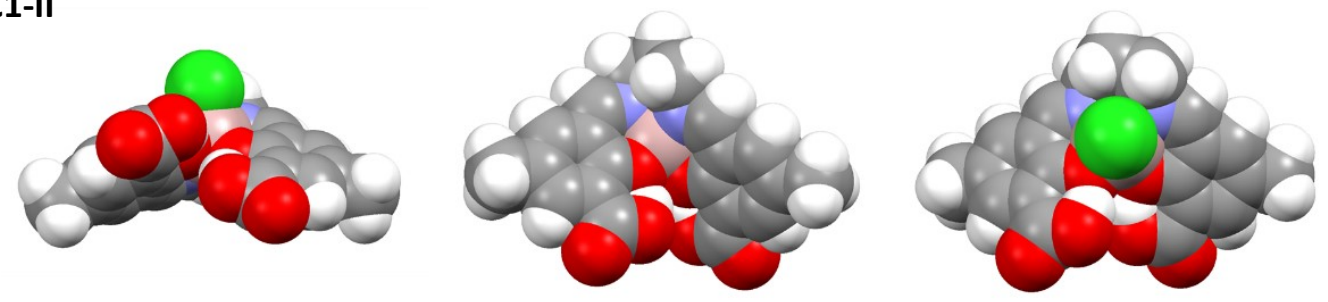

C1-I
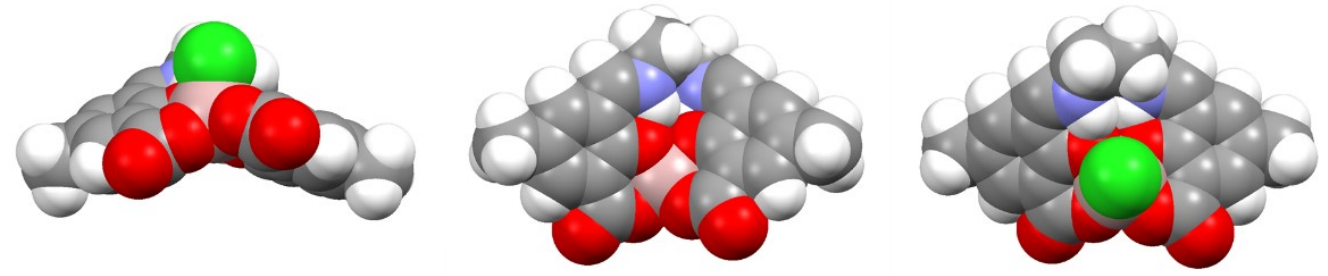

Figure S61 (top to bottom) Geometry optimized Spacefill models of form II (top) and form I (bottom) of complexes $\mathbf{C 1 c}, \mathbf{C 1} \mathbf{b}, \mathbf{C 1} \mathbf{a}$ and $\mathbf{C 1}$ respectively.

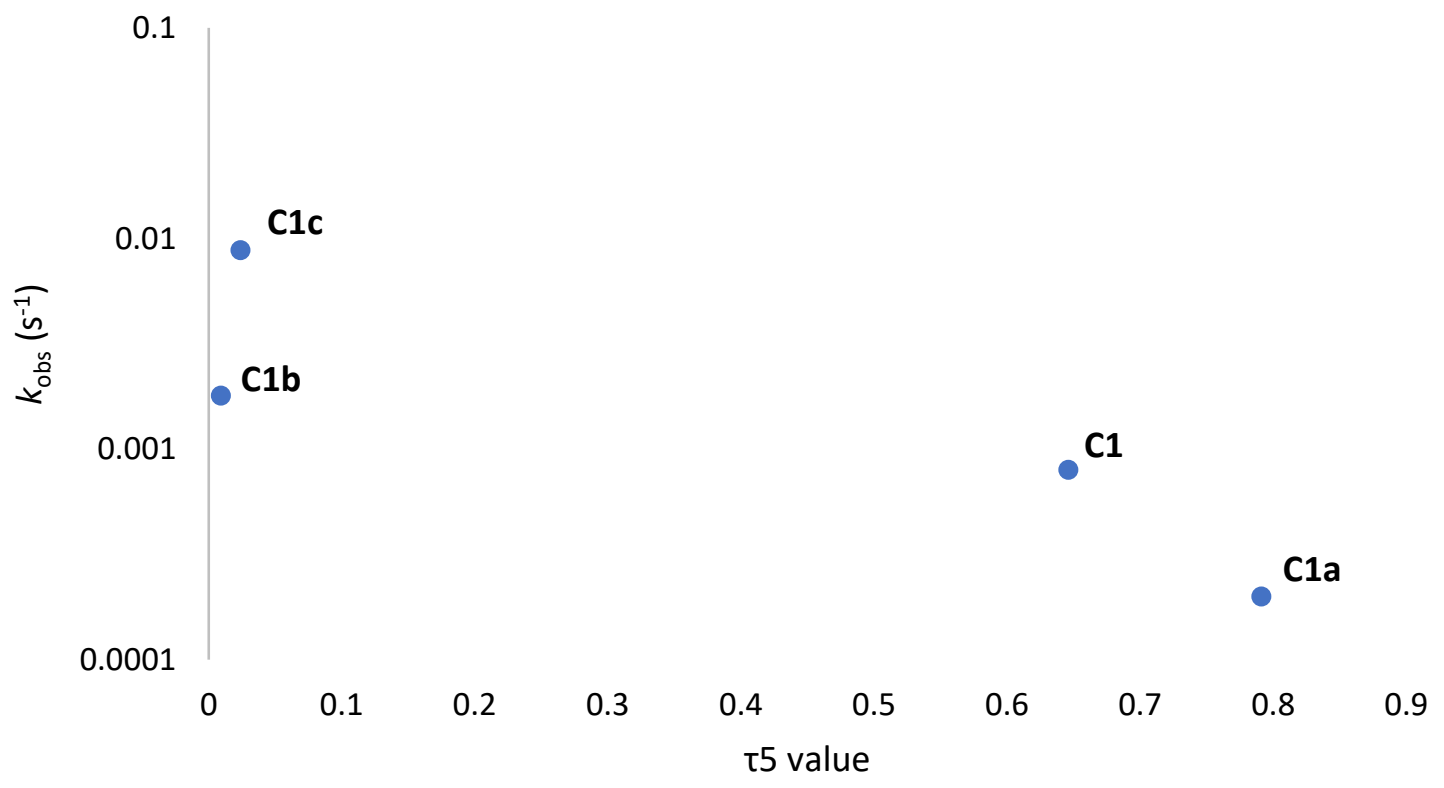

Figure $\mathbf{5 6 2}$ Logarithmic plot of molecular dynamics simulated metal center geometry against polymerization rate for complexes $\mathbf{C 1}, \mathbf{C 1 a}-\mathbf{C 1 c}$. Reaction conditions: [catalyst $] /[\mathrm{PO}] /[$ rac-LA] $=$ 1:50:100, $[$ rac-LA $]=1 \mathrm{M}$ in toluene, $120^{\circ} \mathrm{C}$. 
Table S3 Comparison of the metal geometry, intermetallic separation, and $\mathrm{M}-\mathrm{Cl} / \mathrm{Al}-\mathrm{Cl}$ bond length of complexes C1, C1a - C1c as calculated by Gaussian DFT and molecular dynamics simulations.

\begin{tabular}{cccccc}
\hline & Complex & $\begin{array}{c}\text { T5 } \\
\text { character }^{[\mathrm{a}]}\end{array}$ & $\begin{array}{c}\text { Intermetallic } \\
\text { separation }(\AA)\end{array}$ & $\begin{array}{c}\mathrm{Al}-\mathrm{Cl} \text { bond } \\
\text { length }(\AA)\end{array}$ & $\begin{array}{c}\mathrm{M}-\mathrm{Cl} \text { bond length } \\
\text { / distance (Å) }\end{array}$ \\
\hline \multirow{2}{*}{ C1 } & Gaussian Calcs & 0.711 & - & 2.199 & - \\
& Mol Dynamic Sim & $0.646^{[\mathrm{b}]}$ & - & 2.032 & - \\
\hline \multirow{2}{*}{ C1a } & Gaussian Calcs & 0.567 & 2.927 & 2.272 & 2.320 \\
& Mol Dynamic Sim & 0.791 & 2.960 & 2.282 & 2.299 \\
\hline \multirow{2}{*}{ C1b } & Gaussian Calcs & 0.150 & 3.043 & 2.198 & 3.455 \\
& Mol Dynamic Sim & 0.009 & 2.933 & 2.220 & 2.798 \\
\hline \multirow{2}{*}{ C1c } & Gaussian Calcs & 0.001 & 2.826 & 2.320 & 2.596 \\
& Mol Dynamic Sim & 0.024 & 2.842 & 2.295 & 2.632 \\
\hline
\end{tabular}

[a] $\mathrm{t} 5$ character determined according to the method published by Addison, Reedijk and co-workers. ${ }^{14}$ [b] Al-O bond breaking makes $\tau 5$ character calculation inaccurate. 


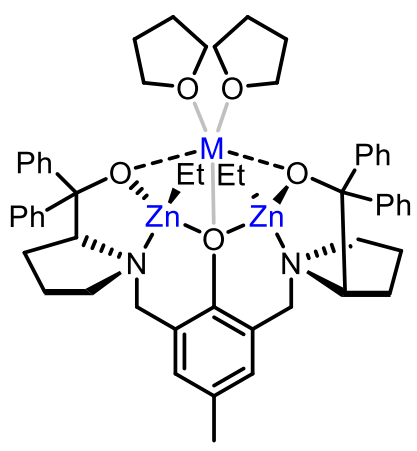

$\mathrm{M}=\mathrm{Na}(\mathbf{A})$ or $\mathrm{K}(\mathbf{B})$

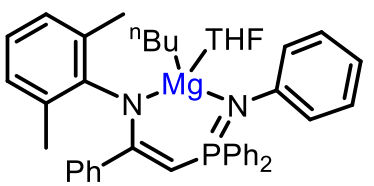

D

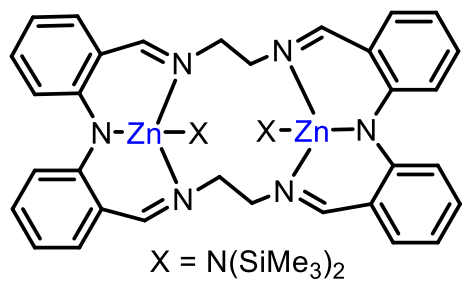

C

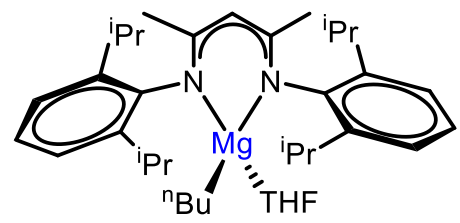

E

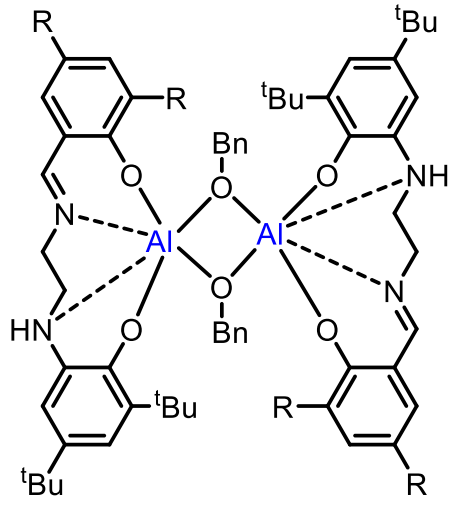

$\mathrm{R}={ }^{\mathrm{t}} \mathrm{Bu}(\mathbf{F}), \mathrm{Cl}(\mathbf{G})$ or $\mathrm{Br}(\mathbf{H})$

Figure S63 Structures of A-H Mg, Zn and Al complexes reported in literature. ${ }^{15-19}$

Table S4 Literature catalysts for the ROP of rac-lactide and associated rates.

\begin{tabular}{|c|c|c|c|c|c|c|c|}
\hline Catalyst & $\begin{array}{c}\text { Additive } \\
\text { (cat:additive) }\end{array}$ & {$[\mathrm{LA}] / \mathrm{M}$} & Solvent & Temp $/{ }^{\circ} \mathrm{C}$ & $\begin{array}{c}\text { [cat]:[lac } \\
\text { tide] }\end{array}$ & $k_{\text {obs }}($ reported) & $\begin{array}{c}k_{\text {obs }}(\text { calculated }) \\
/ \mathrm{s}^{-1}\end{array}$ \\
\hline$A^{15}$ & $\mathrm{BnOH}(1: 2)$ & 1.00 & THF & r.t. & $1: 100$ & $3.2 \times 10^{-3} \mathrm{~s}^{-1}$ & $3.2 \times 10^{-3}$ \\
\hline $\mathbf{B}^{15}$ & $\mathrm{BnOH}(1: 2)$ & 1.00 & THF & r.t. & $1: 100$ & $1.7 \times 10^{-2} \mathrm{~s}^{-1}$ & $1.7 \times 10^{-2}$ \\
\hline $\mathbf{C}^{16}$ & 'PrOH (1:10) & 1.00 & THF & 25 & 1:1000 & $0.139 \mathrm{~s}^{-1}$ & 0.139 \\
\hline $\mathbf{D}^{17}$ & - & 0.333 & THF & 20 & $1: 159$ & $9.21 \times 10^{-3} \mathrm{~s}^{-1}$ & $9.21 \times 10^{-3}$ \\
\hline $\mathbf{E}^{18}$ & - & 0.089 & $\mathrm{CH}_{2} \mathrm{Cl}_{2}$ & 25 & $1: 180$ & $0.587 \mathrm{~s}^{-1}$ & 0.587 \\
\hline $\mathbf{F}^{19}$ & $\mathrm{BnOH}(1: 1)$ & 0.69 & toluene & 80 & $1: 100$ & $9.2 \times 10^{-2} \mathrm{~min}^{-1}$ & $1.53 \times 10^{-3}$ \\
\hline $\mathbf{G}^{19}$ & $\mathrm{BnOH}(1: 1)$ & 0.69 & toluene & 80 & $1: 100$ & $6.2 \times 10^{-3} \mathrm{~min}^{-1}$ & $1.03 \times 10^{-4}$ \\
\hline $\mathbf{H}^{19}$ & $\mathrm{BnOH}(1: 1)$ & 0.69 & toluene & 80 & $1: 100$ & $10.8 \times 10^{-2} \mathrm{~min}^{-1}$ & $1.80 \times 10^{-3}$ \\
\hline
\end{tabular}




\section{References}

1 Y. Hongwei, H. Feng, Z. Wu, H. Yunling, C. Xia and Y. Zhaowen, Huaxue Yanjiu., 2006, 17, 41-44.

2 T. M. Ovitt and G. W. Coates, J. Am. Chem. Soc., 2002, 124, 1316-1326.

3 J. Baran, A. Duda, A. Kowalski, R. Szymanski and S. Penczek, Macromol. Rapid Commun., 1997, 18, 325333.

4 A. J. Gaston, G. Navickaite, G. S. Nichol, M. P. Shaver and J. A. Garden, Eur. Polym. J., 2019, 119, 507513.

A. Rae, A. J. Gaston, Z. Greindl and J. A. Garden, Eur. Polym. J., 2020, 138, 109917-109921.

Y. Zhu, C. Romain, V. Poirier and C. K. Williams, Macromolecules, 2015, 48, 2407-2416.

M. J. Frisch, G. W. Trucks, H. B. Schlegel, G. E. Scuseria, M. A. Robb, J. R. Cheeseman, G. Scalmani, V. Barone, G. A. Petersson, H. Nakatsuji, X. Li, M. Caricato, A. V. Marenich, J. Bloino, B. G. Janesko, R. Gomperts, B. Mennucci, H. P. Hratchian, J. V. Ortiz, A. F. Izmaylov, J. L. Sonnenberg, D. Williams-Young, F. Ding, F. Lipparini, F. Egidi, J. Goings, B. Peng, A. Petrone, T. Henderson, D. Ranasinghe, V. G. Zakrzewski, J. Gao, N. Rega, G. Zheng, W. Liang, M. Hada, M. Ehara, K. Toyota, R. Fukuda, J. Hasegawa, M. Ishida, T. Nakajima, Y. Honda, O. Kitao, H. Nakai, T. Vreven, K. Throssell, J. Montgomery, J. A., J. E. Peralta, F. Ogliaro, M. J. Bearpark, J. J. Heyd, E. N. Brothers, K. N. Kudin, V. N. Staroverov, T. A. Keith, R. Kobayashi, J. Normand, K. Raghavachari, A. P. Rendell, J. C. Burant, S. S. Iyengar, J. Tomasi, M. Cossi, J. M. Millam, M. Klene, C. Adamo, R. Cammi, J. W. Ochterski, R. L. Martin, K. Morokuma, O. Farkas, J. B. Foresman and D. J. Fox, Gaussian16 Revision A.03, 2016.

8 J. Vandevondele, M. Krack, F. Mohamed, M. Parrinello, T. Chassaing and J. Hutter, Comput. Phys. Commun., 2005, 167, 103-128.

9 J. P. Perdew, K. Burke and M. Ernzerhof, Phys. Rev. Lett., 1996, 77, 3865-3868.

J. VandeVondele and J. Hutter, J. Chem. Phys., 2007, 127, 114105-114113.

A. M. Reilly, D. A. Wann, C. A. Morrison and D. W. H. Rankin, Chem. Phys. Lett., 2007, 448, 61-64. 134519.

C. chemical reviewsF. MacRae, I. Sovago, S. J. Cottrell, P. T. A. Galek, P. McCabe, E. Pidcock, M. Platings, G. P. Shields, J. S. Stevens, M. Towler and P. A. Wood, J. Appl. Crystallogr., 2020, 53, 226-235.

A. W. Addison, T. N. Rao, J. Reedijk, J. Van Rijn and G. C. Verschoor, J. Chem. Soc. Dalt. Trans., 1984, 0, 1349-1356.

W. Gruszka, A. Lykkeberg, G. S. Nichol, M. P. Shaver, A. Buchard and J. A. Garden, Chem. Sci., 2020, 11, 11785-11790.

A. Thevenon, C. Romain, M. S. Bennington, A. J. P. White, H. J. Davidson, S. Brooker and C. K. Williams, Angew. Chemie - Int. Ed., 2016, 55, 8680-8685. 